San Jose State University

SJSU ScholarWorks

Mineta Transportation Institute Publications

$3-2020$

\title{
Development of a Quality Control Method and Guidelines for Hot Mix Asphalt Using Recycled Concrete Aggregate
}

Xiaojun Li

California State University, Fresno

Dingxin Cheng

California State University, Chico

Kun Zhang

California State University, Chico

Kanwar M. S. Jakhar

Uday V. Pericherla

Follow this and additional works at: https://scholarworks.sjsu.edu/mti_publications

Part of the Construction Engineering and Management Commons

\section{Recommended Citation}

Xiaojun Li, Dingxin Cheng, Kun Zhang, Kanwar M. S. Jakhar, and Uday V. Pericherla. "Development of a Quality Control Method and Guidelines for Hot Mix Asphalt Using Recycled Concrete Aggregate" Mineta Transportation Institute Publications (2020). https://doi.org/10.31979/mti.2020.1854

This Report is brought to you for free and open access by SJSU ScholarWorks. It has been accepted for inclusion in Mineta Transportation Institute Publications by an authorized administrator of SJSU ScholarWorks. For more information, please contact scholarworks@sjsu.edu. 


\section{SJSU}

\section{MTI//}

Development of a Quality Control Method and Guidelines for Hot Mix Asphalt Using Recycled Concrete Aggregate

Xiaojun Li, PhD

Dingxin Cheng, PhD

Kun Zhang, PhD
Kanwar M. S. Jakhar

Uday V. Pericherla 


\section{MINETA TRANSPORTATION INSTITUTE}

Founded in 199I, the Mineta Transportation Institute (MTI), an organized research and training unit in partnership with the Lucas College and Graduate School of Business at San José State University (SJSU), increases mobility for all by improving the safety, efficiency, accessibility, and convenience of our nation's transportation system. Through research, education, workforce development, and technology transfer, we help create a connected world. MTI leads the four-university. MTI leads the four-university California State University Transportation Consortium funded by the State of California through Senate Bill I.

MTl's transportation policy work is centered on three primary responsibilities:

\section{Research}

MTI works to provide policy-oriented research for all levels of government and the private sector to foster the development of optimum surface transportation systems. Research areas include: bicycle and pedestrian issues; financing public and private sector transportation improvements; intermodal connectivity and integration; safety and security of transportation systems; sustainability of transportation systems; transportation / land use / environment; and transportation planning and policy development. Certified Research Associates conduct the research. Certification requires an advanced degree, generally a Ph.D., a record of academic publications, and professional references. Research projects culminate in a peer-reviewed publication, available on TransWeb, the MTI website (http://transweb.sjsu.edu).

\section{Education}

The Institute supports education programs for students seeking a career in the development and operation of surface transportation systems. MTI, through San José State University, offers an AACSBaccredited Master of Science in Transportation Management and graduate certificates in Transportation Management, Transportation Security, and High-Speed Rail Management that serve to prepare the nation's transportation managers for the 2 I st century. With the active assistance of the California Department ofTransportation (Caltrans), MTI delivers its classes over a state-of-the-art videoconference network throughout the state of California and via webcasting beyond, allowing working transportation professionals to pursue an advanced degree regardless of their location. To meet the needs of employers seeking a diverse workforce, MTl's education program promotes enrollment to under-represented groups.

\section{Information and Technology Transfer}

MTI utilizes a diverse array of dissemination methods and media to ensure research results reach those responsible for managing change. These methods include publication, seminars, workshops, websites, social media, webinars, and other technology transfer mechanisms. Additionally, MTI promotes the availability of completed research to professional organizations and journals and works to integrate the research findings into the graduate education program. MTl's extensive collection of transportation- related publications is integrated into San José State University's world-class Martin Luther King, Jr. Library.

\section{Disclaimer}

The contents of this report reflect the views of the authors, who are responsible for the facts and accuracy of the information presented herein. This document is disseminated in the interest of information exchange. The report is funded, partially or entirely, by a grant from the State of California. This report does not necessarily reflect the official views or policies of the State of California or the Mineta Transportation Institute, who assume no liability for the contents or use thereof. This report does not constitute a standard specification, design standard, or regulation. 
REPORT 20-06

\title{
DEVELOPMENT OF A QUALITY CONTROL METHOD AND GUIDELINES FOR HOT MIX ASPHALT USING RECYCLED CONCRETE AGGREGATE
}

\author{
Xiaojun Li, PhD \\ Dingxin Cheng, PhD \\ Kun Zhang PhD \\ Kanwar M.S. Jakhar \\ Uday V. Pericherla
}

March 2020

A publication of

Mineta Transportation Institute

Created by Congress in 1991

College of Business

San José State University

San José, CA 95192-0219 


\section{TECHNICAL REPORT DOCUMENTATION PAGE}

1. Report No. 20-06

4. Title and Subtitle

Development of a Quality Control Method and Guidelines for Hot Mix Asphalt Using Recycled Concrete Aggregate

2. Government Accession No.

3. Recipient's Catalog No.

5. Report Date

March 2020

6. Performing Organization Code

8. Performing Organization Report CA-MTI-1854

10. Work Unit No.

11. Contract or Grant No. ZSB12017-SJAUX

San José State University

San José, CA 95192-0219

12. Sponsoring Agency Name and Address

State of California SB1 2017/2018

Trustees of the California State

University

Sponsored Programs Administration

401 Golden Shore, 5th Floor

Long Beach, CA 90802

15. Supplemental Notes

DOI: 10.31979/mti.2020.1854

\section{Abstract}

Each year, about 122 million tons of aggregates, a major structural component of pavement, are used in asphaltic mixtures in pavement construction. At the same time, aging U.S. infrastructure produces around 200 million tons of demolition waste each year, half of which is concrete debris. Therefore, introducing recycled concrete aggregate (RCA) as hot mix asphalt (HMA) aggregate could not only relieve the disposal pressure but also result in considerable reductions in cost, energy usage, and greenhouse gas emissions in the paving industry.

A limited number of studies regarding the use of RCA to substitute virgin aggregate in HMA (RCA-HMA) exist. More importantly, the findings reveal discrepant or even contradictory results, regarding the effects of RCA on almost all the volumetrics and performance indicators of RCA-HMA. Because RCA is different from virgin aggregate, as RCA particles are at least partially covered by a residual cement mortar (RCM) layer, the attached RCM in RCAs from different concrete sources could significantly differ in terms of content, porosity, and distribution on the RCA surface.

This study aims to determine the characteristics of RCA and RCM, such as RCM content, specific gravity, and absorption, and to evaluate their effects on the volumetrics and performance indicators of RCA-HMA. This research evaluates the variation in the properties of RCA and RCM obtained from different sources and their effects on RCA-HMA's performance. The research revealed the properties of RCA from different sources vary significantly. It is insufficient to predict the volumetrics and performance of RCA-HMA using only the information of RCA, such as RCA replacement rate and gradation. Information pertaining to the RCM's properties, such as the RCM content, specific gravity, and absorption, is critical for the prediction of the RCA-HMA properties, including optimum binder content (OBC), voids in mineral aggregate (VMA), voids filled with asphalt (VFA), resistance to permanent deformation, and moisture damage susceptibility. The results of this investigation can help to ensure reliable performance of RCA-HMA in practice by controlling the properties of RCM in the RCA.

\begin{tabular}{|l|l|l|l|}
\hline 17. Key Words & $\begin{array}{l}\text { 18. Distribution Statement } \\
\text { No restrictions. This document is available to the public through } \\
\text { The National Technical Information Service, Springfield, VA } 22161\end{array}$ \\
\hline $\begin{array}{l}\text { 19. Security Classif. (of this report) } \\
\text { Unclassified }\end{array}$ & $\begin{array}{l}\text { 20. Security Classif. (of this page) } \\
\text { Unclassified }\end{array}$ & $\begin{array}{l}\text { 21. No. of Pages } \\
75\end{array}$ & 22. Price \\
\hline
\end{tabular}

Form DOT F 1700.7 (8-72) 


\title{
Copyright $\odot 2020$ \\ by Mineta Transportation Institute \\ All rights reserved
}

\author{
DOI: \\ 10.31979/mti.2020.1854
}

\author{
Mineta Transportation Institute \\ College of Business \\ San José State University \\ San José, CA 95192-0219 \\ Tel: (408) 924-7560 \\ Fax: (408) 924-7565 \\ Email: mineta-institute@sjsu.edu
}

transweb.sjsu.edu 


\section{ACKNOWLEDGMENTS}

The authors would like to acknowledge their appreciation for funding from Senate Bill 1 (SB-1) and the Mineta Transportation Institute (MTI). Special thanks to Dr. Hilary Nixon for supporting this project. The authors appreciate Knife River Construction, Inc. for the donation of the materials and technical advice. The authors also appreciate the support of student research assistants at the California Pavement Preservation Center, Ernesto Lopez, Marwan, Albukhari, Christopher Jensen, Jocelyn Perez, and Mario Jaquiz, who have conducted laboratory testing on RCA-HMA materials.

The authors thank Editing Press, for editorial services, as well as MTI staff, including Executive Director Karen Philbrick, PhD; Deputy Executive Director Hilary Nixon, PhD; Graphic Designer Alverina Eka Weinardy; and Executive Administrative Assistant Jill Carter. 


\section{TABLE OF CONTENTS}

Executive Summary

1

Project Summary

1

Project Background

Process

Findings

Recommendations

I. Introduction

Background

4

Current Study and Problems $\quad 5$

$\begin{array}{ll}\text { Objectives } & 6\end{array}$

$\begin{array}{ll}\text { II. Materials and Experiments } & 7\end{array}$

$\begin{array}{ll}\text { Materials } & 7\end{array}$

$\begin{array}{ll}\text { Experiments } & 8\end{array}$

III. Results and Analysis 13

Characterization of RCA and RCM 13

Characterization of Performance of HMA and RCA-HMA 18

Relationship Between RCA/RCM Properties and HMA/RCA-HMA Performance 32

IV. Conclusions and Recommendations $\quad 44$

$\begin{array}{ll}\text { Conclusions } & 44\end{array}$

$\begin{array}{ll}\text { Recommendations } & 45\end{array}$

Appendix A: Gradation Test Results 446

$\begin{array}{ll}\text { Appendix B: HWTT Test Results } & 47\end{array}$

Appendix C: TSR Test Results $\quad 56$

$\begin{array}{ll}\text { Abbreviations and Acronyms } & 64\end{array}$

$\begin{array}{lc}\text { Endnotes } & 65\end{array}$

$\begin{array}{ll}\text { Bibliography } & \mathbf{7 0}\end{array}$

$\begin{array}{ll}\text { About the Authors } & 74\end{array}$

$\begin{array}{ll}\text { Peer Review } & 75\end{array}$ 


\section{LIST OF FIGURES}

1. RCA and Schematic of HMA With and Without RCA 6

2. RCA from Demolition of a 50-Year-Old Bridge 7

3. Concrete Cylinder for a Recent Bridge Pour Project 8

4. HWTT Equipment and Test Setup 11

5. TSR Test Equipment 12

6. RCM Content for Different Size Groups of RCAs from Different Sources 14

7. Specific Gravity for Different Size Groups of RCAs from Different Sources 15

8. Specific Gravity of RCA, Agg. (after removing RCM), and RCM for Chico RCA Sampled at Different Time 16

9. Absorption of RCA, Agg. (after removing RCM), and RCM for Chico RCA Sampled at Different Time $\quad 17$

10. Specific Gravity of Virgin Agg. for Different Size Groups 19

11. Gradation Used for Control HMA Mix and RCA-HMA Mixes 21

12. OBC of Control HMA Mix 23

13. OBC of RCA-HMA: RCA Replacement of 4.75-9.5mm 24

14. OBC of RCA-HMA: RCA Replacement of 9.5-12.5mm 25

15. OBC of RCA-HMA: RCA Replacement of 12.5-19.1mm 26

16. Surface Aggregate-Binder Stripping for RCA 4.75-9.5mm at 5\% Binder Content 27

17. HWTT of Each RCA-HMA Mix at OBC and at 5.0\% Binder Content (OBC of control mix)

18. HWTT of Control Mix and Different RCA-HMA Mix at OBC and at $5.0 \%$ Binder Content (OBC of control mix) 30

19. Dry Strength, Wet Strength, and TSR Results of HMA and RCA-HMA 31

20. (a) Cracked Aggregates in the Wet Specimens of Control HMA Mix; (b) Asphalt Binder Stripping in the Wet Specimens of RCA-HMA with RCA 4.75-9.5mm 
21. Cracked RCA Aggregates in the Dry Specimens of RCA-HMA with RCA $12.5-19.1 \mathrm{~mm}$

22. Relationship between OBC and RCA Replacement Rate or RCM Addition Rate 35

23. Relationship between OBC Increment and Absorption due to RCA Replacement or Absorption due to RCM Addition

24. Relationship between VMA Increment and RCA Replacement Rate or RCM Addition Rate

25. Relationship between VFA Increment and RCA Replacement Rate or RCM Addition Rate

26. Relationship between Rutting Depth and Loading Cycles of HWTT

27. Relationship between Rutting Depth at 12k Loading Cycles and RCA Replacement Rate or RCM Addition Rate

28. Relationship between Rutting Depth at $12 \mathrm{k}$ Loading Cycles and Absorption due to RCA Replacement or Absorption due to RCM Addition

29. Dry Strength, Wet Strength, and TSR Results of HMA and RCA-HMA

30. Relationship between TSR Change and RCA Replacement Rate or RCM Addition Rate

31. Relationship between TSR Change and Absorption due to RCA Replacement or Absorption due to RCM Addition

32. Figure Appendix B-1: HWTT Photo of RCA 4.75-9.5mm with $5.0 \%$ Binder Content (OBC of control mix)

33. Figure Appendix B-2: HWTT Photo of RCA 4.75-9.5mm with $5.9 \%$ OBC

34. Figure Appendix B-3: HWTT Photo of RCA 9.5-12.5mm with $5.4 \%$ OBC

35. Figure Appendix B-4: HWTT Photo of RCA 12.5-19.1mm with $5.0 \%$ Binder Content (OBC of control mix)

36. Figure Appendix B-5: HWTT Photo of RCA $12.5-19.1 \mathrm{~mm}$ with $5.8 \%$ OBC

37. Figure Appendix C-1: AASHTO 283 Test Photos of Control HMA Mix (100\% virgin aggregate). Left (Dry), Right (Wet)

38. Figure Appendix C-2: AASHTO 283 Test Photos of RCA 9.5-12.5mm Mix. Left (Dry), Right (Wet) 
39. Figure Appendix C-3: AASHTO 283 Test Photos of RCA 4.75-9.5mm Mix. Left (Dry), Right (Wet)

40. Figure Appendix C-4: AASHTO 283 Test Photos of RCA 12.5-19.1mm Mix. Upper (Dry), Lower (Wet) 


\section{LIST OF TABLES}

1. Experiment Matrix for RCA and RCM 9

2. Experiment Matrix for Performance of HMA and RCA-HMA 11

3. RCM Content for Different Size Groups of RCAs from Different Sources 14

4. Specific Gravity and Absorption Test Results of RCA 15

5. Gradation Results for Virgin Aggregates 18

6. Bulk Specific Gravity and Water Absorption of Coarse Aggregates 19

7. Specific Gravity of Fine Aggregate and Fines 19

8. Final Gradation of Control HMA and RCA-HMA Mixes 21

9. Summary Results of Volumetrics of HMA and RCA-HMA 22

10. Volumetric Mix Design of Control Mix: 100\% Virgin Agg. 22

11. Volumetric Mix Design of RCA Replacement of 4.75-9.5mm 23

12. Volumetric Mix Design of RCA Replacement of 9.5-12.5mm 24

13. Volumetric Mix Design of RCA Replacement of 12.5-19.1mm 25

14. Summarized Hamburg Wheel Track Test Results 27

15. Summarized Results of Moisture Damage Susceptibility 30

16. Summary of Results of RCA, RCM, HMA, and RCA-HMA 33

17. Table Appendix A: Mixture Design Results 46

18. Table Appendix B-1: HWTT Results of Control Mix (100\% virgin aggregate) 47

19. Table Appendix B-2: HWTT Results of RCA 4.75-9.5mm Mix: $5.0 \%$ binder content (OBC of control mix) 48

20. Table Appendix B-3: HWTT Results of RCA 4.75-9.5mm Mix: $5.9 \%$ OBC 49

21. Table Appendix B-4: HWTT Results of RCA 9.5-12.5mm Mix: $5.0 \%$ binder content (OBC of control mix)

22. Table Appendix B-5: HWTT Results of RCA 9.5-12.5mm Mix: $5.4 \%$ OBC 51 
23. Table Appendix B-6: HWTT Results of RCA 12.5-19.1mm Mix: $5.0 \%$ binder content (OBC of control mix)

24. Table Appendix B-7: HWTT Results of RCA $12.5-19.1 \mathrm{~mm}$ Mix: $5.8 \%$ OBC

25. Table Appendix C-1: AASHTO 283 Test Results of Control HMA Mix (100\% virgin aggregate)

26. Table Appendix C-2: AASHTO 283 Test Results of RCA 9.5-12.5mm Mix

27. Table Appendix C-3: AASHTO 283 Test Results of RCA 4.75-9.5mm Mix 60

28. Table Appendix C-4: AASHTO 283 Test Results of RCA 12.5-19.1mm Mix

62 


\section{EXECUTIVE SUMMARY}

\section{PROJECT SUMMARY}

This research comprised of an experimental characterization of the material properties of recycled concrete aggregate (RCA) and residual cement mortar $(R C M)$ in RCA. The material properties of the RCA and RCM studied include RCM content, as well as specific gravity and absorption of RCA and RCM. Using $100 \%$ virgin aggregate as control hot mix asphalt (HMA) mix, this study evaluated the effects of the RCA and/or RCM properties on the performance of HMA when RCA was used to partially replace the virgin aggregate (RCA-HMA).

\section{PROJECT BACKGROUND}

Aggregate is a major structural component of pavement and is typically obtained by mining and crushing natural stone. Each year, about 122 million tons of aggregates are used in asphaltic mixtures in pavement construction. At the same time, aging U.S. infrastructure produces around 200 million tons of demolition waste each year, half of which are concrete debris. Therefore, introducing RCA as HMA aggregate can not only relieve the disposal pressure but also result in considerable reductions of cost and environmental footprint in the paving industry.

There are a limited number of studies regarding the use of RCA to substitute virgin aggregate in HMA. More importantly, the findings in the literature show very discrepant, sometimes even contradictory results regarding the effects of RCA on almost all the volumetrics and performance indicators of HMA. The discrepancy and contradiction in the findings have become a critical problem and obstacle that limit the use of RCA in HMA.

Why do these studies have such disparate and even contradictory findings? The research team believes that the answer relies on the fundamental difference between RCA and virgin aggregate. RCA is different from virgin aggregate mainly because RCA particles are fully or

partially covered by an RCM layer, which has smaller specific gravity, larger porosity and absorption, lower modulus and strength, and different surface texture compared with natural aggregate. More importantly, the attached RCM in RCA obtained from different concrete sources could be significantly different in terms of age, composition, modulus, strength, porosity, surface texture, thickness, content, its distribution on RCA surface, and so on, due to the mix design, loading history, and environmental conditions of the concrete sources. Previous studies used the current HMA mix design procedure by only considering RCA substitution rates and gradation without considering the variation of RCA from different sources, not to mention the variation of the RCM within RCA. This might be the reason the findings in the literature on properties of RCA-HMA do not agree with one another.

The goal of this study has been to determine the characteristics of RCA and/or RCM and evaluate its effects on the volumetrics and performance indicators of RCA-HMA.

\section{PROCESS}

RCAs from different sources were collected. Laboratory characterization of the properties 
of the RCA and RCM was conducted, including RCM content, specific gravities of RCA and RCM, and absorptions of RCA and RCM. Using 100\% virgin aggregate for the fabrication of the control HMA mix, RCA was used to replace each one of the three size groups of the virgin aggregate in the control HMA mix $-4.75-9.5 \mathrm{~mm}, 9.5-12.5 \mathrm{~mm}$, and $12.5-19.1 \mathrm{~mm}-$ to fabricate specimens of RCA-HMA mixes. With this method in mind, the gradation of the RCA-HMA could be controlled the same as for the control HMA mix. The optimum binder content $(\mathrm{OBC})$ of the control HMA mix and the RCA-HMA mixes was then determined. Following this, the performance of the control HMA mix and the RCA-HMA mixes was evaluated in terms of resistance to permanent deformation through the Hamburg wheel tracking test (HWTT) and the moisture damage susceptibility through tensile strength ratio (TSR) test. Finally, relationships between the properties of the RCA and RCM and performance indicators of the HMA and RCA-HMA were analyzed.

\section{FINDINGS}

1. There are significant variations in terms of specific gravity, absorption, and RCM content among different sources of RCA. The specific gravity and absorption of RCM from different sources vary significantly as well. These variations also exist among different size groups of the RCA from the same source. The variation of the RCA properties is mainly due to the variations of the RCM contents and RCM's absorption. This finding suggests that only considering the replacement rate and gradation of RCA without considering properties of RCM is not sufficient in the RCA-HMA mix design and the study of the RCA-HMA performance.

2. The variation of the RCA and RCM properties has effects on the performance of the RCA-HMA in terms of OBC, VMA, VFA, resistance to permanent deformation, and moisture damage susceptibility. Generally, the OBC increased, the resistance to permanent deformation was reduced, and the moisture damage susceptibility improved after RCA replacement.

3. The OBC increment of the RCA-HMA compared with the control HMA has good correlation with the RCM addition rate and the absorption due to RCM addition. There is a clear trend that the $\mathrm{OBC}$ increment increases with the increases of RCM addition rate and the absorption due to RCM addition. For the materials used in this study, the OBC increment increases linearly with the RCM addition rate until about $6 \%$ and then levels out. The OBC increment almost increases linearly with the increase of the absorption due to RCM addition. However, the RCA replacement rate and the absorption due to RCA replacement do not show a clear trend with respect to the OBC increment. The results of this study also demonstrate that there is a stronger correlation between the VMA increments and the RCM addition rates rather than between the VMA increments and the RCA replacement rates. Similarly, there is a stronger correlation between the VFA increments and the RCM addition rates than between the VFA increments and the RCA replacement rates. These results indicate that solely considering the RCA replacement rate is insufficient for characterizing the volumetrics of RCA-HMA. RCM plays a more critical role in the mix design of RCA-HMA.

4. The resistance to permanent deformation characterized by the rutting depth at 12,000 
loading cycles in HWTT has good correlation with the RCM addition rate and absorption due to RCM addition. There is a clear trend that the rutting depth at 12,000 loading cycles in HWTT increases with the increase of RCM addition rate and the absorption due to RCM addition. However, the RCA replacement rate and the absorption due to RCA replacement do not show a clear trend with respect to the rutting depth at 12,000 loading cycles in HWTT.

5. The moisture damage susceptibility characterized by the TSR has good correlation with the RCM addition rate and the absorption due to RCM addition. The change of the TSR after RCA addition tends to reduce with the increase of RCM addition rate and the absorption due to RCM addition. However, the RCA replacement rate and the absorption due to RCA replacement do not show a clear trend with respect to the TSR change.

6. The results of this study indicate that information of the RCM properties, such as the RCM content, specific gravity and absorption of the RCM, are critical for the prediction of the RCA-HMA properties such as OBC, VMA, VFA, resistance to permanent deformation, and moisture damage susceptibility. Information regarding the RCA properties such as RCA replacement rates and gradation, which have been used in previous studies, are not sufficient for these predictions. The nature of the RCM in the RCA must be characterized and controlled when studying the performance of the RCA-HMA mixture and when using RCA for the production of the HMA in practice.

\section{RECOMMENDATIONS}

1. $R C A$ replacement rate is not a good indicator of the volumetrics and performance of RCA-HMA. Using RCA replacement rate as a RCA-HMA mix design control parameter or criterion is not recommended.

2. Since the RCM content can be closely related to the volumetrics, resistance to permanent deformation, and moisture damage susceptibility of the RCA-HMA, it is recommended that the RCM content should be monitored and controlled in the RCAHMA mix design. A criterion setting out the RCM content upper limit based on local materials ought to be determined through further extensive experimental study. As long as the RCM content is controlled below some criterion, the performance of RCAHMA can be well controlled. Based on the results of this study, further research on potential ways to control RCM content within RCA, both practically and effectively, may become a viable way for using RCA in HMA.

3. The results of this study show that the OBC will be increased after the addition of the RCA compared with the OBC of $100 \%$ virgin aggregate mix. However, the increase of the OBC could be detrimental to the resistance to permanent deformation of the RCAHMA based on the results of this study. It is recommended to control the absorption increment due to addition of the RCA through the control of RCM addition rate, in order to control the OBC increment. 


\section{INTRODUCTION}

\section{BACKGROUND}

Aggregate is a major structural component of infrastructure and is typically obtained by mining and crushing natural stone. Based on the estimation of the U.S. Geological Survey (USGS), there were 931 million metric tons of sand and gravel, worth $\$ 7.2$ billion, produced in $2015,{ }^{1}$ of which around $13.1 \%$ or 122 million tons were used in asphaltic mixtures in pavement construction. ${ }^{2}$ The procurement of quality construction aggregate requires mining, quarrying, crushing, and transporting natural earth materials, which not only consumes a substantial amount of energy but also releases large amounts of greenhouse gases. Increased environmental awareness and sustainable development have limited the quarrying areas of virgin aggregate, which makes it more attractive to use recycled materials instead of virgin aggregate. Currently, recycled asphalt pavement (RAP) is the major source material for the substitution of virgin aggregate for the production of asphaltic mixtures, of which the majority is hot mix asphalt (HMA). However, due to field performance considerations such as fatigue cracking and thermal cracking, especially regarding the uncertainty of the long-term performance of HMA, the substitution ratio of virgin aggregate with RAP in HMA is limited to $25 \%$ or less for most of the transportation agencies. Therefore, an alternative source for the substitution of virgin aggregate in HMA is of extreme importance to both the transportation agencies and to society.

At the same time, aging U.S. infrastructure produces around 200 million tons of demolition waste each year, half of which are concrete debris. ${ }^{3}$ Disposing this waste in landfills has been a longstanding solution. However, more restrictive environmental regulations, increasing costs, and limited landfill areas have constrained safe disposal of this waste. These problems have led to a search for alternative ways of reusing demolition waste through recycling.

Recycled concrete aggregate (RCA), which can be used to substitute for virgin aggregates, is produced by crushing the demolished concrete debris after removing the embedded reinforcement, and then sieving to an appropriate aggregate size. ${ }^{4}$ Recycled concrete has been found to be a good source of construction materials. Recycling of concrete waste not only could be a solution of waste disposal problem, but it could also reduce the need for quarrying virgin aggregate. However, based on USGS, although recycling of concrete waste increased from 2011 to 2015, this only constitute a small percentage of aggregate consumption. ${ }^{5}$ One of the reasons is that so far, the use of recycled concrete has been limited to the construction of concrete structures (rigid pavements, buildings, and runways) or as a granular layer of pavement base/subbase. ${ }^{6}$ Although recycled concrete may be used in the construction of base and/or subbase layers of pavements, the more cost effective and sustainable way of recycling concrete is to use it in the HMA surface layers, as these layers are the most expensive and carry the most environmental footprint among all layers of asphaltic pavement. Therefore, introducing RCA as HMA aggregate could not only relieve the disposal pressure of the demolition waste but also result in considerable reductions in cost, energy usage, and greenhouse gas emission in the asphalt paving industry. 


\section{CURRENT STUDY AND PROBLEMS}

There are limited studies regarding the use of RCA to substitute virgin aggregate in HMA (RCA-HMA). More importantly, the findings show very discrepant, even contradictory results regarding the effects of RCA on almost all the volumetrics and performance indicators of HMA. Some studies have indicated that the Voids in Mineral Aggregate (VMA) and Voids Filled with Asphalt (VFA) decrease with the increase of the RCA percentage ${ }^{7}$ while others have found a contrary trend..$^{8}$ It was reported that the moisture damage resistance of RCAHMA decreased with the increase of RCA substitution rate ${ }^{9}$ while other studies ${ }^{10}$ observed contradictory results. As for stiffness, some studies ${ }^{11}$ obtained lower resilient moduli or dynamic moduli of RCA-HMA comparing with conventional HMA mixtures which are contradictory to those reported by other researchers. ${ }^{12}$ Similarly, some studies have indicated that RCAHMA mixtures had comparable or better resistance to permanent deformation, ${ }^{13}$ while others have found that an increase in the RCA percentage resulted in a decrease of the resistance to permanent deformation. ${ }^{14}$

Although studies agree that using RCA in HMA tends to increase the optimum binder content $(\mathrm{OBC})^{15}$ and result in similar or better resistance to fatigue cracking ${ }^{16}$ and thermal cracking, ${ }^{17}$ the significance of the effect of RCA substitution rate on these factors obtained by various studies are very different.

Since the volumetrics and performance indicators of HMA mixtures are extremely important for their field performance, the discrepancy and contradiction in the findings of the literature have become a critical problem and obstacle that limits the use of RCA in HMA.

Why do these studies have such greatly divergent and even contradictory findings? The research team believes that the answer is due to the fundamental difference between RCA and virgin aggregate. RCA is different from virgin aggregate mainly because RCA particles are fully or partially covered by an RCM layer (as shown in Figure 1), which has smaller specific gravity, larger porosity and absorption, lower modulus and strength, and different surface texture comparing with the natural aggregate..$^{18}$ The properties and performance of HMA are affected by the interaction of its constituents. When using RCA in HMA, the attached RCM on the surface of RCA from different concrete sources could be significantly different in terms of age, composition, modulus, strength, porosity, surface texture, thickness, content, and distribution, etc., due to the mix design, loading history, and environmental conditions of source concrete, and RCA producing process. Almost all previous studies used the current HMA mix design procedure by only considering RCA substitution rate without considering the variation of RCA from different sources, not to mention the variation of the $\mathrm{RCM}$ within RCA. This might be the reason for the contradictory findings in the literature on the properties of RCA-HMA. 

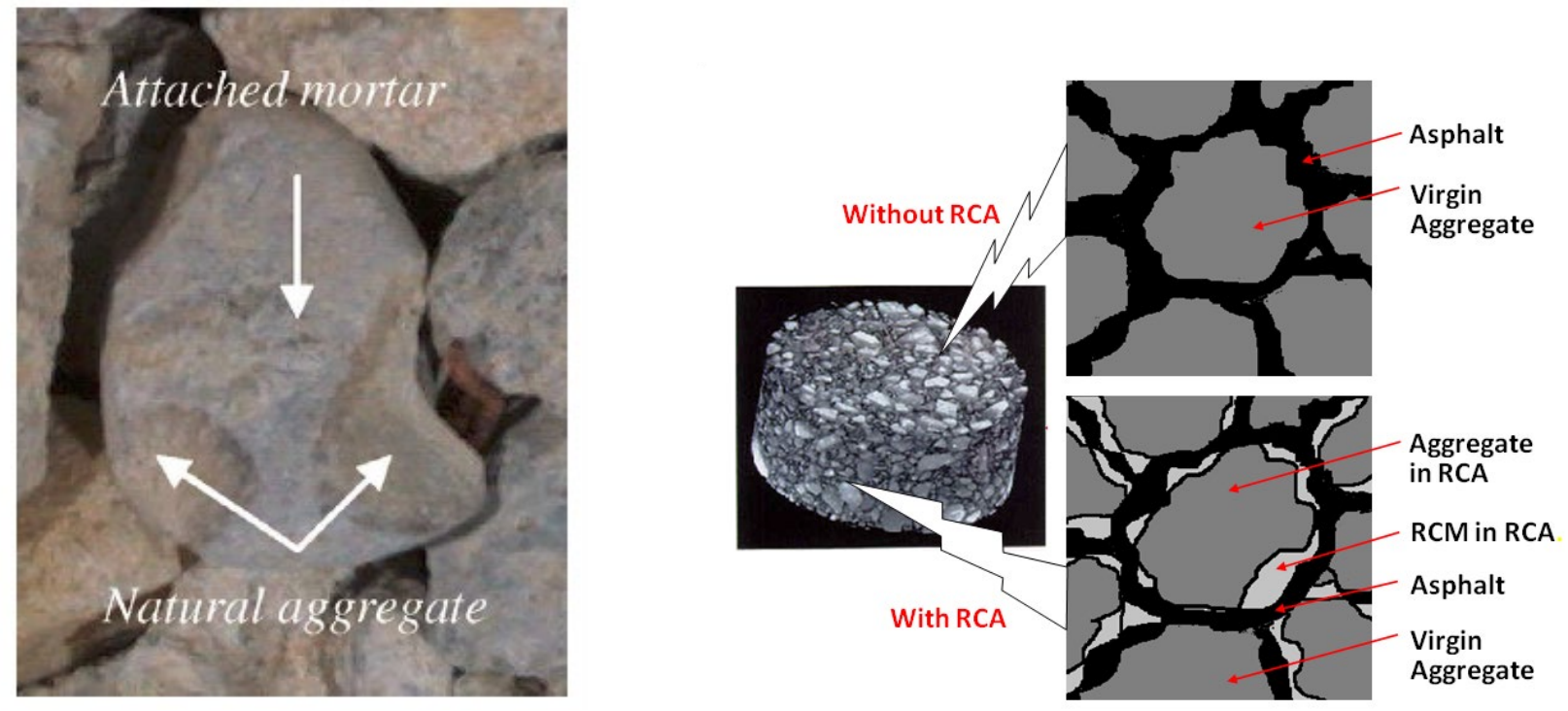

Figure 1. RCA and Schematic of HMA With and Without RCA

The assumption that the variation of the RCM within RCA plays a critical role in the properties of RCA-HMA could be indirectly validated by other researchers. In the literature, some researchers ${ }^{19}$ indicated that using $\mathrm{RCA}$ as a filler, fine fraction, or coarse fraction can have different effects on the resilient modulus of RCA-HMA. Other studies ${ }^{20}$ have also reported different effects on the resistance to permanent deformation when using RCA to substitute coarse or fine fractions of the virgin aggregate in HMA. This could be because the contents and distributions of the RCM in coarse and fine RCAs are different. It was reported that for different sources of RCA and different particle size fractions of RCA of the same source, both the RCM content and their distribution are quite different. ${ }^{21}$ Therefore, it could be misleading to only consider how the RCA substitution rate affects the HMA properties without looking at the details of RCM attached on the surface of RCA. The nature of the RCM in the RCA could play a critical role and must be considered when study the performance of the RCA-HMA mixture. Up until now, however, there have been no reported studies correlating RCM properties, such as RCM content, absorption, and addition rates, etc. with the properties of RCA-HMA.

\section{OBJECTIVES}

The objective of this study is to determine the characteristics of RCA and RCM, such as RCM content, specific gravity, and absorption, and to evaluate their effects on the volumetrics and performance indicators of RCA-HMA. Based on laboratory evaluation results of raw materials (RCA and virgin aggregate) and mixtures (HMA and RCA-HMA), this study intends to identify the trend of RCA-HMA performance and understand the mechanism behind this trend, in order to provide a quality control guideline for RCA-HMA. The major difference between this study and previous research is that RCM's properties has been experimentally characterized and correlated with the performance of RCA-HMA. 


\section{MATERIALS AND EXPERIMENTS}

This section discusses the materials used and the experiments conducted in this study.

\section{MATERIALS}

This study used materials which are locally available and commonly used for highway construction at Fresno and Chico, California, including recycled concrete aggregate (RCA), asphalt, and virgin aggregate.

\section{Recycled Concrete Aggregate (RCA)}

One of the objectives of this study is to investigate the variation of properties of RCAs from different concrete sources. However, RCA plants typically crush mixture of demolished concrete from all available sources without separation. Therefore, typically in practice, the source concrete of RCA cannot be controlled. It depends on what is under demolition and available in the local area. It is more meaningful in engineering practice to investigate the variation of RCA properties sampled at different dates and from different sources. To this end, this study used some RCA samples with well controlled sources but limited quantities and some samples without detailed source concrete information but with adequate supply. To study the variation of the RCA properties from different sources, four RCA sources were obtained. These are 1) RCA from the Knife River Construction, Chico Plant, Chico, CA sampled in December 2018, which will be referred as "Chico RCA 2018" hereafter; 2) RCA from the same plant (Knife River Construction, Chico Plant) at Chico, CA sampled in March 2019, which will be referred as "Chico RCA 2019"; 3) RCA from a demolished 50-year old bridge at Fresno, CA, as shown in Figure 2, which will be referred as "50-Year Bridge RCA"; and 4) RCA from the crushed concrete cylinders with several months' age for a recent bridge pour as shown in Figure 3, which will be referred as "Recent-Bridge-Pour RCA". The reason that the Recent-Bridge-Pour RCA was incorporated into the study is that in practice this source concrete was recycled to produce RCA together with other demolished concrete.

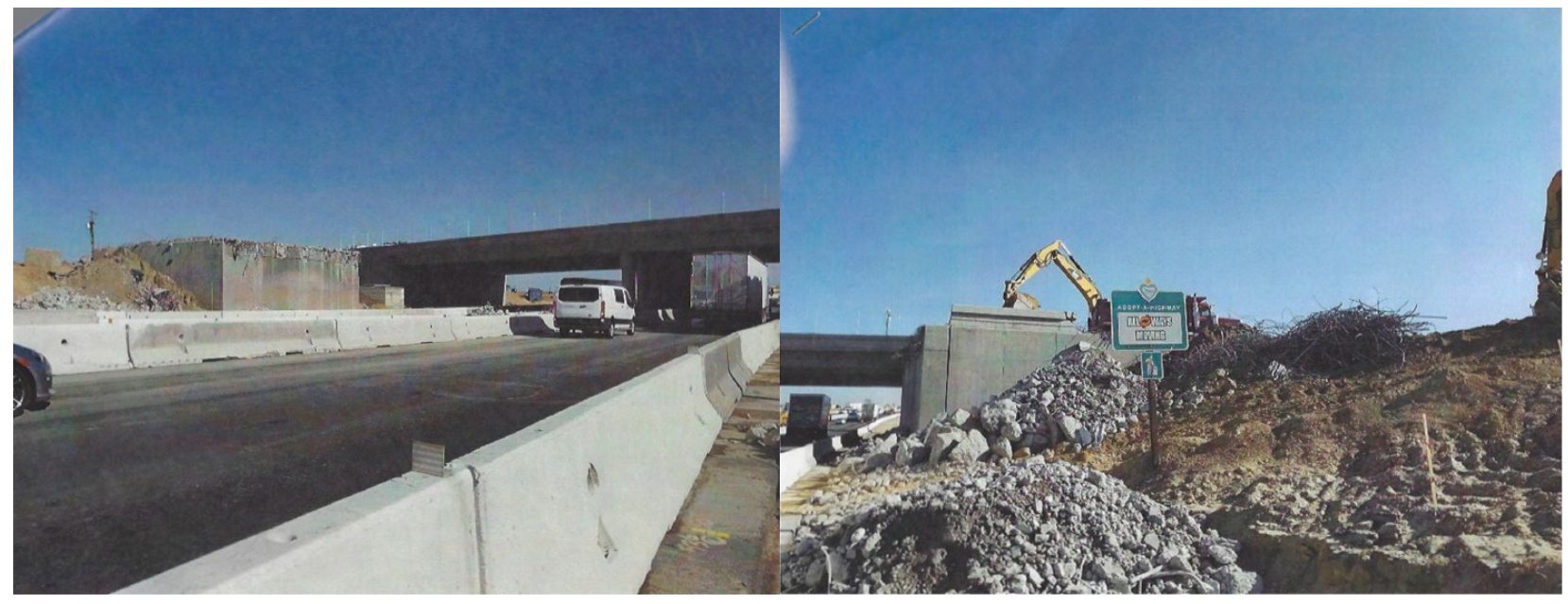

Figure 2. RCA from Demolition of a 50-Year-Old Bridge 


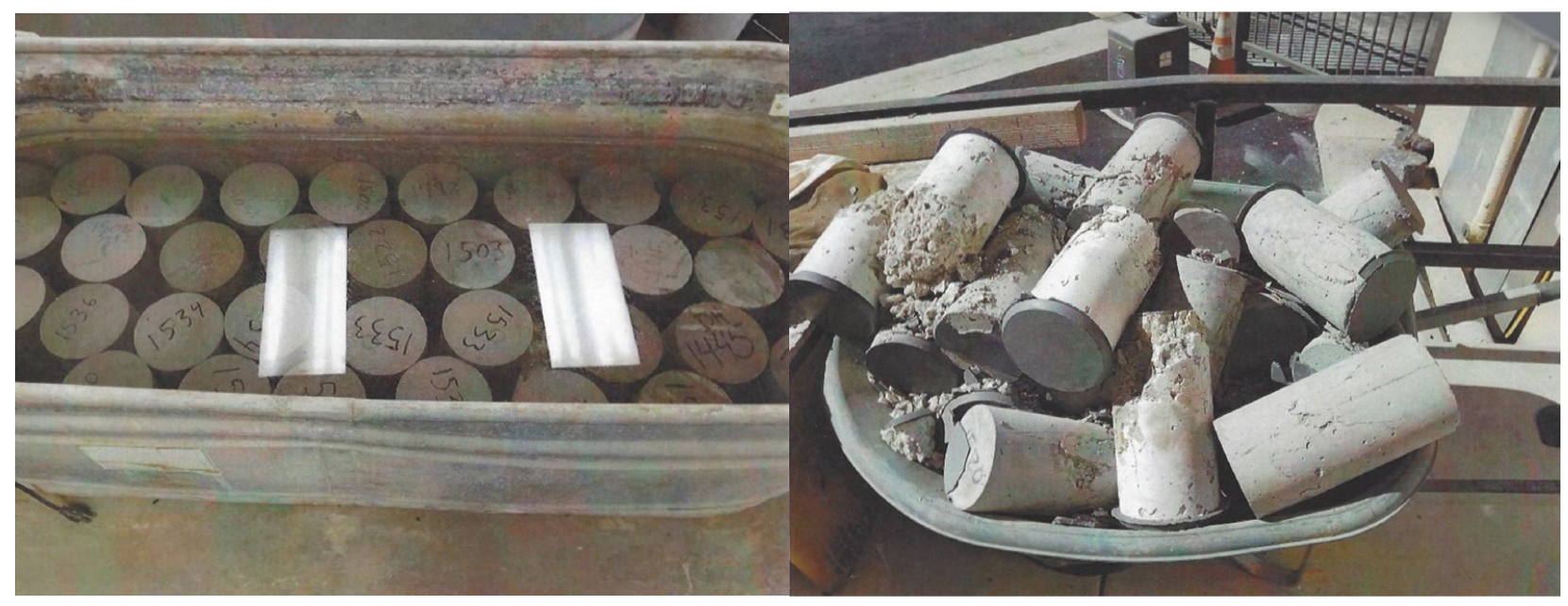

Figure 3. Concrete Cylinder for a Recent Bridge Pour Project

\section{Asphalt}

The asphalt binder was collected from the Knife River Construction and supplied by Pacific Northwest Oil. The performance grade of the asphalt binder is PG 64-16. Based on the temperature-viscosity chart, the recommended mixing temperature range is $155-161^{\circ} \mathrm{C}$ $\left(311-322^{\circ} \mathrm{F}\right)$ and the compaction temperature range is $143-148^{\circ} \mathrm{C}\left(289-298^{\circ} \mathrm{F}\right)$. In the laboratory, the mixing and compaction temperatures used are $160^{\circ} \mathrm{C}$ and $148^{\circ} \mathrm{C}$, respectively.

\section{Virgin Aggregate}

The virgin aggregates were collected from Knife River Construction, Orland Plant. Five sizes of virgin aggregates were collected as $19.1 \mathrm{~mm}$ (3/4") Crushed, $12.5 \mathrm{~mm}(1 / 2$ ") Crushed, $9.5 \mathrm{~mm}(3 / 8 ")$ Crushed, Crushed Dust, and Washed Crushed Dust. Since the objective of this study is to investigate the effects of RCA on the performance of the RCA-HMA, the effects of gradation on the performance of mixtures need to be excluded. Therefore, it was determined that different sizes of RCA was used to replace the corresponding sizes of virgin aggregates in order to maintain the same gradation after RCA replacement. To this end, the coarse virgin aggregates and the RCA were dried and sieved into each size group of 12.5-19.1 $\mathrm{mm}$, $9.5-12.5 \mathrm{~mm}, 4.75-9.5 \mathrm{~mm}$, and $<4.75 \mathrm{~mm}$ and stored in different buckets for future use.

\section{EXPERIMENTS}

\section{Experiments for RCA and RCM}

This section discusses the experiments used for the characterization of RCA and RCM properties/parameters, as listed in Table 1. The properties/parameters include RCM content, specific gravity of RCA and RCM, and absorption of RCA and RCM. Since the RCM's content and its distribution among different RCA particle sizes could be different, ${ }^{22}$ the RCAs from different sources were separated into four size groups: $<4.75 \mathrm{~mm}, 4.75-9.5 \mathrm{~mm}, 9.5$ $12.7 \mathrm{~mm}$, and $12.7-19.1 \mathrm{~mm}$. Preliminary literature ${ }^{23}$ indicates that the $<4.75 \mathrm{~mm}$ group of $\mathrm{RCA}$ is mainly composed of RCM and aggregate with high absorption. It is uneconomical to use this fine RCA fraction to replace corresponding virgin fine aggregate in HMA. ${ }^{24}$ RCA 
properties/parameters were measured for each fraction of each source of RCA, as shown in Table 1.

Table 1. Experiment Matrix for RCA and RCM

\begin{tabular}{cll}
\hline RCA Source & \multicolumn{1}{c}{ Fraction } & \multicolumn{1}{c}{ Parameter } \\
\hline Source I; & & RCA: Specific Gravity; \\
Source II; & $4.75-9.5 \mathrm{~mm} ;$ & Absorption; \\
Source III; & $9.5-12.7 \mathrm{~mm} ;$ & RCM: Content, \\
Source IV & $12.7-19.1 \mathrm{~mm}$. & Specific Gravity, \\
& & Absorption. \\
\hline
\end{tabular}

Due to the relatively small portion of RCM within RCA and the difficulty of separating RCM from RCA, it is not practical to quantify the RCM properties/parameters directly. Since RCA is a mixture of original natural aggregate and RCM, in this study, the RCA properties/ parameters were measured directly and the RCM properties/parameters were calculated from RCA parameters and the measured RCM content.

\section{(1) RCM Content}

The RCM content in RCA was determined using method developed by Abbas et al. ${ }^{25}$ for its convenience and accuracy. It can separate the residual cement mortar from the original natural aggregate in RCA by the following procedure: 1) oven dry representative sample for 24 hours at $105^{\circ} \mathrm{C}$, and take the mass; 2) submerge oven-dried sample in a $26 \%$ by weight sodium sulphate solution for 24 -hour; 3 ) RCA submerged in sodium sulphate solution experiencing five cycles of freezing and thawing, where each cycle includes 16 -hour freezing at $-17^{\circ} \mathrm{C}$ and 8 -hour thawing at $80^{\circ} \mathrm{C}$; 4) drain solution, wash sample with tap water through No. $4(4.75 \mathrm{~mm})$ sieve; and 5) oven dry aggregate retained on No. 4 sieve for 24 -hour at $105^{\circ} \mathrm{C}$, and take the mass. The RCM content is then determined by Equation (1). Detailed procedure can be found in references. ${ }^{26}$

$$
R C M \%=\frac{M_{i-} M_{f}}{M_{i}}
$$

where: $M_{i}=$ initial oven-dry mass of RCA sample before test (g);

$M_{f}=$ final oven-dry mass of RCA sample after experiencing freezing-thawing cycles while submerged under sodium sulfate solution;

\section{(2) Specific Gravity and Absorption of RCA and RCM}

The specific gravity and absorption of RCA were measured directly following AASHTO T-84 (Standard Method of Test for Specific Gravity and Absorption of Fine Aggregate) for fine aggregate and AASHTO T-85 (Standard Method of Test for Specific Gravity and Absorption of Coarse Aggregate) for coarse aggregate. After the RCM is removed from RCA using the method developed by Abbas et al. (introduced previously), the specific gravity of the original natural aggregate in RCA without RCM can be measured directly following AASHTO T-84 and AASHTO T-85. Then, the specific gravity and absorption of RCM can be calculated. 
The absorption of the blended materials is simply the weighted average of the absorption of the components. ${ }^{27}$ Therefore, the absorption of the RCM can be calculated from absorption of the RCA and the absorption of the aggregate after removing RCM by Equation (2):

$$
A_{R C M}=\frac{A_{R C A}-(1-p) A_{a g g}}{p}
$$

where: $A_{R C M}=$ absorption of RCM;

$\mathrm{p}=\mathrm{RCM}$ content;

$A_{R C A}=$ absorption of RCA;

$A_{\text {agg }}=$ absorption of original natural aggregate.

The blended specific gravity of a mixture is not the weighted average of ingredients, but it can be calculated with Equation (3): 28

$$
G_{s b, R C A}=\frac{1}{\frac{p}{G_{s b, R C M}}+\frac{1-p}{G_{s b, a g g}}}
$$

Then the specific gravity of the RCM can be calculated with specific gravity of RCA, specific gravity of aggregate after the RCM was removed, and the RCM content by Equation (4):

$$
G_{s b, R C M}=\frac{p}{\frac{1}{G_{s b, R C A}}-\frac{1-p}{G_{s b, a g g}}}
$$

where: $\quad G_{s b, R C M}=$ specific gravity of RCM;

$\mathrm{p}=\mathrm{RCM}$ content;

$G_{s b, R C A}=$ specific gravity of RCA;

$G_{s b, a g g}=$ specific gravity of original natural aggregate

\section{Experiments for HMA and RCA-HMA}

This section discusses the experiments carried out for the characterization of HMA and RCA-HMA properties. The experimental design and HMA performance indicators are listed in Table 2, considering the following two factors. One factor is RCA substitution rate: the substitution will be limited to one of the three coarse particle size groups, i.e., 4.75-9.5mm, 9.5-12.7mm, or $12.7-19.1 \mathrm{~mm}$, with $100 \%$ RCA replacement, but maintain other size of particles with $100 \%$ virgin aggregate and keep the gradation the same as the control mix. The other factor is HMA Performance indicators: three generally accepted HMA performance indicators, i.e., volumetrics, resistance to permanent deformation, and moisture damage susceptibility; the fine particle size RCA $(<4.75 \mathrm{~mm})$ was not considered for usage because of its greater RCM content and larger surface area, which would result in an uneconomical high $\mathrm{OBC} .{ }^{29}$ 
Table 2. Experiment Matrix for Performance of HMA and RCA-HMA

\begin{tabular}{ccll}
\hline HMA Mixture & RCA Substitution Rate (\%) & & HMA and RCA-HMA Performance Indicator \\
\hline Caltrans 3/4" HMA & $100 \%$ substitution: one of the & - & Volumetrics (VMA, VFA, OBC); \\
Type A & particle size groups & - & Resistance to Permanent Deformation (HWTT); \\
& $4.75-9.5 \mathrm{~mm} ;$ & - & Moisture Damage Susceptibility (TSR); \\
& $9.5-12.7 \mathrm{~mm} ;$ & & \\
$12.7-19.1 \mathrm{~mm}$. & & \\
& &
\end{tabular}

Note: VMA: mineral aggregate content; VFA: voids filled with asphalt content; OBC: optimum binder content; HWTT: Hamburg wheel tracking test; TSR: tensile strength ratio.

(1) Mixture design and volumetrics (VMA, VFA, and OBC)

The control HMA and RCA-HMA mix design followed AASHTO R-28 and M-323 to determine $\mathrm{OBC}$. The VMA and VFA was calculated based on mix design results.

(2) Resistance to permanent deformation (HWTT)

The Hamburg wheel tracking test (HWTT) was used to characterize the resistance to permanent deformation following AASHTO T-324 standard. The HWTT has been used for laboratory evaluation of the rutting and moisture damage properties of asphaltic mixture. A HWTT device uses a rolling steel wheel across the surface of asphaltic mixture specimen which can simulate field traffic loading, as shown in Figure 4. With the increase of the loading cycles, the rutting depth will be recorded. It has been reported that the HWTT results could be correlated well with field rutting and moisture damage performance. ${ }^{30} \mathrm{In}$ this study, the temperature was controlled at $50^{\circ} \mathrm{C}$ during HWTT. A target air void level of $7 \%( \pm 1) \%$ was used for specimen fabrication.

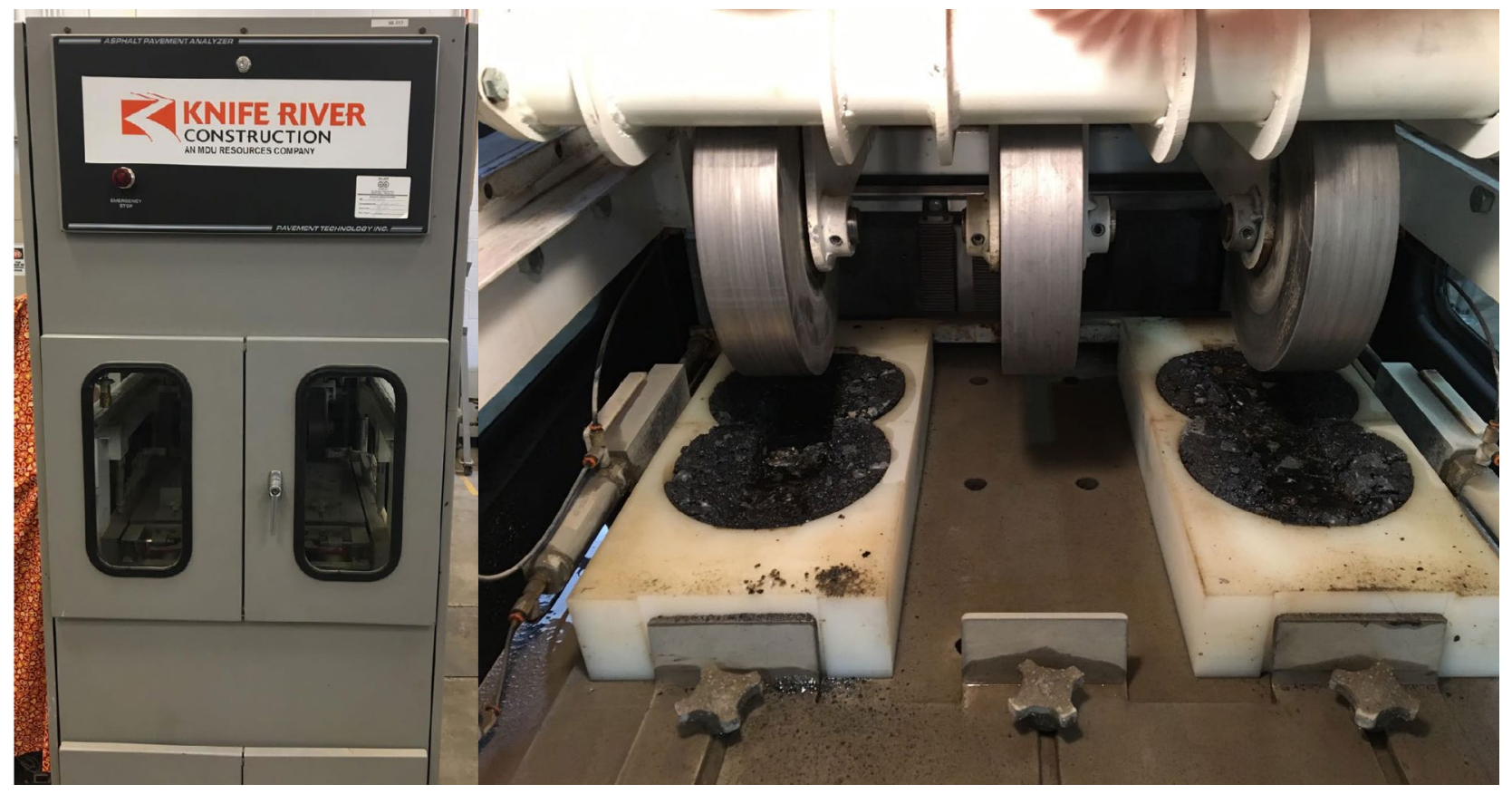

Figure 4. HWTT Equipment and Test Setup 
(3) Moisture damage susceptibility (TSR)

Tensile strength ratio (TSR) was used as an indicator of moisture damage susceptibility. The TSR tests were performed following AASHTO T-283. Test specimens were fabricated to an air void level of $7 \%( \pm 1 \%)$ to simulate field condition at early pavement service age after construction.

The TSR test involved conditioned and unconditioned specimens. Conditioned specimens, referred as "wet specimens" hereafter, underwent a simulated freeze-thaw cycle before being tested. Its indirect tensile (IDT) strength is referred as "wet strength." The conditioned specimens were first vacuum saturated with water to achieve a degree of saturation between $70 \%$ and $80 \%$. Then, the specimens were frozen for 18 hours at $-18^{\circ} \mathrm{C}$. Following the freeze-cycle, the specimens were placed in a $60^{\circ} \mathrm{C}$ water bath to thaw for 24 hours. The unconditioned specimens, referred as "dry specimens" hereafter, did not undergo freeze-thaw cycle before being tested. Their IDT strength is referred as "dry strength" in this study. All specimens were placed in a room-temperature water bath for two hours prior to testing to ensure thermal equilibrium. The average TSR value was then calculated for the specimens by comparing the IDT strength of the conditioned specimens to that of the unconditioned specimens. The equipment used for the TSR test is shown in Figure 5.

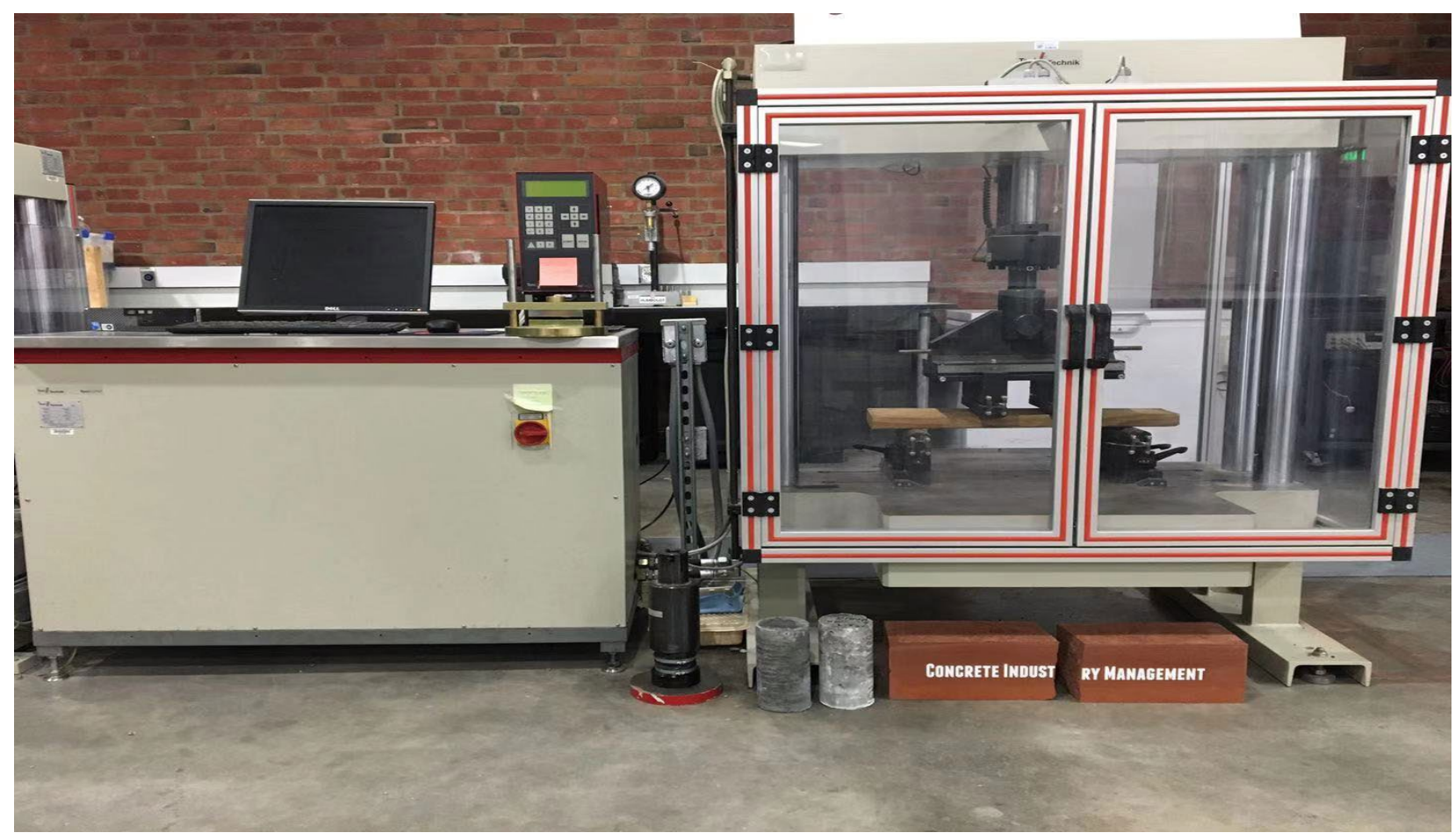

Figure 5. TSR Test Equipment 


\section{RESULTS AND ANALYSIS}

The results and analysis will be separated into 1) results of RCA and RCM characterization, 2) results of HMA and RCA-HMA characterization, and 3) relationship between RCA/RCM properties and HMA/RCA-HMA properties.

\section{CHARACTERIZATION OF RCA AND RCM}

The material properties used for the characterization of RCA and RCM include RCM content, specific gravity, and absorption. As discussed previously, to identify the variations of RCM content, specific gravity, and absorption among different RCA sources and RCA particle sizes, the measurements were conducted for different sources and size groups, namely: 4.75-9.5mm, 9.5-12.7mm, and 12.7-19.1mm.

\section{RCM Content}

Table 3 and Figure 6 show the RCM contents of RCAs from different sources for the three size groups.

Firstly, the average RCM contents of RCAs from different sources show large variation, even for the RCAs from the same plant but sampled at different times (Chico RCA plant sampled in December 2018 and March 2019). The average RCM content of all size groups for Chico RCA plant sampled in December 2018 and March 2019, and the Recent-BridgePour RCA are $27.3 \%, 35.1 \%$, and $49.9 \%$, respectively, which is comparable with the RCM content ranging from $23 \%$ to $41 \%$ in the literature. ${ }^{31}$ The reason that the Recent-Bridge-Pour RCA has a very high RCM content (49.9\%) is possibly because that the age of the source concrete is less than one year and the cement paste has not gained sufficient strength yet. This indicates the significant variation of RCM contents of RCAs from different sources, at different concrete ages, and even from the same plant but sampled at different times. In practice, the source concrete of the RCA could be a mixture from any demolishing projects available. Although particle size distribution of the RCA can be well controlled, the plant does not control the RCM content.

Secondly, the results clearly indicate that the RCM contents are reducing with the increase of the particle size for all the RCAs from different sources used in this study. For the same RCA source, the difference in RCM contents between relatively fine particles $(4.75-9.5 \mathrm{~mm})$ and relatively coarse particles $(12.7-19.1 \mathrm{~mm})$ can be as large as $21.5 \%(17.4 \%-21.5 \%$ for the RCAs tested in this study). The variation of the RCM contents for the same size groups but sampled at different times (in December 2018 and March 2019) from the same plant are, respectively, $6.7 \%, 5.7 \%$, and $10.8 \%$ for $12.5-19.1 \mathrm{~mm}, 9.5-12.5 \mathrm{~mm}$, and $4.75-9.5 \mathrm{~mm}$ size group. This indicates that the variation of the RCM contents is larger for smaller particle sizes than for larger particle sizes from the three different sources. These results establish the significant variation of the RCA properties in terms of RCM contents among different particle size groups, even when they are processed by the same plant. 
Table 3. RCM Content for Different Size Groups of RCAs from Different Sources

\begin{tabular}{cccc}
\hline RCA Source & Group Size $(\mathbf{m m})$ & RCM Content & Average \\
\hline \multirow{2}{*}{ Chico RCA 2018 } & $4.75-9.5$ & $36.1 \%$ & \\
& $9.5-12.5$ & $27.1 \%$ & $27.3 \%$ \\
Chico RCA 2019 & $12.5-19.1$ & $18.7 \%$ & \\
& $4.75-9.5$ & $47.0 \%$ & \\
& $9.5-12.5$ & $32.8 \%$ & $35.1 \%$ \\
Recent-Bridge-Pour RCA & $12.5-19.1$ & $25.5 \%$ & \\
& $4.75-9.5$ & $60.1 \%$ & $49.9 \%$ \\
\hline
\end{tabular}

\section{RCM Content for Different Size Groups}

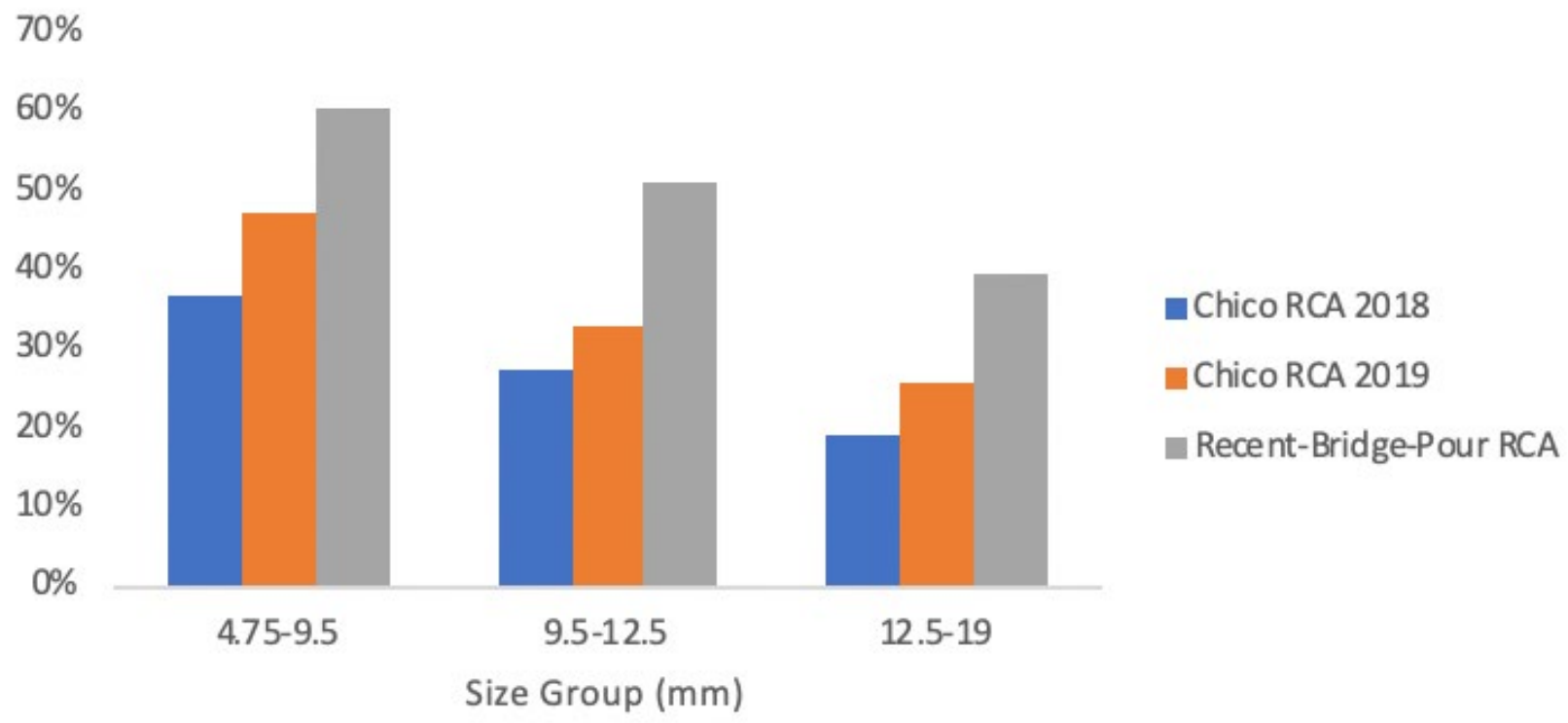

Figure 6. RCM Content for Different Size Groups of RCAs from Different Sources

\section{Specific Gravity and Absorption of RCA and RCM}

As previously discussed in section "Experiments for RCA and RCM", the specific gravity and absorption of RCA and the original aggregates (after the RCM was removed from the RCA) were measured directly following AASHTO T84 and AASHTO T85. Then, the specific gravity and absorption of the RCM were calculated. The results for the specific gravities and absorptions of RCA, original aggregate in RCA (after removing RCM), and RCM from different sources are summarized in Table 4. 
Table 4. Specific Gravity and Absorption Test Results of RCA

\begin{tabular}{|c|c|c|c|c|c|c|c|c|c|}
\hline \multirow[b]{2}{*}{$\begin{array}{c}\text { RCA } \\
\text { Source }\end{array}$} & \multirow[b]{2}{*}{$\begin{array}{l}\text { Group } \\
\text { Size } \\
(\mathrm{mm})\end{array}$} & \multirow[b]{2}{*}{$\begin{array}{c}\text { RCM } \\
\text { Content }\end{array}$} & \multirow[b]{2}{*}{ Average } & \multicolumn{3}{|c|}{ Specific Gravity } & \multicolumn{3}{|c|}{ Absorption } \\
\hline & & & & RCA & $\begin{array}{c}\text { Agg. } \\
\text { (after } \\
\text { remove } \\
\text { RCM) }\end{array}$ & RCM & RCA & $\begin{array}{c}\text { Agg. } \\
\text { (after } \\
\text { remove } \\
\text { RCM) }\end{array}$ & $\mathrm{RCM}$ \\
\hline \multirow{4}{*}{$\begin{array}{l}\text { Chico RCA } \\
2018\end{array}$} & $4.75-9.5$ & $36.1 \%$ & & 2.323 & 2.499 & 2.013 & $6.5 \%$ & $3.4 \%$ & $12.0 \%$ \\
\hline & $9.5-12.5$ & $27.1 \%$ & $27.3 \%$ & 2.386 & 2.553 & 1.938 & $5.0 \%$ & $3.0 \%$ & $10.4 \%$ \\
\hline & $12.5-19$ & $18.7 \%$ & & 2.415 & 2.525 & 1.938 & $4.5 \%$ & $3.0 \%$ & $11.0 \%$ \\
\hline & $4.75-9.5$ & $47.0 \%$ & & 2.234 & 2.533 & 1.896 & $7.3 \%$ & $3.1 \%$ & $11.9 \%$ \\
\hline \multirow{2}{*}{$\begin{array}{l}\text { Chico RCA } \\
2019\end{array}$} & $9.5-12.5$ & $32.8 \%$ & $35.1 \%$ & 2.294 & 2.500 & 1.870 & $5.9 \%$ & $3.4 \%$ & $11.0 \%$ \\
\hline & $12.5-19$ & $25.5 \%$ & & 2.321 & 2.497 & 1.806 & $5.5 \%$ & $3.5 \%$ & $11.4 \%$ \\
\hline \multirow{3}{*}{$\begin{array}{l}\text { Recent- } \\
\text { Bridge- } \\
\text { Pour RCA }\end{array}$} & $4.75-9.5$ & $60.1 \%$ & \multirow{3}{*}{$49.9 \%$} & 2.202 & & & \multirow{6}{*}{$\mathrm{n} / \mathrm{a}$} & & \\
\hline & $9.5-12.5$ & $50.7 \%$ & & 2.291 & & & & & \\
\hline & $12.5-19$ & $39.0 \%$ & & 2.362 & & & & & \\
\hline \multirow{3}{*}{$\begin{array}{l}\text { 50-year } \\
\text { Bridge } \\
\text { RCA }\end{array}$} & $4.75-9.5$ & & \multirow{3}{*}{$\mathrm{n} / \mathrm{a}$} & 2.261 & & & & & \\
\hline & $9.5-12.5$ & & & 2.361 & & & & & \\
\hline & $12.5-19$ & & & 2.443 & & & & & \\
\hline
\end{tabular}

Figure 7 shows the specific gravities of RCAs from four different sources. It can be seen that the specific gravities show large variation from 2.202 to 2.443 (which is comparable with a typical range of the RCA specific gravities from 2.31 to 2.42). ${ }^{32}$ This indicates the significant variation of the specific gravities of RCAs from different sources. The results also show that the specific gravities increase with the increase of the particle size for the four RCAs from different sources.

\section{Specific Gravity of RCA}

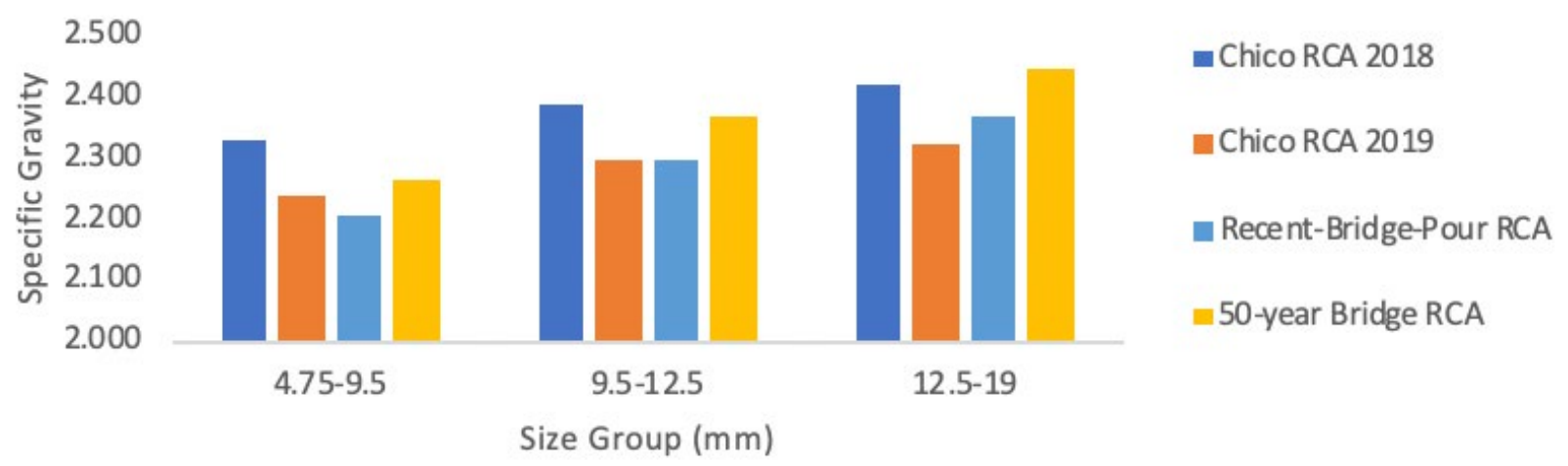

Figure 7. Specific Gravity for Different Size Groups of RCAs from Different Sources

The specific gravity results for the RCA samples of Chico RCA 2018 and Chico RCA 2019 are shown in Figure 8.

Firstly, the specific gravities of Chico RCA 2018 and Chico RCA 2019 increase with the increase of the particle size. However, for the same particle size group, the specific gravities of RCAs sampled at different times (Chico RCA2018 and Chico RCA2019) are very different, even though they are sampled from the same plant. Again, this establishes the significant 
variation of the RCA properties even when they are processed by the same plant, since the source concrete of the RCA could be a mixture from any demolishing projects available.

Secondly, the specific gravities of the aggregate after the RCM was removed are consistent with small variation, regardless of the size groups or sampling time (December 2018 or March 2019). The average specific gravity is 2.518 with a standard deviation of 0.023 , which is shown as the red line in Figure 8 . The specific gravity of the aggregate after removing $\mathrm{RCM}$ is much larger than that of the RCA and RCM.

Thirdly, the specific gravities of RCA are increasing with the increase of the particle size groups, due to the reducing RCM contents as shown in previous section.

Lastly, the specific gravities of the RCM from RCA sampled in December 2018 are relatively consistent with an average of 2.043 and a standard deviation of 0.021 . The specific gravities of the RCM from RCA sampled in March 2019 are relatively consistent, as well, with an average of 1.952 and a standard deviation of 0.025 . However, the average specific gravities of the RCMs from RCAs sampled in December 2018 and March 2019 show a difference of 0.090 , which indicates the variation of the RCM properties even they are sampled from the same plant. This variation is shown as the blue line and green line in Figure 8.

The results of the specific gravities of RCAs, original aggregates, and RCMs for Chico (2018) and Chico (2019) are possible given that different sources of concrete used to produce RCAs were made with typical source aggregates available in the local area. Their properties were quite consistent. However, the properties of the RCM could vary significantly due to source concrete mix design.

\section{Specific Gravity}

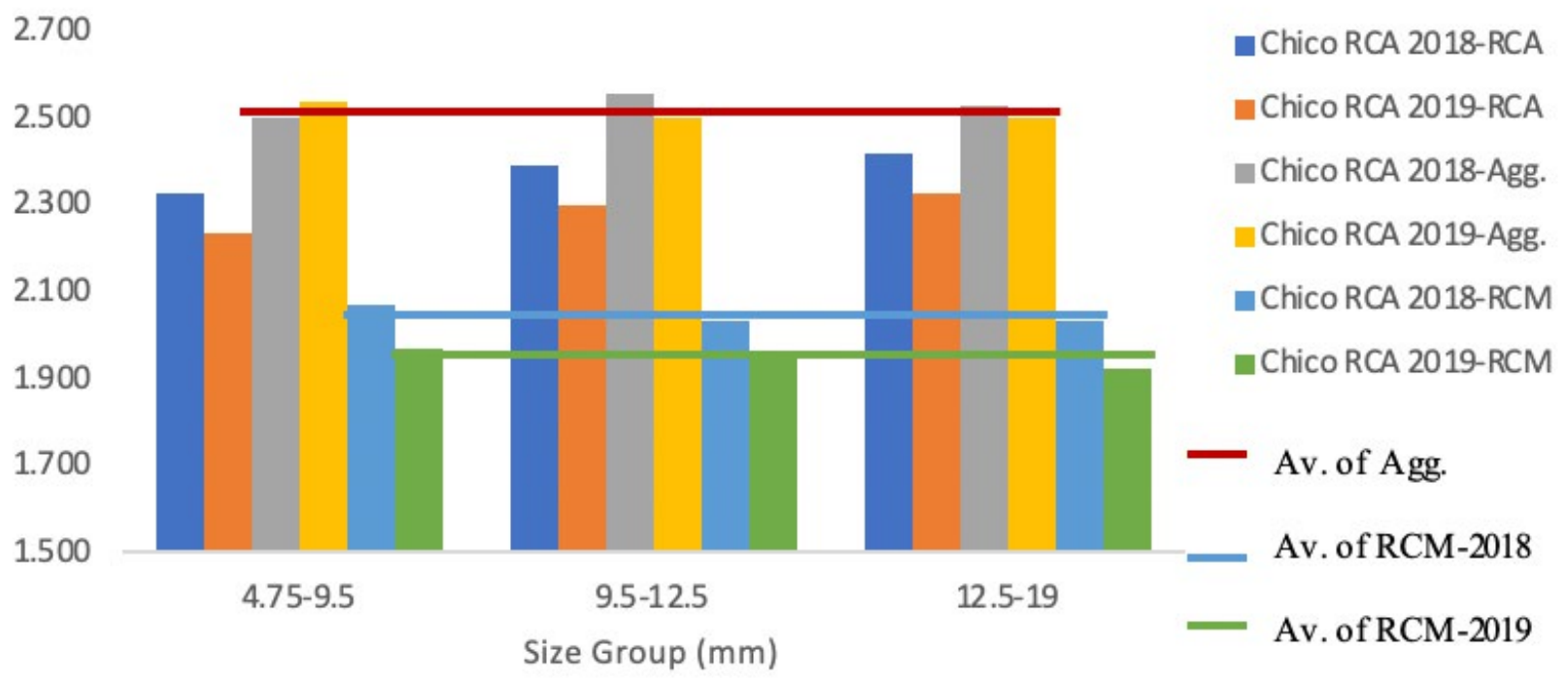

Figure 8. Specific Gravity of RCA, Agg. (after removing RCM), and RCM for Chico RCA Sampled at Different Time

As shown in Figure 9, the absorptions for different particle sizes from different RCA sources ranges from $4.5 \%$ to $7.3 \%$, which is comparable with a range found in the literature $(3.3 \%$ 
to $5.4 \%),{ }^{32}$ considering the large variation in RCA properties. The absorptions of the RCA decrease with the increase of the particle size. For the same size group, the absorptions of the RCA sampled in December 2018 and March 2019 also show discrepancies. However, the absorption of the original aggregate after removing RCM and the absorption of the RCM are consistent with small variation, regardless of the size groups or the sampling time (December 2018 or March 2019). The average absorption of the original aggregate after removing RCM is $3.2 \%$ with a standard deviation of $0.2 \%$, and the average absorption of the $\mathrm{RCM}$ is $11.3 \%$, with a standard deviation of $0.6 \%$, which are shown as the green line and the red line, respectively, in Figure 9 . The possibility of relative consistent absorption in the original aggregates and RCMs can be due to similar source aggregate used to produce concrete. However, the absorptions of the RCAs for the same size group sampled in December 2018 and March 2019 show discrepancy, due to variation of the RCM contents and its properties. This results also shows the importance of the RCM content on RCA properties.

It can be seen from Figures 8 and 9 that both the specific gravities and absorptions of the aggregate after the RCM was removed are consistent for RCAs sampled at different times, possibly due to the consistency of the locally available aggregates. However, for the RCAs sampled at different time from the same plant, although both the RCM contents (Figure 6) and specific gravities of the RCMs (Figure 8) show large discrepancies, the absorptions of the RCMs do not show significant variation, as shown in Figure 9 by the red line.

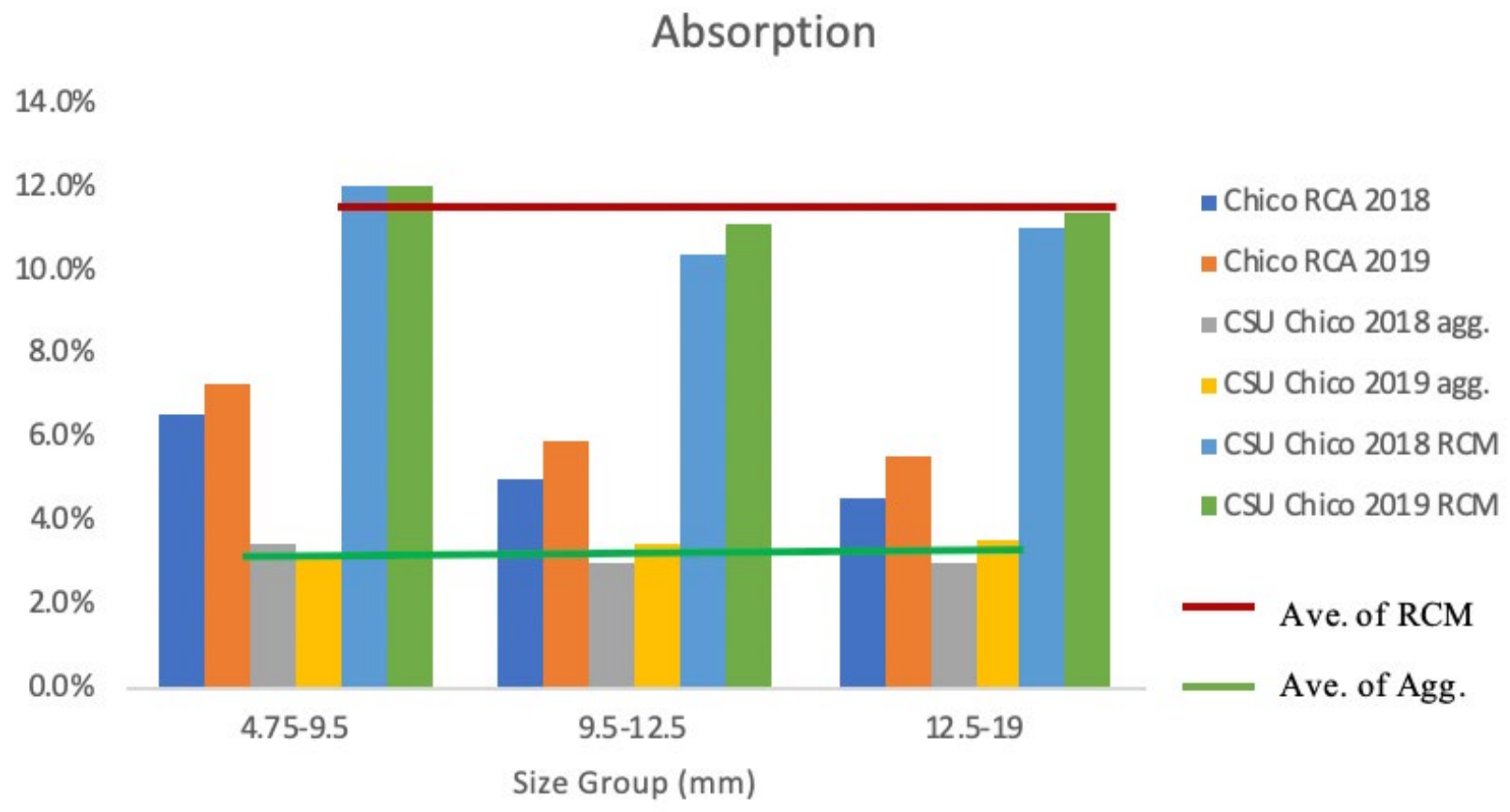

Figure 9. Absorption of RCA, Agg. (after removing RCM), and RCM for Chico RCA
Sampled at Different Time

Since the specific gravities and absorptions of the original aggregate in RCA are consistent with each other, while the RCM contents and its properties being drastically different, we can conclude that the variation of the RCA properties is mainly due to the variations of the RCM contents and its properties. This conclusion indicates that RCA replacement rates and gradations are unsuitable for studying RCA-HMA performance. These results partially verify 
the hypothesis that the nature of the RCM in the RCA can play a critical role in RCA-HMA performance and invites investigation on how RCM properties affect RCA-HMA performance.

\section{CHARACTERIZATION OF PERFORMANCE OF HMA AND RCA-HMA}

\section{Mixture Design}

The mixture design was carried out following the Superpave HMA mixture design procedure, using $100 \%$ virgin aggregate as the control mix.

\section{(1) Virgin Aggregate Properties}

The sieve analysis results of the five size virgin aggregates from plant stockpiles are shown in Table 5.

Table 5. Gradation Results for Virgin Aggregates

\begin{tabular}{llllcc}
\hline \multicolumn{5}{c}{ Sieve Analysis (\% Passing) } \\
\hline Materials Size (mm) & $\mathbf{1 9 . 1}$ & $\mathbf{1 2 . 5}$ & $\mathbf{9 . 5}$ & Crushed Dust & Washed Crushed Dust \\
\hline 25.4 & 100.0 & 100.0 & 100.0 & 100.0 & 100.0 \\
19.1 & 88.0 & 100.0 & 100.0 & 100.0 & 100.0 \\
12.5 & 3.3 & 70.9 & 99.9 & 100.0 & 100.0 \\
9.5 & 1.5 & 21.4 & 97.6 & 100.0 & 100.0 \\
No.4 & 0.8 & 2.0 & 20.9 & 98.6 & 96.7 \\
No.8 & 0.6 & 1.2 & 5.0 & 75.0 & 68.0 \\
No.16 & 0.6 & 0.8 & 2.7 & 54.5 & 44.9 \\
No.30 & 0.6 & 0.8 & 2.0 & 40.7 & 29.7 \\
No.50 & 0.5 & 0.7 & 1.6 & 30.1 & 18.1 \\
No.100 & 0.4 & 0.6 & 1.1 & 21.9 & 8.5 \\
No.200 & 0.37 & 0.50 & 0.80 & 16.81 & 3.42 \\
\hline
\end{tabular}

Since this study needs to investigate the replacement of different sizes of virgin aggregates with the corresponding sizes of RCA, the coarse virgin aggregates were dried and sieved into different size groups and stored in different buckets for future use. The bulk specific gravity and water absorption of coarse virgin aggregates were tested following AASHTO T85, and the results are shown in Table 6 . It can be seen that the specific gravities of particles of the same size group but sieved from different stockpiles are slightly different but within normal variations. 
Table 6. Bulk Specific Gravity and Water Absorption of Coarse Aggregates

\begin{tabular}{|c|c|c|c|c|c|c|}
\hline Resources & $\begin{array}{l}19.1 \mathrm{~mm} \\
\text { Crushed }\end{array}$ & $\begin{array}{l}19.1 \mathrm{~mm} \\
\text { Crushed }\end{array}$ & $\begin{array}{l}12.5 \mathrm{~mm} \\
\text { Crushed }\end{array}$ & $\begin{array}{l}12.5 \mathrm{~mm} \\
\text { Crushed }\end{array}$ & $\begin{array}{l}12.5 \mathrm{~mm} \\
\text { Crushed }\end{array}$ & $\begin{array}{c}9.5 \mathrm{~mm} \\
\text { Crushed }\end{array}$ \\
\hline Aggregate Size (passing) & $19.1 \mathrm{~mm}$ & $12.5 \mathrm{~mm}$ & $12.5 \mathrm{~mm}$ & $9.5 \mathrm{~mm}$ & No.4 & No.4 \\
\hline Bulk, Gsb & 2.823 & 2.776 & 2.763 & 2.737 & 2.697 & 2.671 \\
\hline Apparent, Gsa & 2.888 & 2.865 & 2.851 & 2.837 & 2.826 & 2.808 \\
\hline Bulk in SSD, Gsb, SSD & 2.845 & 2.807 & 2.794 & 2.773 & 2.742 & 2.720 \\
\hline Absorption (\%) & 0.80 & 1.11 & 1.12 & 1.28 & 1.69 & 1.83 \\
\hline
\end{tabular}

The fine aggregates from the crushed dust stockpile and the washed crushed dust stockpile were dried, sieved, and combined into different size groups of No. 8 through No. 200 and <No. 200. The bulk specific gravity and water absorption of the No. 8 through No. 200 size group were measured following AASHTO T84. The fines of $<$ No. 200 size group were tested to determine the apparent specific gravity following AASHTO T84 and used to determine the combined bulk specific gravity. ${ }^{34}$ The results are shown in Table 7. Figure 10 is a plot of the specific gravities of different size groups of virgin aggregate.

Table 7. Specific Gravity of Fine Aggregate and Fines

\begin{tabular}{lcc}
\hline \multicolumn{1}{c}{ Specific Gravity } & Fine Aggregate (No.8-200) & Fines (<No. 200) \\
\hline Bulk, Gsb & 2.665 & -- \\
Apparent, Gsa & 2.770 & 2.721 \\
Bulk in SSD, Gsb, SSD & 2.703 & -- \\
Absorption (\%) & 1.42 & --- \\
\hline
\end{tabular}

\section{Bulk Gsb}

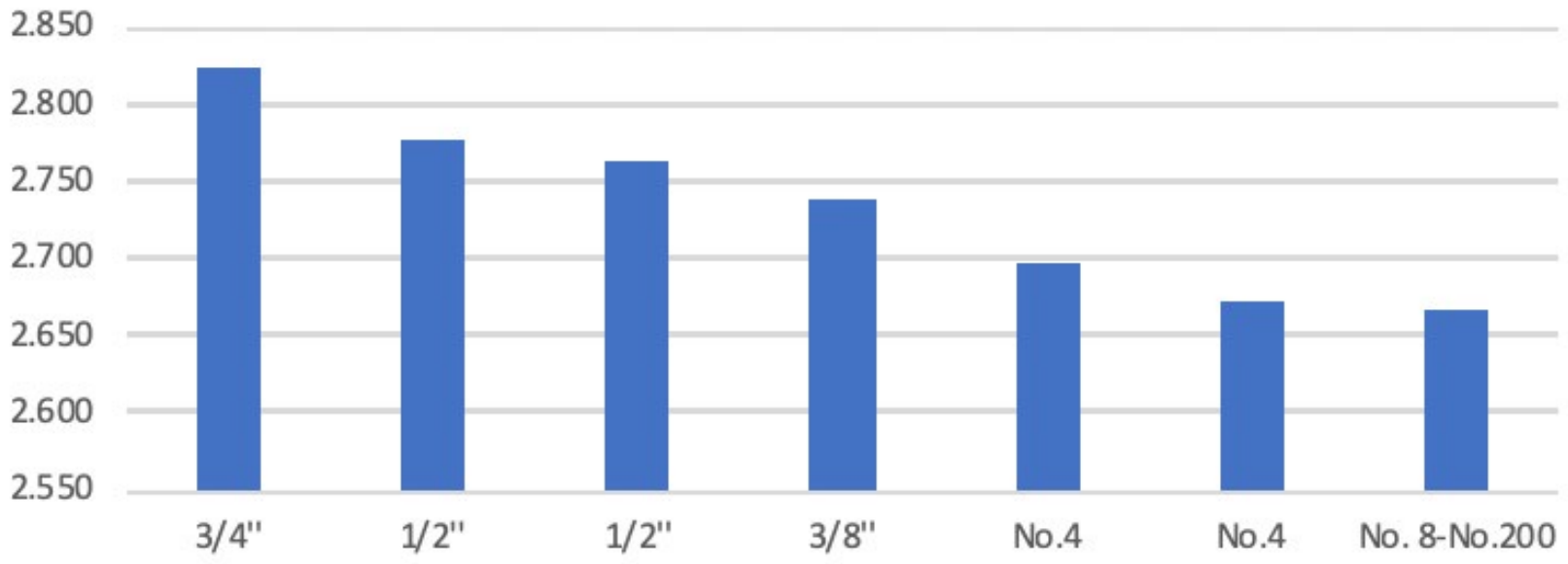

Figure 10. Specific Gravity of Virgin Agg. for Different Size Groups 


\section{(2) Gradation of HMA and RCA-HMA}

The mix design of control HMA (with $100 \%$ virgin aggregate) was performed following a job mix formula (JMF) of Caltrans 3/4" Type A HMA. ${ }^{35}$ This HMA is used as the control mixture to compare its volumetric and mechanical performances with those of the RCAHMA. It shall be mentioned that the original JMF from the Knife River Construction contains $15 \%$ RAP, while the control mixture used in this study does not contain the RAP because the research team wanted to reduce the possibility of the influence from RAP. Therefore, the proportions of five sizes of virgin aggregate were adjusted to match the final blended gradation of the original JMF.

Three control HMA mixtures were initially designed to match JMF and meet the Caltrans specification requirements. The control mix 1 matches the gradation of JMF; however, the OBC was determined to be $6.0 \%$ at air voids of $4 \%$. This OBC is significantly higher than the OBC in the original JMF. The discrepancy in OBC could be attributed to the adoption of the $15 \%$ RAP in the JMF, since RAP has already been coated with asphalt binders and it has lower binder absorption. Then, the control mix 2 was designed by increasing the content of fines passing No. 200 sieve size to $6 \%$. Although the OBC was reduced close to the $\mathrm{OBC}$ in the original JMF, the dust proportion of this mix was 1.5 , which exceeds the Caltrans requirement of dust proportion between 0.6 and 1.3.

Based on these two control mixes' results, a new control mix 3 was designed with the content of fines of $4.5 \%$; the OBC of this control mix was $5.3 \%$ and the VMA, VFA, and dust proportions met the Caltrans requirement. However, this mix cannot pass the Hamburg wheel track test specified by Caltrans. The rut depth reached $12.5 \mathrm{~mm}$ (halfinch) at 4,916 passes, which is far lower than the Caltrans-required 15,000 passes.

After consulting with plant engineers, the research team designed a new control mixture by increasing the proportions of coarse aggregate. This increases the interlocking of aggregates to improve the rutting resistance and meet all Caltrans requirements. After the mixture design of control mix with $100 \%$ virgin aggregate was determined, a $100 \%$ of each size group of $4.75-9.5 \mathrm{~mm}, 9.5-12.5 \mathrm{~mm}$, or $12.5-19.1 \mathrm{~mm}$ in the control mixture was replaced with the same size group of RCA, but keeping the remaining aggregates of all other sizes unchanged. After each replacement, a new mix design was carried out to determine the volumetrics and $\mathrm{OBC}$. In this way, the gradation of the control mixture and the mixtures after RCA replacement can be held constant.

Table 8 and Figure 11 show the gradation used for all the mixtures including control mixture (100\% virgin aggregate), RCA $4.75-9.5 \mathrm{~mm}$ mix (replace $100 \%$ particles between $4.75 \mathrm{~mm}$ and $9.5 \mathrm{~mm}$ with RCA), RCA 9.5-12.5mm mix (replace $100 \%$ particles between $9.5 \mathrm{~mm}$ and $12.5 \mathrm{~mm}$ with RCA), and RCA $12.5-19.1 \mathrm{~mm}$ mix (replace $100 \%$ particles between $12.5 \mathrm{~mm}$ and $19.1 \mathrm{~mm}$ with RCA). The details of the mix design test results are shown in Appendix A. 
Table 8. Final Gradation of Control HMA and RCA-HMA Mixes

\begin{tabular}{lllll}
\hline \multirow{2}{*}{ Sieve Size $(\mathbf{m m})$} & \multicolumn{3}{c}{ \% Passing and Gsb } \\
\cline { 2 - 5 } & \multicolumn{1}{c}{ Control Mix } & RCA 4.75-9.5mm & RCA 9.5-12.5mm & RCA 12.5-19.1 mm \\
\hline 25.4 & 100 & 100 & 100 & 100 \\
19.1 & 93 & 93 & 93 & 93 \\
12.5 & 71 & 71 & 71 & 71 \\
9.5 & 63 & 63 & 63 & 63 \\
No.4 & 42 & 42 & 42 & 42 \\
No.8 & 29 & 29 & 29 & 29 \\
No.16 & 17 & 17 & 17 & 17 \\
No.30 & 14 & 14 & 14 & 14 \\
No.50 & 7 & 7 & 7 & 7 \\
No.100 & 6 & 6 & 6 & 6 \\
No.200 & 4.5 & 4.5 & 4.5 & 4.5 \\
Combined Gsb & 2.709 & 2.603 & 2.675 & 2.622 \\
\hline
\end{tabular}

\section{Gradation Curve}

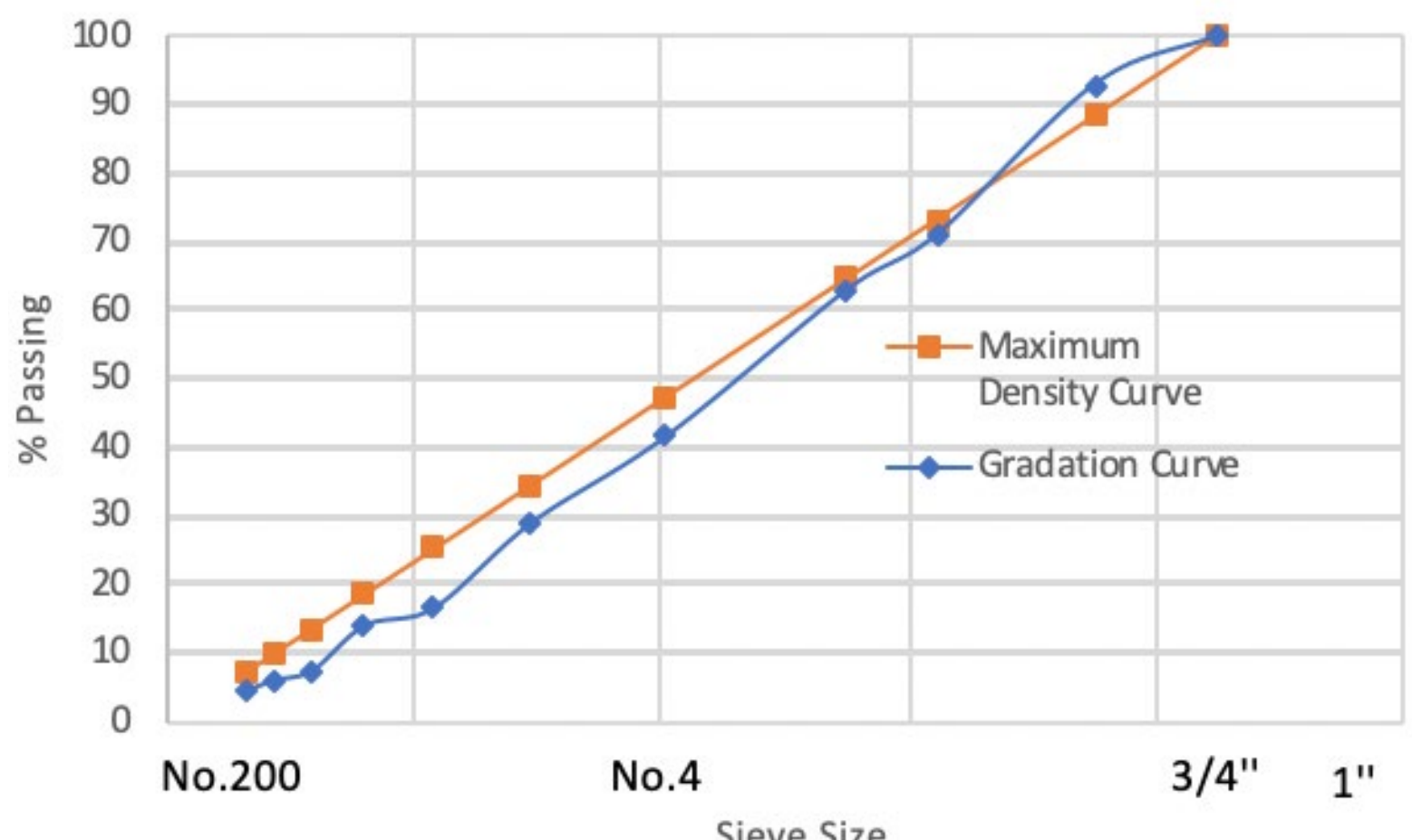

Figure 11. Gradation Used for Control HMA Mix and RCA-HMA Mixes

(3) Optimum Binder Content and Volumetrics of HMA and RCA-HMA

Table 9 shows a summary of the volumetrics of control HMA mix and RCA-HMA mixes. Tables 10 to 13 and Figures 12 through 15 show the result of volumetrics and OBC of the HMA and the RCA-HMAs.

The results of this study show that the inclusion of RCA aggregates in HMA increases 
the OBCs, varying from $5.0 \%$ for the control mix to $5.9 \%, 5.4 \%$, and $5.8 \%$ for $\mathrm{RCA}$ 4.75-9.5mm mix, RCA 9.5-12.5mm mix, and RCA 12.5-19.1mm mix, respectively. The increments of $\mathrm{OBC}$ are mainly due to the higher absorption of RCA that resulted from RCM content. It shall be noted that although the RCA replacement rate is $100 \%$ for each aggregate size group of $4.75-9.5 \mathrm{~mm}, 9.5-12.5 \mathrm{~mm}$, or $12.5-19.1 \mathrm{~mm}$, the RCA replacement rates in terms of overall aggregate weight are different due to the actual gradation used. For example, when the 12.5-19.1 mm size group of RCA was used to replace the same size group of the virgin aggregate in HMA, the replacement rate was $22.0 \%$ of the total aggregate weight. Meanwhile, when the $9.5-12.5 \mathrm{~mm}$ size group of RCA was used to replace the same size group of the virgin aggregate in HMA, the replacement rate was $8.0 \%$. Likewise, the replacement rate of RCA 4.75-9.5mm was $21.5 \%$. Because of this, the increments of the OBCs for RCA-HMA with RCA replacement of these three size groups are $0.86,0.36$, and 0.76 , respectively.

The VMA and dust proportion values of the control mix and the RCA-HMA mixes met the Caltrans requirement. Generally, the inclusion of RCA increased the VMA. This is because the bulk specific gravity of RCA is significantly lower than the bulk specific gravity of virgin aggregates and the OBC is increased after adding RCA due to an increase of the absorption. When the aggregate gradation was kept the same, for example, using $12.5-19.1 \mathrm{~mm}$ size group of RCA to replace $100 \%$ of the same size group of the virgin aggregate, the weight of RCA in the mixture is the same as the weight of the replaced virgin aggregate. However, due to the lower specific gravity, the volume of RCA is larger than the volume of the virgin aggregate replaced. This slightly increases the relative volume of the coarse aggregates (4.75-19.1mm in this study), which increases the VMA. In addition, the significant increases of VMA are observed in the RCA replacement of $12.5-19.1 \mathrm{~mm}$ and the $4.75-9.5 \mathrm{~mm}$ size groups, which, again, is due to the higher replacement rate for these two size groups.

Table 9. Summary Results of Volumetrics of HMA and RCA-HMA

\begin{tabular}{lccccccc}
\hline \multicolumn{1}{c}{ Volumetrics } & OBC & Gmm & Gmb & Air Voids & VMA & VFA & $\begin{array}{c}\text { Dust } \\
\text { Proportion }\end{array}$ \\
\hline Control Mix & $\mathrm{OBC}=5.0 \%$ & 2.549 & 2.447 & $4.00 \%$ & $14.20 \%$ & $71.80 \%$ & 1.05 \\
$\mathrm{RCA} 4.75-9.5 \mathrm{~mm}$ & $\mathrm{OBC}=5.9 \%$ & 2.473 & 2.374 & $4.00 \%$ & $16.50 \%$ & $75.70 \%$ & 1.02 \\
$\mathrm{RCA} 9.5-12.5 \mathrm{~mm}$ & $\mathrm{OBC}=5.4 \%$ & 2.523 & 2.422 & $4.00 \%$ & $14.30 \%$ & $71.90 \%$ & 1.03 \\
$\mathrm{RCA} 12.5-19.1 \mathrm{~mm}$ & $\mathrm{OBC}=5.8 \%$ & 2.466 & 2.368 & $4.00 \%$ & $15.10 \%$ & $73.60 \%$ & 0.93 \\
\hline
\end{tabular}

Table 10. Volumetric Mix Design of Control Mix: $100 \%$ Virgin Agg.

\begin{tabular}{lcccccccccc}
\hline $\begin{array}{c}\text { Binder } \\
\text { content }\end{array}$ & Gmm & Gmb & $\begin{array}{c}\text { Air } \\
\text { Voids }\end{array}$ & VMA & VFA & $\begin{array}{c}\text { Dust } \\
\text { Proportion }\end{array}$ & Gse & Gsb & $\begin{array}{c}\text { Pba } \\
\text { (\%) }\end{array}$ & $\begin{array}{c}\text { Pbe } \\
\text { (\%) }\end{array}$ \\
\hline $4.2 \%$ & 2.541 & 2.409 & $5.2 \%$ & $14.8 \%$ & $64.9 \%$ & 1.10 & 2.716 & 2.709 & 0.10 & 4.10 \\
$4.7 \%$ & 2.574 & 2.457 & $4.5 \%$ & $13.6 \%$ & $66.5 \%$ & 1.19 & 2.780 & 2.709 & 0.97 & 3.77 \\
$5.2 \%$ & 2.537 & 2.442 & $3.7 \%$ & $14.5 \%$ & $74.3 \%$ & 0.99 & 2.759 & 2.709 & 0.69 & 4.55 \\
$5.7 \%$ & 2.532 & 2.458 & $2.9 \%$ & $14.4 \%$ & $79.8 \%$ & 0.93 & 2.778 & 2.709 & 0.94 & 4.82 \\
OBC=5.0\% & 2.549 & 2.447 & $4.0 \%$ & $14.2 \%$ & $71.8 \%$ & 1.05 & & & & \\
\hline
\end{tabular}




\section{OBC: Control Mix (100\% virgin agg.)}

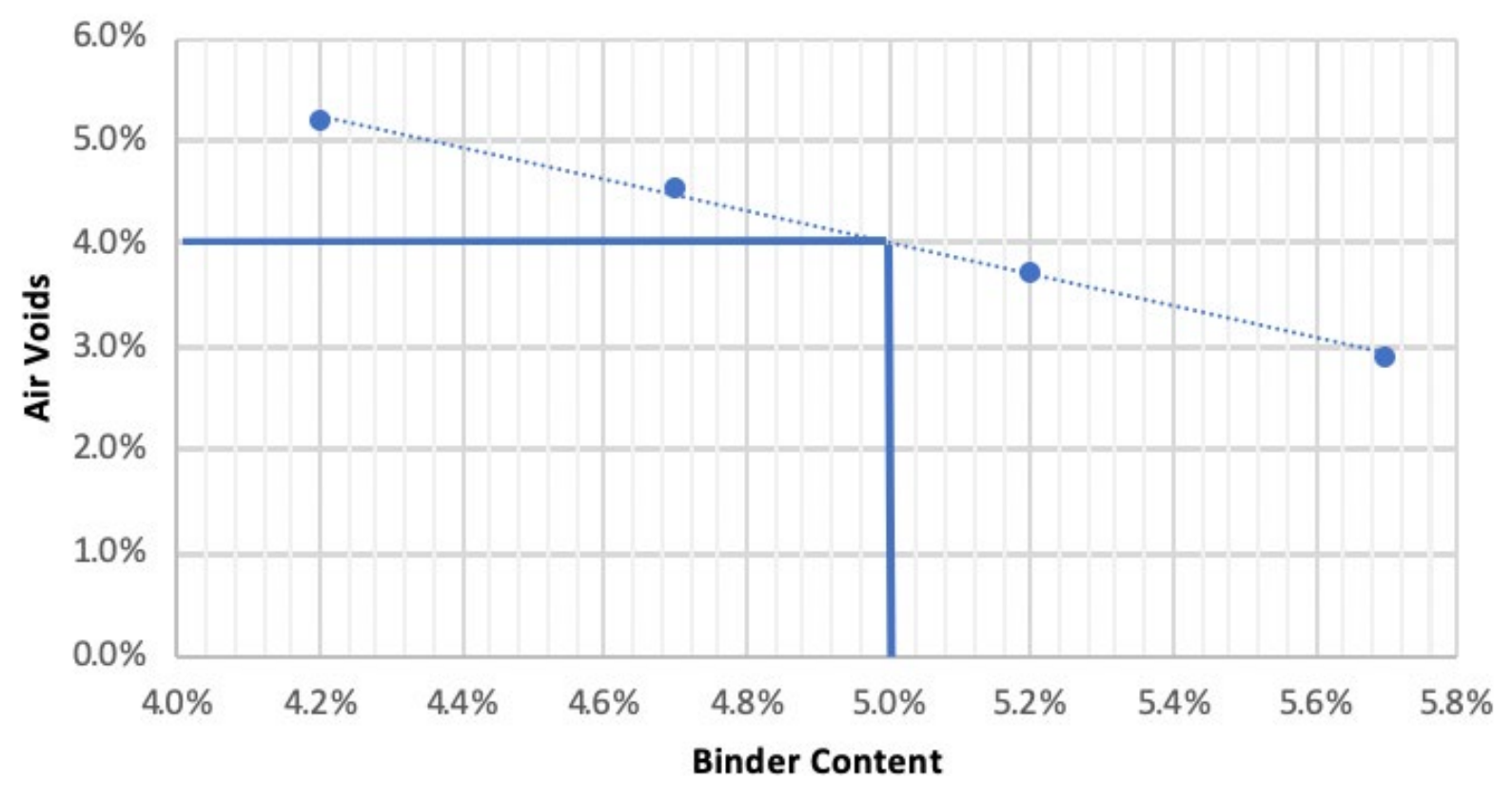

Figure 12. OBC of Control HMA Mix

Table 11. Volumetric Mix Design of RCA Replacement of 4.75-9.5mm

\begin{tabular}{lccllclllll}
\hline $\begin{array}{c}\text { Binder } \\
\text { content }\end{array}$ & Gmm & Gmb & Air Voids & VMA & VFA & $\begin{array}{c}\text { Dust } \\
\text { Proportion }\end{array}$ & Gse & Gsb & $\begin{array}{c}\text { Pba } \\
(\%)\end{array}$ & $\begin{array}{c}\text { Pbe } \\
(\%)\end{array}$ \\
\hline $4.5 \%$ & 2.508 & 2.340 & $6.7 \%$ & $16.5 \%$ & $59.3 \%$ & 1.37 & 2.691 & 2.603 & 1.28 & 3.27 \\
$5.0 \%$ & 2.487 & 2.350 & $5.5 \%$ & $16.5 \%$ & $66.7 \%$ & 1.18 & 2.688 & 2.603 & 1.25 & 3.82 \\
$5.5 \%$ & 2.483 & 2.357 & $5.1 \%$ & $16.7 \%$ & $69.7 \%$ & 1.10 & 2.706 & 2.603 & 1.50 & 4.08 \\
$6.0 \%$ & 2.470 & 2.380 & $3.6 \%$ & $16.4 \%$ & $77.7 \%$ & 1.00 & 2.713 & 2.603 & 1.60 & 4.50 \\
OBC=5.9\% & 2.473 & 2.374 & $4.0 \%$ & $16.5 \%$ & $75.7 \%$ & 1.02 & & & & \\
\hline
\end{tabular}




\section{OBC: RCA 4.75-9.5 mm Replacement}

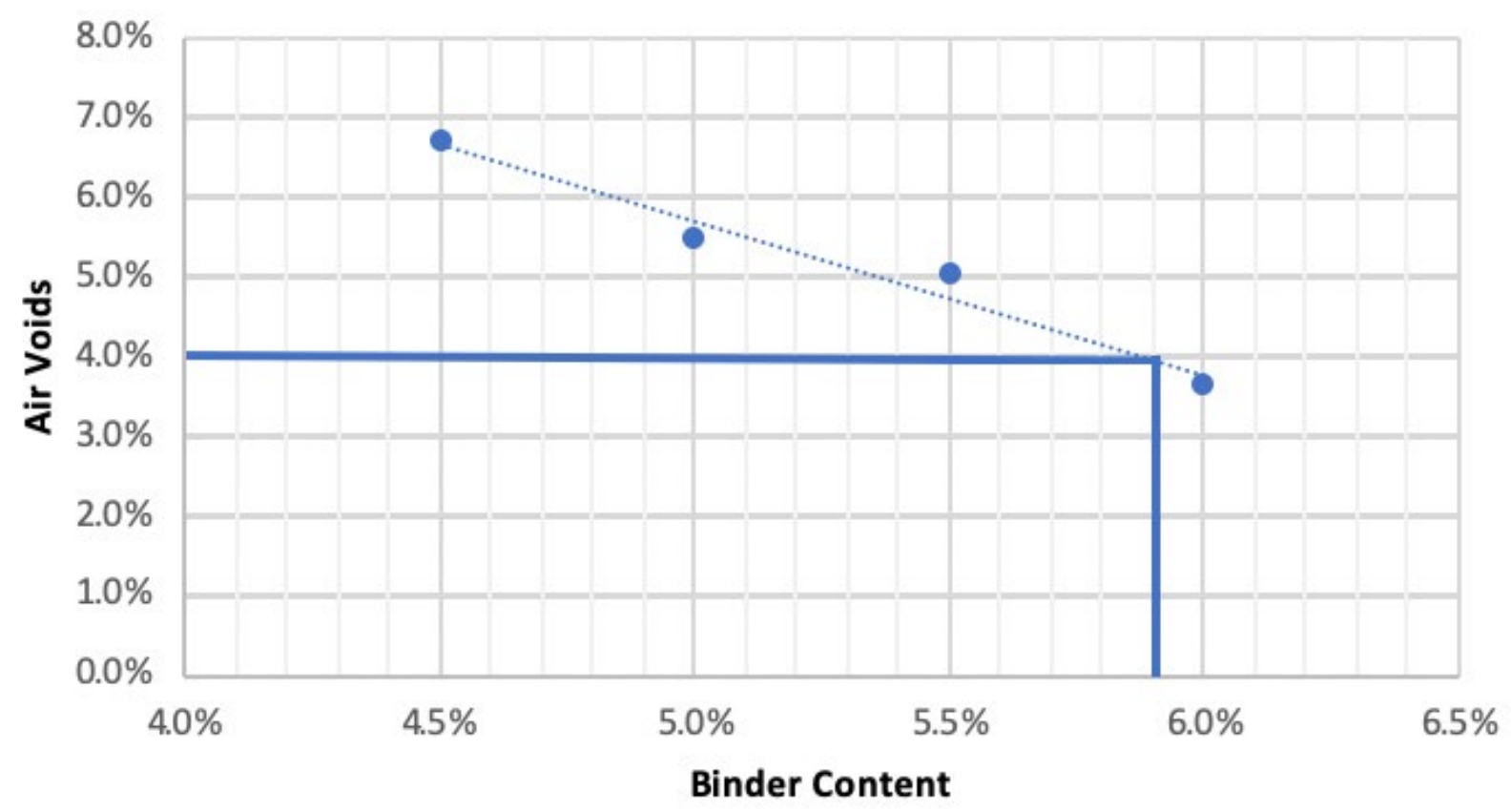

Figure 13. OBC of RCA-HMA: RCA Replacement of $4.75-9.5 \mathrm{~mm}$

Table 12. Volumetric Mix Design of RCA Replacement of $9.5-12.5 \mathrm{~mm}$

\begin{tabular}{lcclccccccc}
\hline $\begin{array}{c}\text { Binder } \\
\text { content }\end{array}$ & Gmm & Gmb & Air Voids & VMA & VFA & $\begin{array}{c}\text { Dust } \\
\text { Proportion }\end{array}$ & Gse & Gsb & $\begin{array}{c}\text { Pba } \\
(\%)\end{array}$ & $\begin{array}{c}\text { Pbe } \\
(\%)\end{array}$ \\
\hline $4.5 \%$ & 2.551 & 2.398 & $6.0 \%$ & $14.4 \%$ & $58.3 \%$ & 1.25 & 2.742 & 2.675 & 0.95 & 3.60 \\
$5.0 \%$ & 2.538 & 2.421 & $4.6 \%$ & $14.0 \%$ & $67.1 \%$ & 1.13 & 2.751 & 2.675 & 1.06 & 4.00 \\
$5.5 \%$ & 2.514 & 2.423 & $3.6 \%$ & $14.4 \%$ & $74.9 \%$ & 0.98 & 2.745 & 2.675 & 0.98 & 4.57 \\
$6.0 \%$ & 2.502 & 2.432 & $2.8 \%$ & $14.5 \%$ & $80.8 \%$ & 0.91 & 2.754 & 2.675 & 1.10 & 4.96 \\
OBC=5.4\% & 2.523 & 2.422 & $4.0 \%$ & $14.3 \%$ & $71.9 \%$ & 1.03 & & & & \\
\hline
\end{tabular}




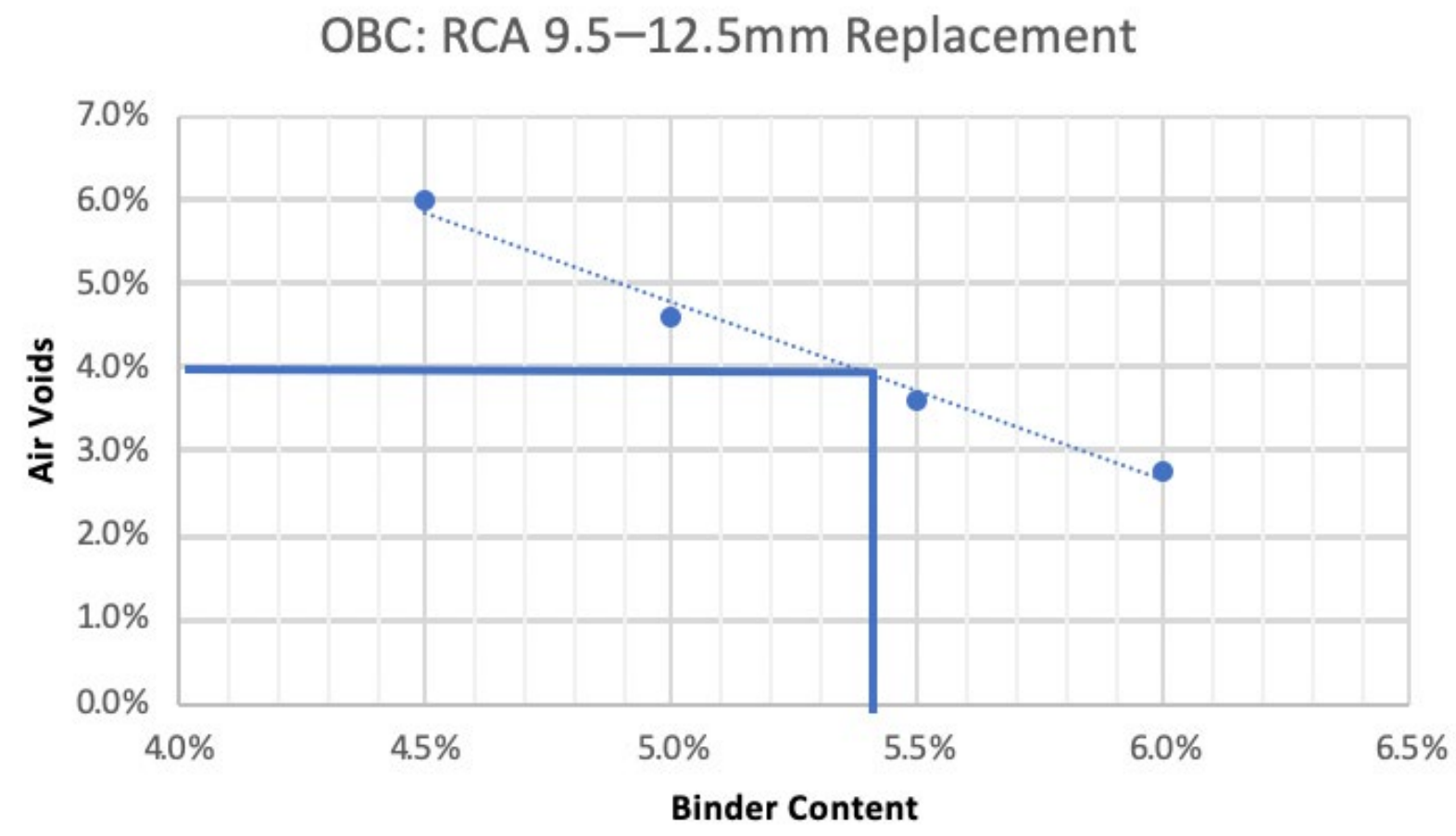

Figure 14. OBC of RCA-HMA: RCA Replacement of $9.5-12.5 \mathrm{~mm}$

Table 13. Volumetric Mix Design of RCA Replacement of 12.5-19.1mm

\begin{tabular}{lcclccccccc}
\hline $\begin{array}{c}\text { Binder } \\
\text { content }\end{array}$ & Gmm & Gmb & Air Voids & VMA & VFA & $\begin{array}{c}\text { Dust } \\
\text { Proportion }\end{array}$ & Gse & Gsb & $\begin{array}{c}\text { Pba } \\
(\%)\end{array}$ & $\begin{array}{c}\text { Pbe } \\
(\%)\end{array}$ \\
\hline $5.0 \%$ & 2.502 & 2.359 & $5.7 \%$ & $14.5 \%$ & $60.7 \%$ & 1.17 & 2.706 & 2.622 & 1.22 & 3.84 \\
$5.5 \%$ & 2.488 & 2.374 & $4.6 \%$ & $14.4 \%$ & $68.3 \%$ & 1.05 & 2.712 & 2.622 & 1.30 & 4.27 \\
$6.0 \%$ & 2.467 & 2.367 & $4.1 \%$ & $15.1 \%$ & $73.2 \%$ & 0.93 & 2.709 & 2.622 & 1.26 & 4.82 \\
$6.5 \%$ & 2.443 & 2.390 & $2.2 \%$ & $14.8 \%$ & $85.3 \%$ & 0.83 & 2.702 & 2.622 & 1.15 & 5.42 \\
OBC=5.8\% & 2.466 & 2.368 & $4.0 \%$ & $15.1 \%$ & $73.6 \%$ & 0.93 & & & & \\
\hline
\end{tabular}




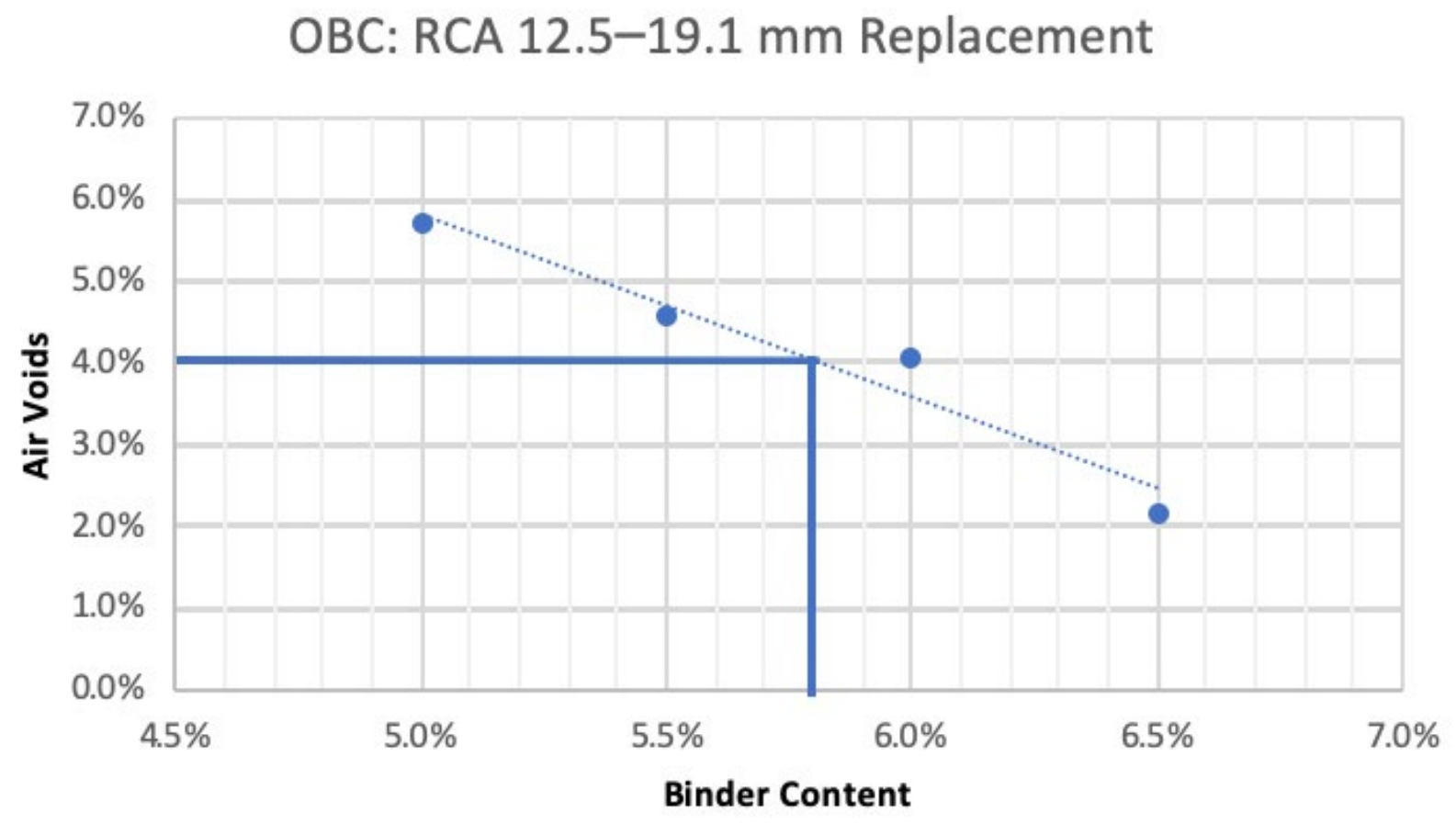

Figure 15. OBC of RCA-HMA: RCA Replacement of $12.5-19.1 \mathrm{~mm}$

\section{HMA and RCA-HMA Performance Evaluation}

After the mix designs, the performance of the HMA and RCA-HMA was evaluated in terms of resistance to permanent deformation using HWTT and moisture damage susceptibility using TSR tests.

\section{(1) Resistance to Permanent Deformation (HWTT)}

The HWTT were performed following AASHTO T 324. For type A HMA mix with a binder having a high performance grade $(P G)$ of $64^{\circ} \mathrm{C}$, the Caltrans specifies the minimum number of loading cycles at $12.5 \mathrm{~mm}\left(0.5\right.$ ") rut depth to be $15,000^{36}$ and the minimum number of loading cycles at the inflection point to be 10,000. For present research purposes, the number of loading cycles is set at 20,000 with the testing temperature of $50^{\circ} \mathrm{C}$. The test stopping deformation criterion is set to be $14 \mathrm{~mm}(0.55$ "). For RCA-HMA, the specimens were prepared at their $\mathrm{OBC}$, as well at the binder content $(\mathrm{BC})$ of $5.0 \%$, which is the $\mathrm{OBC}$ of the control HMA, so that the resistance to permanent deformation of mixtures with the same gradation and the same $\mathrm{BC}$ can be compared. The results are summarized in Table 14. Generally, the addition of the RCA in HMA compromises the rutting resistance. The RCA-HMA with RCA 4.75-9.5mm has the lowest rutting resistance at both OBC values of $5.9 \%$ and $\mathrm{BC}$ of $5.0 \%$. The RCA-HMA with RCA 9.5$12.5 \mathrm{~mm}$ can pass the rutting depth criterion of $12.5 \mathrm{~mm}$ at loading cycles of 15,000 . This, again, might be due to the fact that in this RCA-HMA mix, the RCA replacement rate by the total weight of aggregate is $8.0 \%$, which is the lowest in the three RCA-HMA mixes.

Another possible reason that leads to the low rutting resistance of RCA-HMA mixes is 
the binder-aggregate stripping, which was observed on the surface of aggregates after HWTT. Figure 16 shows the evidence of surface stripping for the RCA-HMA with RCA 4.75-9.5mm after HWTT. The picture also shows that the fine aggregate on the specimen surface disintegrated during the test. However, the test data do not clearly show the inflection point to characterize the moisture damage. Appendix $B$ shows details of the HWTT results and additional photos that demonstrate the surface stripping of RCAHMA after HWTT. The authors suggest adding anti-stripping additive or lime in future experiments for RCA-HMA to reduce moisture damage and improve rutting resistance.

Table 14. Summarized Hamburg Wheel Track Test Results

\begin{tabular}{|c|c|c|c|c|c|c|c|}
\hline $\begin{array}{c}\text { Controlled } \\
\text { Binder Content }\end{array}$ & Wheels & $\begin{array}{c}\text { Rut Depth } \\
(\mathrm{mm}) \text { at } \\
5,000 \\
\text { cycles }\end{array}$ & $\begin{array}{c}\text { Rut Depth } \\
(\mathrm{mm}) \text { at } \\
10,000 \\
\text { cycles }\end{array}$ & $\begin{array}{c}\text { Rut Depth } \\
(\mathrm{mm}) \text { at } \\
15,000 \\
\text { cycles }\end{array}$ & $\begin{array}{c}\text { Rut Depth } \\
(\mathrm{mm}) \text { at } \\
20,000 \\
\text { recycles }\end{array}$ & $\begin{array}{c}\text { Failure } \\
\text { Cycles at } \\
\text { Rut-Depth } \\
12.5 \mathrm{~mm}\end{array}$ & Pass or Fail \\
\hline \multirow{2}{*}{$\begin{array}{l}\text { Control mix at } 5.0 \% \\
\text { BC }\end{array}$} & Left & 4.783 & 5.540 & 6.090 & 6.595 & --- & Pass \\
\hline & Right & 4.719 & 5.995 & 7.197 & 8.147 & -- & Pass \\
\hline \multirow{2}{*}{$\begin{array}{l}\text { HMA-RCA }(12.5- \\
19.1 \mathrm{~mm}) \text { at } 5.0 \% \mathrm{BC}\end{array}$} & Left & 3.625 & 5.066 & 6.344 & 7.533 & --- & Pass \\
\hline & Right & 5.210 & 7.140 & 10.124 & -- & 18,000 & Pass \\
\hline \multirow{2}{*}{$\begin{array}{l}\text { HMA-RCA }(12.5- \\
19.1 \mathrm{~mm}) \text { at OBC of } \\
5.8 \%\end{array}$} & Left & 7.130 & 8.987 & 9.879 & 10.651 & --- & Pass \\
\hline & Right & 7.969 & 11.100 & --- & --- & 11634 & Fail \\
\hline \multirow{2}{*}{$\begin{array}{l}\text { HMA-RCA }(9.5- \\
12.5 \mathrm{~mm}) \text { at } 5.0 \% \mathrm{BC}\end{array}$} & Left & 3.802 & 4.397 & 5.258 & 6.164 & --- & Pass \\
\hline & Right & 3.949 & 4.958 & 5.626 & 6.190 & --- & Pass \\
\hline \multirow{2}{*}{$\begin{array}{l}\text { HMA-RCA }(9.5- \\
12.5 \mathrm{~mm}) \text { at OBC of } \\
5.4 \%\end{array}$} & Left & 5.186 & 6.806 & 8.351 & 10.253 & --- & Pass \\
\hline & Right & 5.507 & 7.081 & 8.417 & 9.545 & --- & Pass \\
\hline \multirow{2}{*}{$\begin{array}{l}\text { HMA-RCA }(4.75- \\
9.5 \mathrm{~mm}) \text { at } 5.0 \% \mathrm{BC}\end{array}$} & Left & 6.647 & 8.996 & 13.636 & --- & 13,952 & Fail \\
\hline & Right & 5.997 & 7.734 & 9.055 & 10.599 & --- & Pass \\
\hline \multirow{2}{*}{$\begin{array}{l}\text { HMA-RCA }(4.75- \\
9.5 \mathrm{~mm}) \text { at OBC of } \\
5.9 \%\end{array}$} & Left & 7.073 & 9.941 & --- & --- & 12,096 & Fail \\
\hline & Right & 5.403 & 8.699 & --- & --- & 14,756 & Fail \\
\hline
\end{tabular}

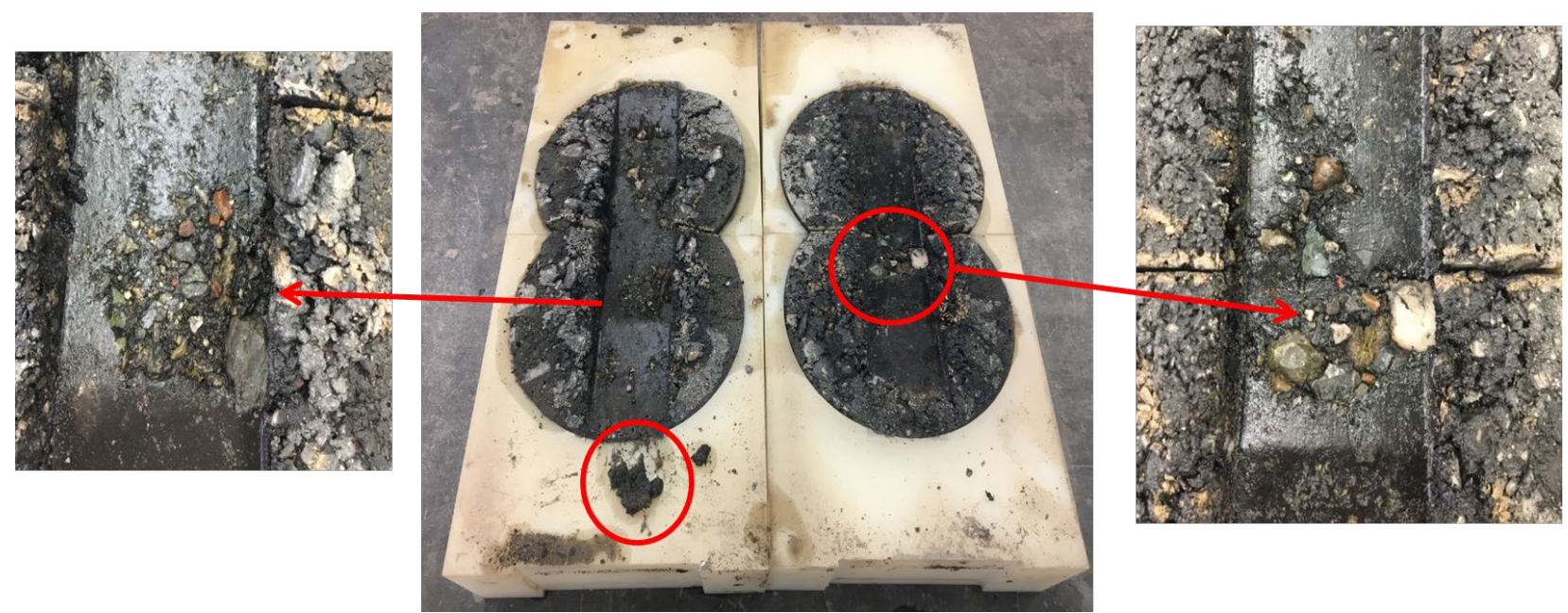

Figure 16. Surface Aggregate-Binder Stripping for RCA 4.75-9.5mm at 5\% Binder Content

Figure 17 plots the average rut depth of left and right wheels for the control mix and the 
RCA-HMA mixes at $5.0 \% \mathrm{BC}$ (which is the OBC of the control $\mathrm{mx}$ ), and at the OBCs of RCA-HMAs as well. The results show that at BC of 5.0\%, the RCA-HMA with RCA 9.5$12.5 \mathrm{~mm}$ performed slightly better than the control mix. It should be noted that RCA 9.5$12.5 \mathrm{~mm}$ mix has RCA replacement rate of $8.0 \%$. However, when the RCA replacement rates are higher than $20 \%$ in the RCA-HMAs, which is the case for RCA $4.75-9.5 \mathrm{~mm}$ and RCA 12.5-19.1 mm, the resistance to permanent deformation has been significantly reduced. At the OBC, all of the RCA-HMAs have lower rutting resistance than the control mix, and RCA-HMA with RCA 12.5-19.1 $\mathrm{mm}$ and RCA 4.75-9.5mm failed to meet the Caltrans HWTT requirement.

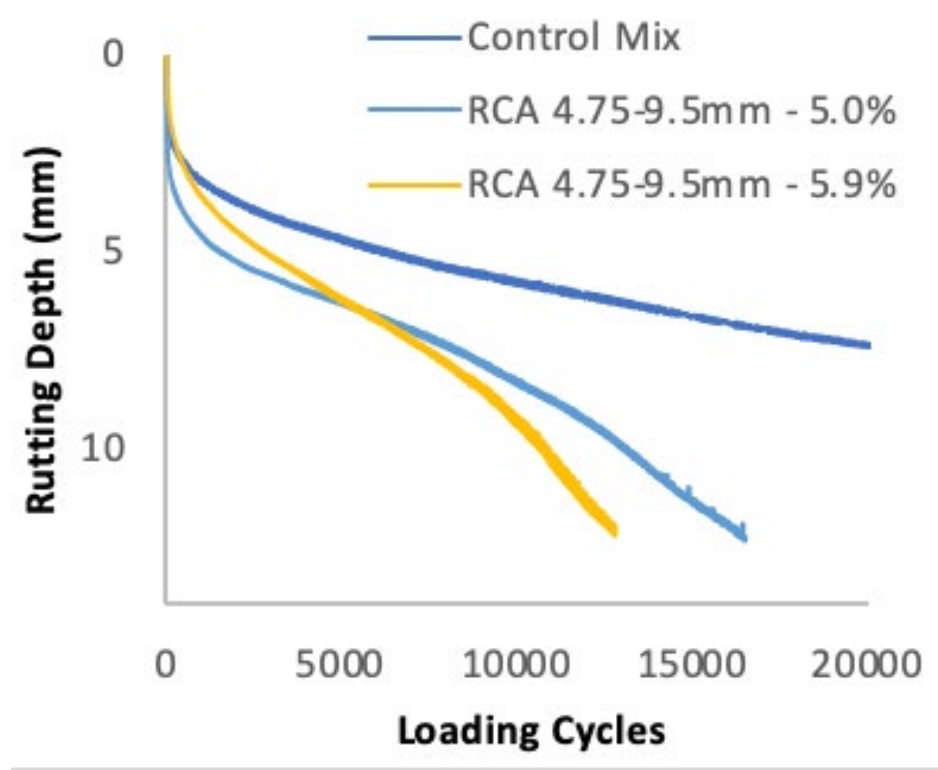

(a) RCA replacement of $4.75-9.5 \mathrm{~mm}$

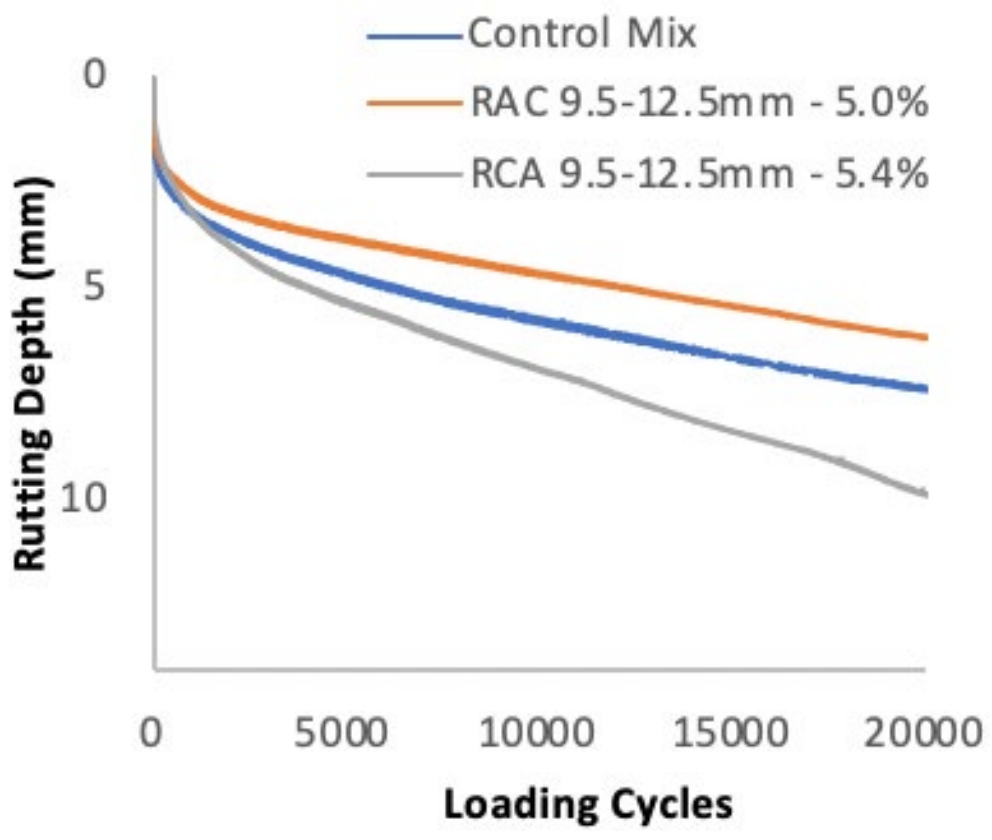

(b) RCA replacement of $9.5-12.5 \mathrm{~mm}$ 


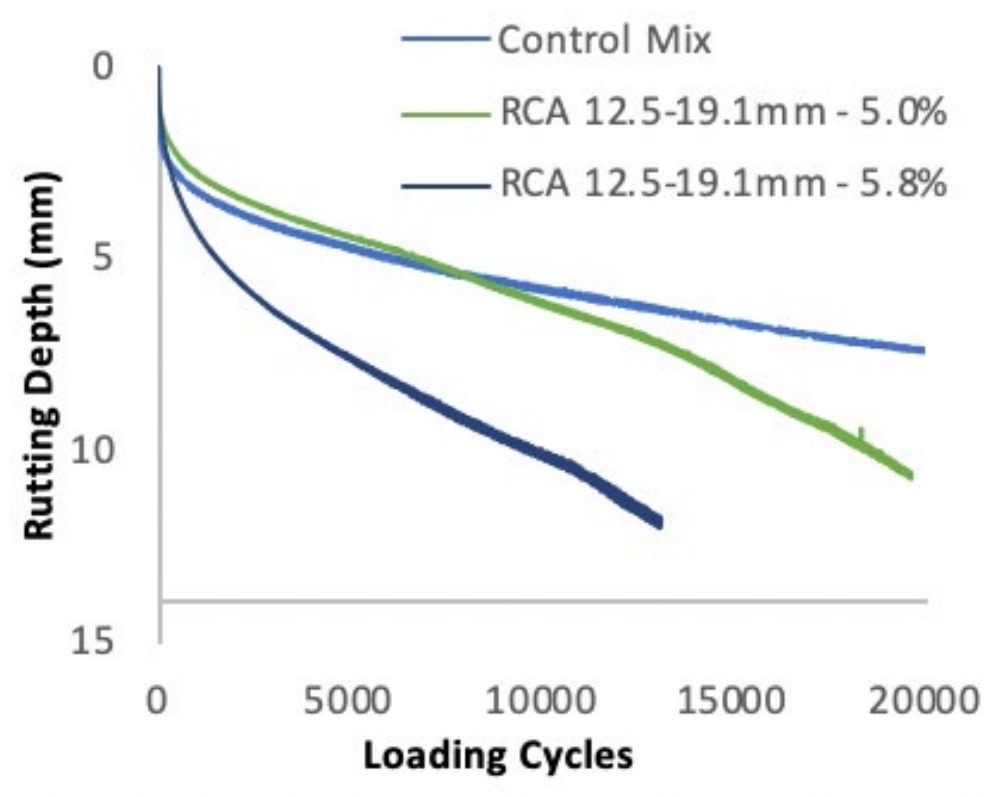

(c) RCA replacement of $12.5-19.1 \mathrm{~mm}$

\section{Figure 17. HWTT of Each RCA-HMA Mix at OBC and at 5.0\% Binder Content (OBC of control mix)}

Figures 18 (a) and (b) show the comparisons of HMA with the RCA-HMAs at the same binder content of 5.0\% (OBC of the control HMA), and at the OBC of each mix, respectively. The results shows that at $5.0 \%$ binder content, RCA $9.5-12.5 \mathrm{~mm} \mathrm{mix}$ has better rutting resistance than the control. The RCA 4.75-9.5mm mix has the worst rutting resistance. However, at $\mathrm{OBC}$ of each mix, all RCA-HMAs have worse rutting resistance than the control mix. This indicates that the increase of the OBC due to RCA replacement will sacrifice the rutting resistance of the mixture. But there is no obvious trend between rutting potential and the particle sizes being replaced.

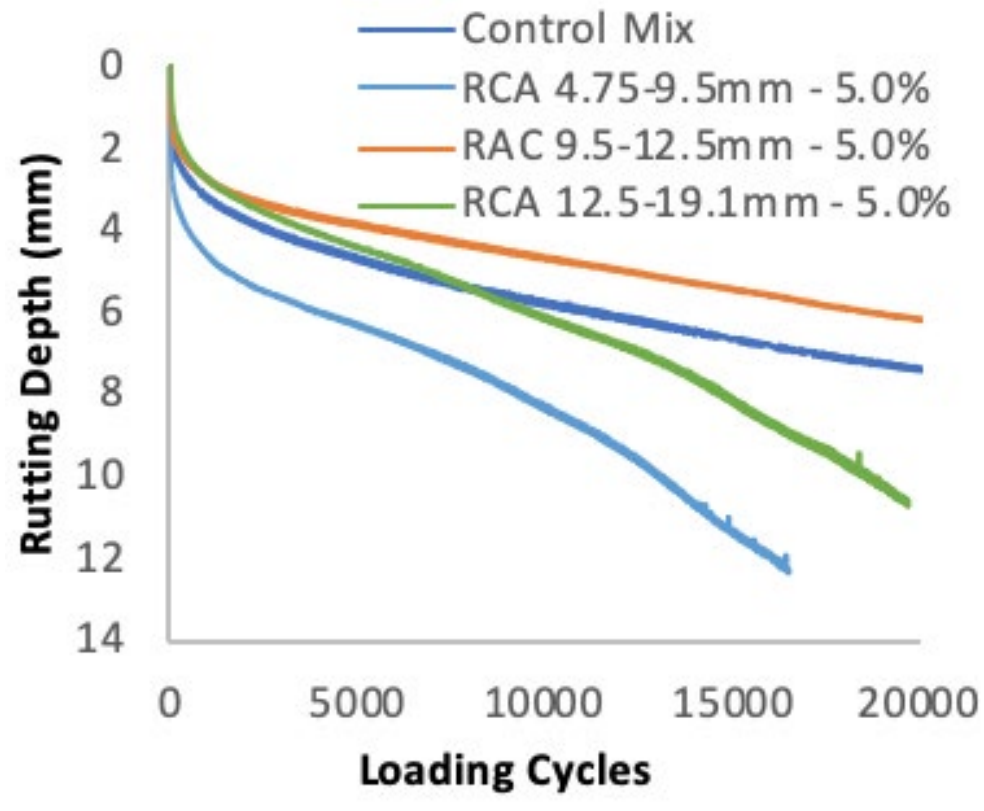

(a) at $5.0 \%$ Binder Content 


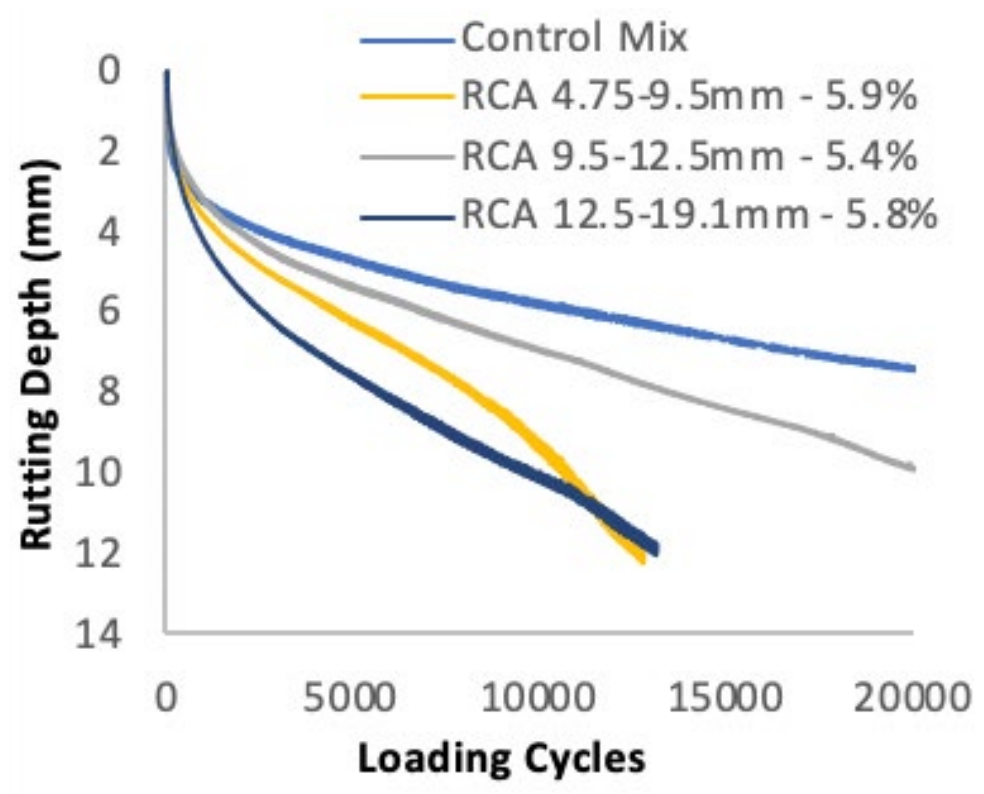

(b) at $\mathrm{OBC}$

Figure 18. HWTT of Control Mix and Different RCA-HMA Mix at OBC and at 5.0\% Binder Content (OBC of control mix)

(2) Moisture Damage Susceptibility (TSR)

The moisture damage susceptibility of control HMA mix and the RCA-HMA mixes was evaluated following AASHTO T283. A summary of the test results is shown in Table 15 and Figure 19. The results show that the addition of the RCA in HMA slightly reduced the IDT dry strength (specimens without freezing-thawing conditioning), which caused the RCA-HMA with RCA 12.5-19.1mm and RCA-HMA with RCA 4.75-9.5mm having lower IDT dry strength than the Caltrans requirement. The IDT wet strengths (specimens after freezing-thawing conditioning) of the control HMA mix and all RCA-HMAs are above the minimum IDT wet strength requirement of $0.48 \mathrm{MPa}(70 \mathrm{psi})$ and the TSR values are all above $70 \%$, which is the Caltrans requirement.

Table 15. Summarized Results of Moisture Damage Susceptibility

\begin{tabular}{llllll}
\hline \multicolumn{1}{c}{ TSR Test Results } & Control mix & $\begin{array}{c}\text { RCA-HMA } \\
\mathbf{1 2 . 5 - 1 9 . 1 m m}\end{array}$ & $\begin{array}{c}\text { RCA-HMA } \\
\mathbf{9 . 5 - 1 2 . 5 m m}\end{array}$ & $\begin{array}{c}\text { RCA-HMA } \\
\mathbf{4 . 7 5 - 9 . 5 m m}\end{array}$ & \multicolumn{1}{c}{$\begin{array}{c}\text { Caltrans } \\
\text { Requirement }\end{array}$} \\
\hline $\begin{array}{l}\text { Average Dry } \\
\begin{array}{l}\text { Strength, psi (MPa) } \\
\text { Average Wet }\end{array}\end{array}$ & $101.7(0.70)$ & $95.2(0.66)$ & $100.1(0.69)$ & $99.8(0.69)$ & $\begin{array}{l}\text { Min. 100 psi (0.69 } \\
\text { MPa) }\end{array}$ \\
$\begin{array}{l}\text { Strength, psi (MPa) } \\
\begin{array}{l}\text { Tensile Strength } \\
\text { Ratio (\%) }\end{array}\end{array}$ & $83.7(0.58)$ & $81.4(0.56)$ & $93.1(0.64)$ & $84.6(0.58)$ & $\begin{array}{l}\text { Min. 70 psi (0.48 } \\
\text { MPa) }\end{array}$ \\
\hline
\end{tabular}



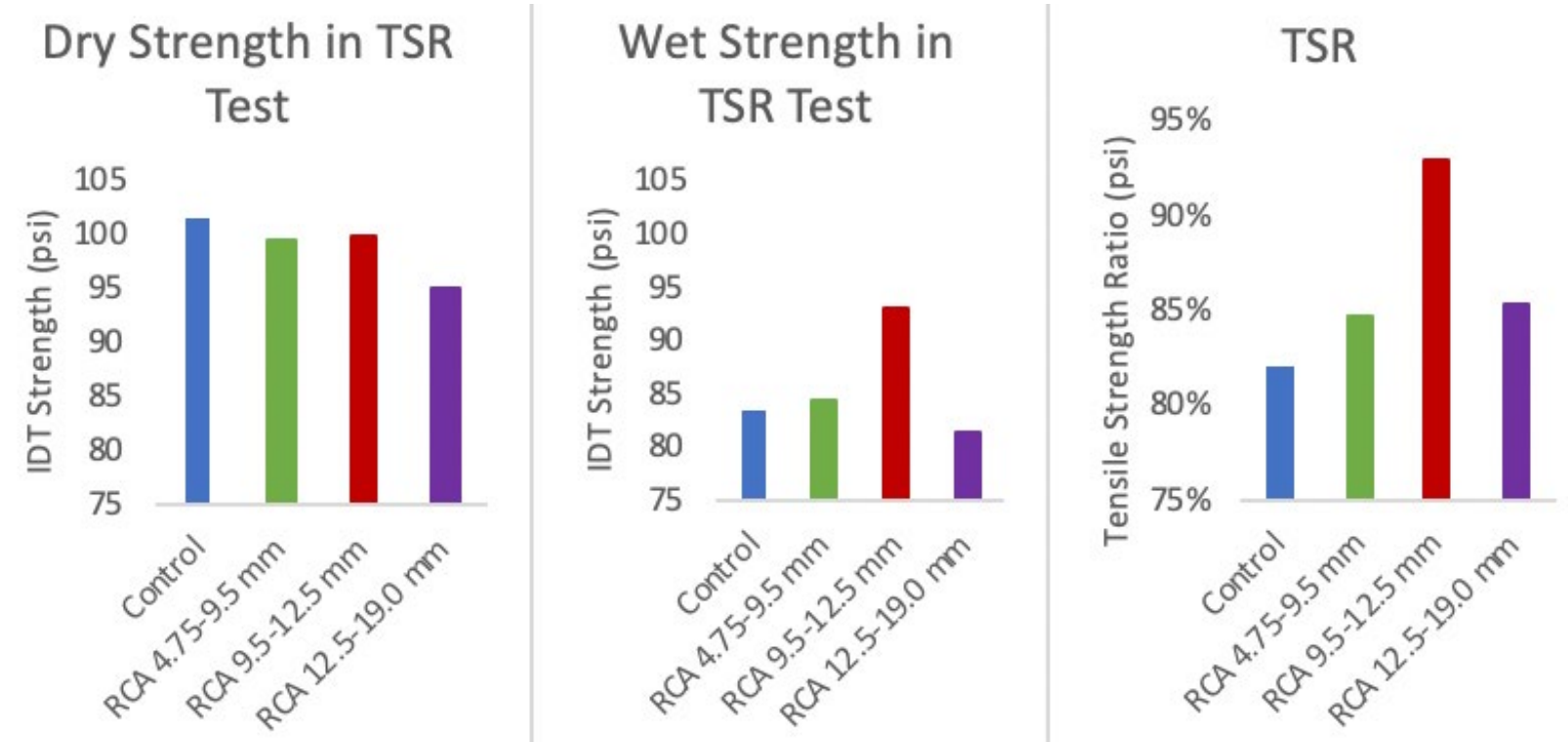

Figure 19. Dry Strength, Wet Strength, and TSR Results of HMA and RCA-HMA

The limited but noticeable cracked aggregates and asphalt binder stripping were observed after IDT strength test on the wet specimens (after freezing and thawing conditioning). Figure 20 shows the cracked aggregates in the wet specimens of the control HMA mix and the asphalt binder stripping in the wet specimens of the RCA-HMA with RCA $4.75-9.5 \mathrm{~mm}$. In addition, the most noticeable cracked aggregate was observed on the dry specimens of the RCA-HMA with RCA $12.5-19.1 \mathrm{~mm}$ on the failure surface after the IDT strength test. As shown in Figure 21, the coarse RCA aggregates were broken during the IDT strength test. This could be the reason that caused the strength reduction of the RCM-HMA compared with the control HMA, since the RCA-HMA mix with RCA $12.5-19.1 \mathrm{~mm}$ has the lowest dry and wet strength among the tested mixtures. Appendix $C$ provides more details of the TSR test results and photos after the tests.

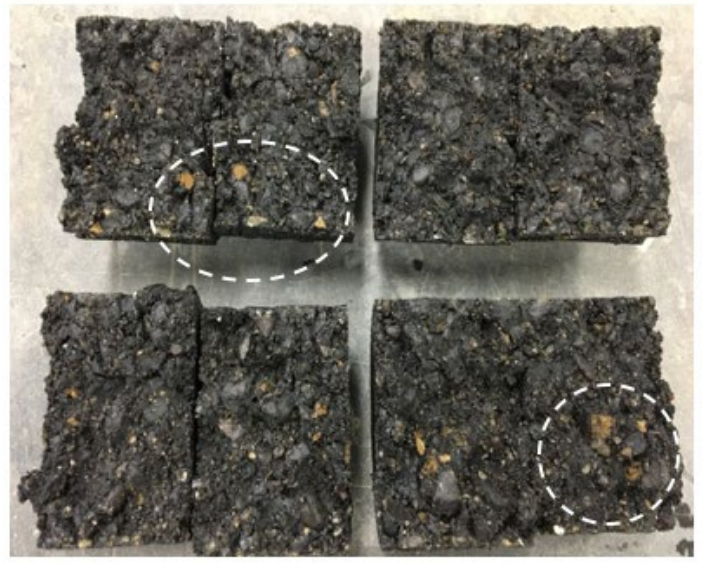

(a)

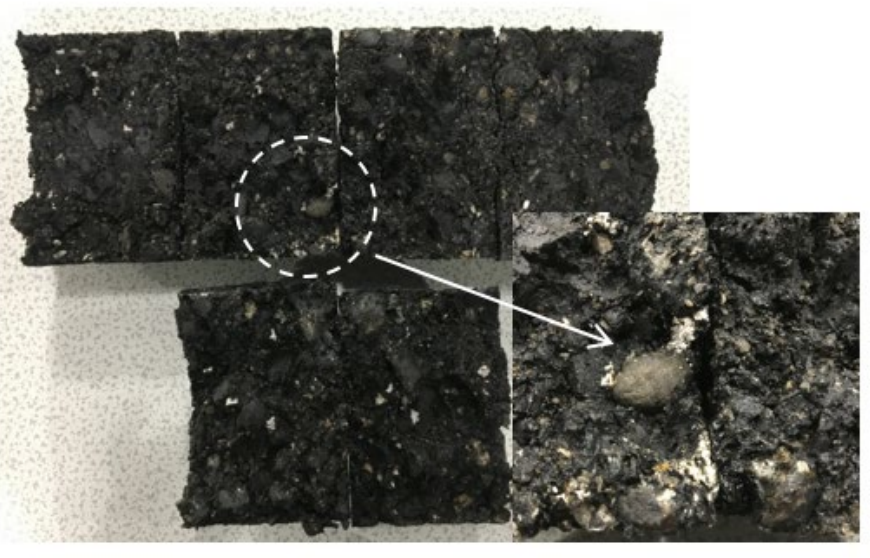

(b)

Figure 20. (a) Cracked Aggregates in the Wet Specimens of Control HMA Mix; (b) Asphalt Binder Stripping in the Wet Specimens of RCA-HMA with RCA 4.75-9.5mm 


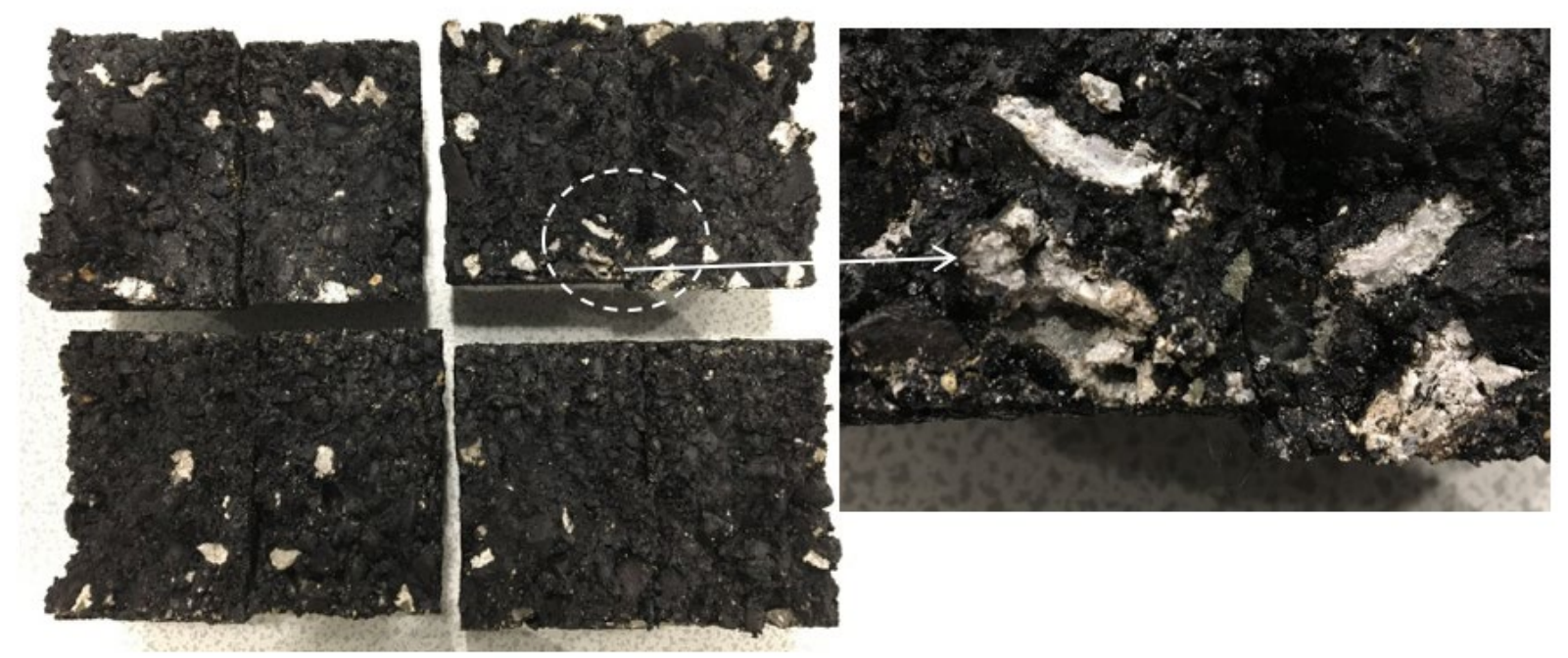

Figure 21. Cracked RCA Aggregates in the Dry Specimens of RCA-HMA with RCA 12.5-19.1mm

\section{RELATIONSHIP BETWEEN RCA/RCM PROPERTIES AND HMA/RCA-HMA PERFORMANCE}

For the purposes of finding the effects of RCA/RCM on the performance of RCA-HMA and the identification of the control material parameters of the RCA, the authors analyze and report on correlations between the properties of RCA and RCM, such as RCA replacement rate, RCM addition rate, and absorption increment calculated from RCA replacement rate and calculated from RCM addition rate, etc., and the volumetrics and performance indicators of HMA and RCA-HMA, such as OBC, VMA, VFA, resistance to permanent deformation, and moisture damage susceptibility.

Table 16 is a summary of the results of $\mathrm{OBC}, \mathrm{RCA}$ replacement rate, RCM addition rate, OBC, VMA and VFA increments after RCA replacement, rutting depth at 12,000 loading cycles in HWTT for resistance to permanent deformation, and the dry and wet strength and TSR of the moisture susceptibility tests, etc.

The RCA replacement rate and the RCM addition rate were calculated in terms of the total weight of the aggregate. The RCM addition rate was calculated from the RCA replacement rate and the actual RCM content of the RCA added into the RCA-HMA mix. The OBC, VMA, and VFA increments after RCA replacement are the increment of the OBC, VMA, and VFA after the RCA replacement compared with the same volumetric parameter of the control HMA mix (100\% virgin aggregate mixture). 


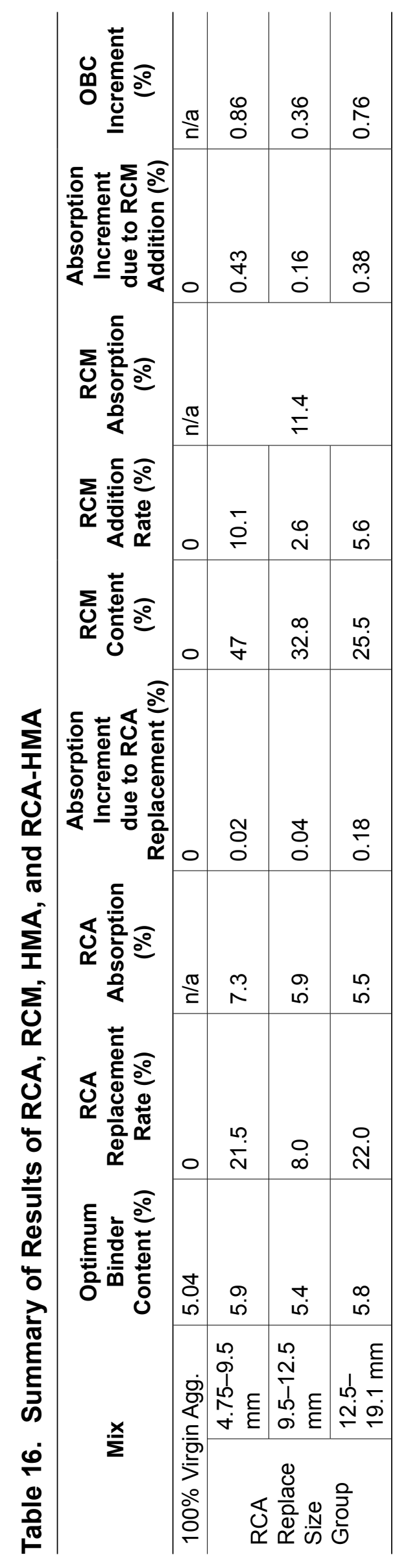




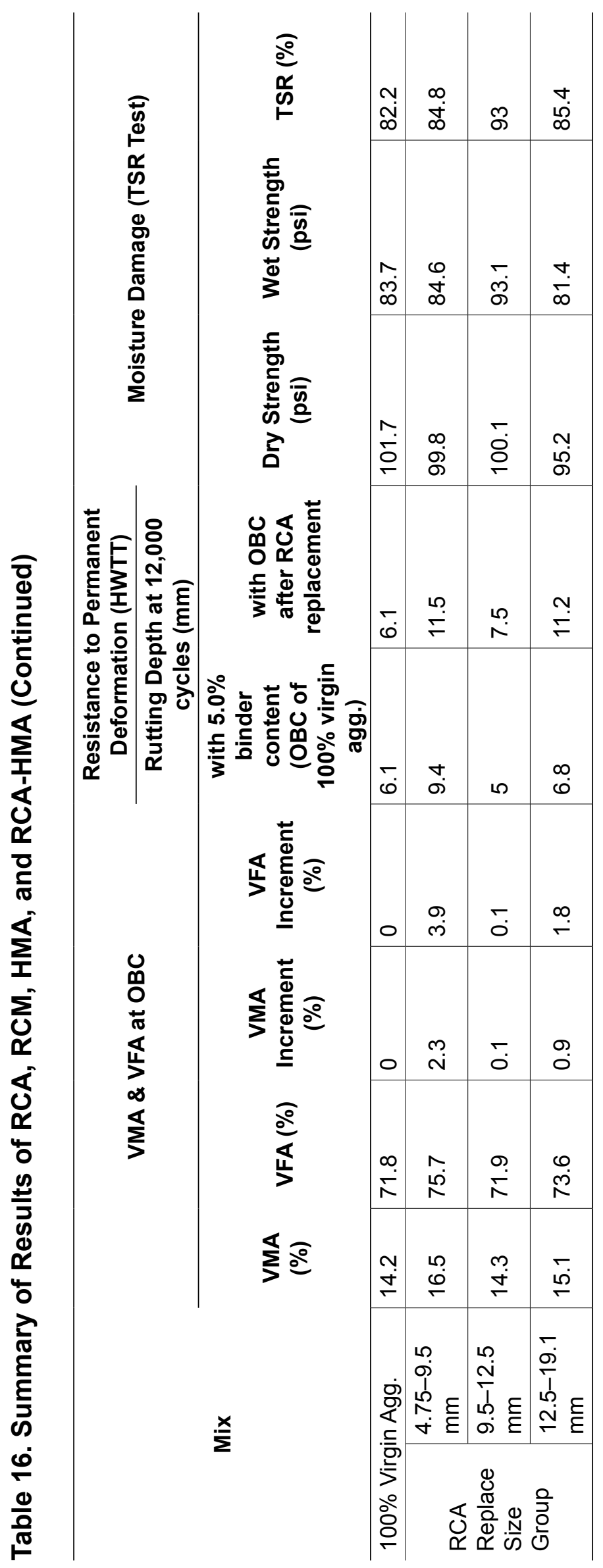




\section{Correlation between RCA/RCM Properties and Optimum Binder Content}

Figure 22 (a) is a plot of the OBC increment versus the RCA replacement rate. It shows a good correlation with respect to the very high $\mathrm{R}^{2}$. However, for the RCA replacement rate of $21.5 \%$, the OBC increment is $0.90 \%$, but when the RCA replacement rate increased to $22.0 \%$, the OBC increment is reduced to $0.80 \%$, which shows that the RCA replacement rate may not be a good indicator of the OBC increment, as shown by the solid trend line of Figure $22(a)$.

Figure $22(b)$ is a plot of the OBC increment versus the RCM addition rate. It can be seen that there is a good correlation between these two parameters. Looking at the solid trend line of Figure 22 (b), it can been seen that the RCM addition rate is a much better indicator of the $\mathrm{OBC}$ increment compared with the RCA replacement rate. It shows that for the materials used in this study, the OBC increment increased almost linearly when the RCM addition rate is below $6.0 \%$ and then when RCM addition rate is above $6.0 \%$, the relationship curve becomes flat.

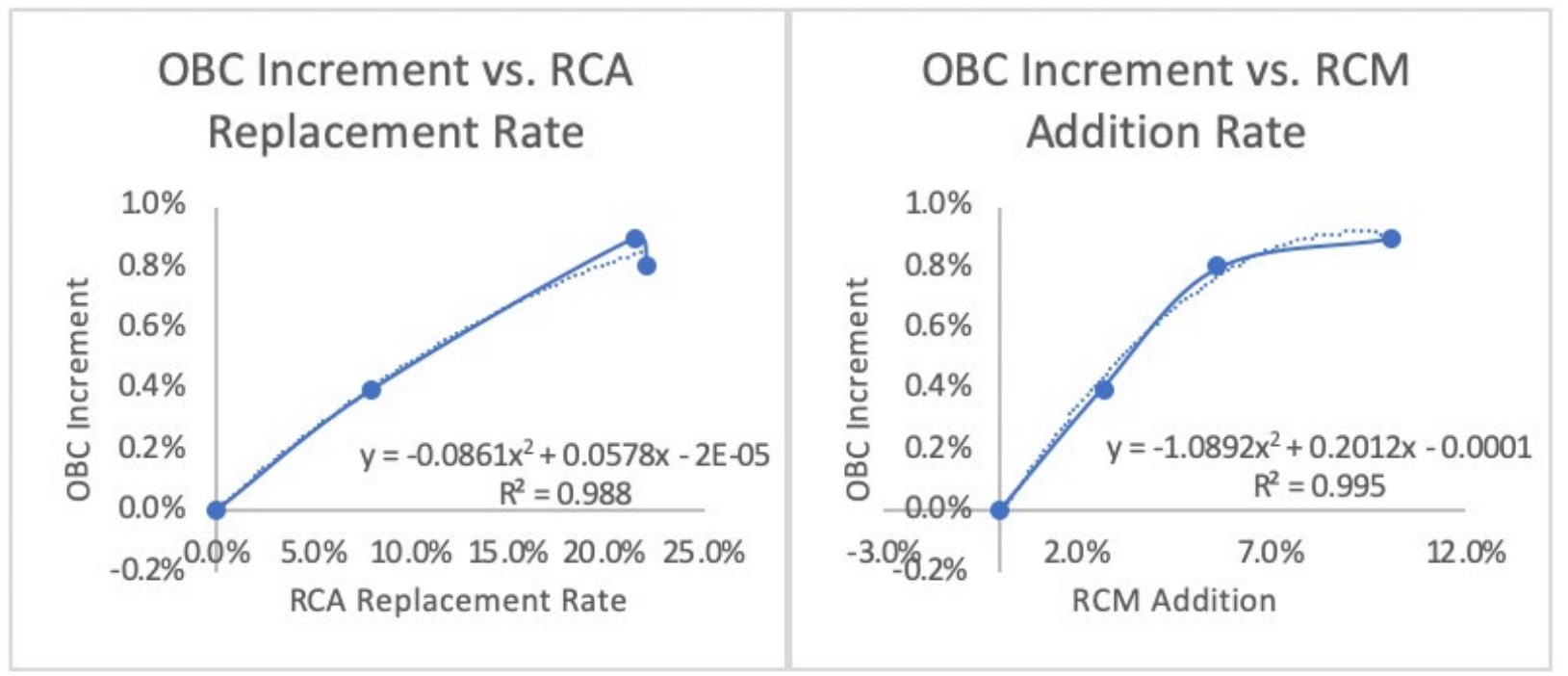

(a)

(b)

\section{Figure 22. Relationship between OBC and RCA Replacement Rate or RCM Addition Rate}

Figure 23 (a) shows the relationship between OBC increment of the RCA-HMA mixes compared with control HMA mix (100\% virgin aggregate mixture) and the "absorption increment due to RCA replacement," which is calculated by Equation (5):

Absorption Increment due to RCA Replacement $=$ (Absorption of RCA Absorption of Virgin Agg.) $\times$ RCA Replacement Rate

Figure 23 (a) indicates that the absorption increment due to RCA replacement, which is calculated from the RCA absorption and RCA replacement rate, is not a good predictor for the OBC increment of the RCA-HMA. There is no obvious correlation between these two parameters. The solid trend line shown in Figure 23 (a) shows that when the absorption 
increment due to RCA replacement increased from $0.02 \%$ to $0.04 \%$, the $\mathrm{OBC}$ increment of the RCA-HMA droped from $0.9 \%$ to $0.4 \%$, while the absorption increment due to RCA replacement increased from $0.02 \%$ to $0.18 \%$ the OBC increment of the RCA-HMA droped from $0.9 \%$ to $0.8 \%$.

Figure 23 (b) shows the relationship between OBC increment of the RCA-HMA mixes compared with control HMA mix and the "absorption increment due to RCM addition," which is calculated using Equation (6):

Absorption Increment due to RCM Addition $=$ (Absorption of RCM Absorption of Virgin Agg.) $\times$ RCM Addition Rate

It can be seen that there is a strong correlation between the OBC increment of the RCAHMA and the absorption increment calculated from RCM absorption and RCM addition rate. Figure 23 indicates that, without information about the $\mathrm{RCM}$, information of the RCA (absorption and RCA replacement rate) is not sufficient for predicting how the OBC and absorption change in RCA-HMA. Information concerning RCM is critical for the determination of these RCA-HMA properties. Practically, the OBC increment is important because of its relation with costs, meaning that a control of RCM addition rates is of greater interest than RCA replacement rates.

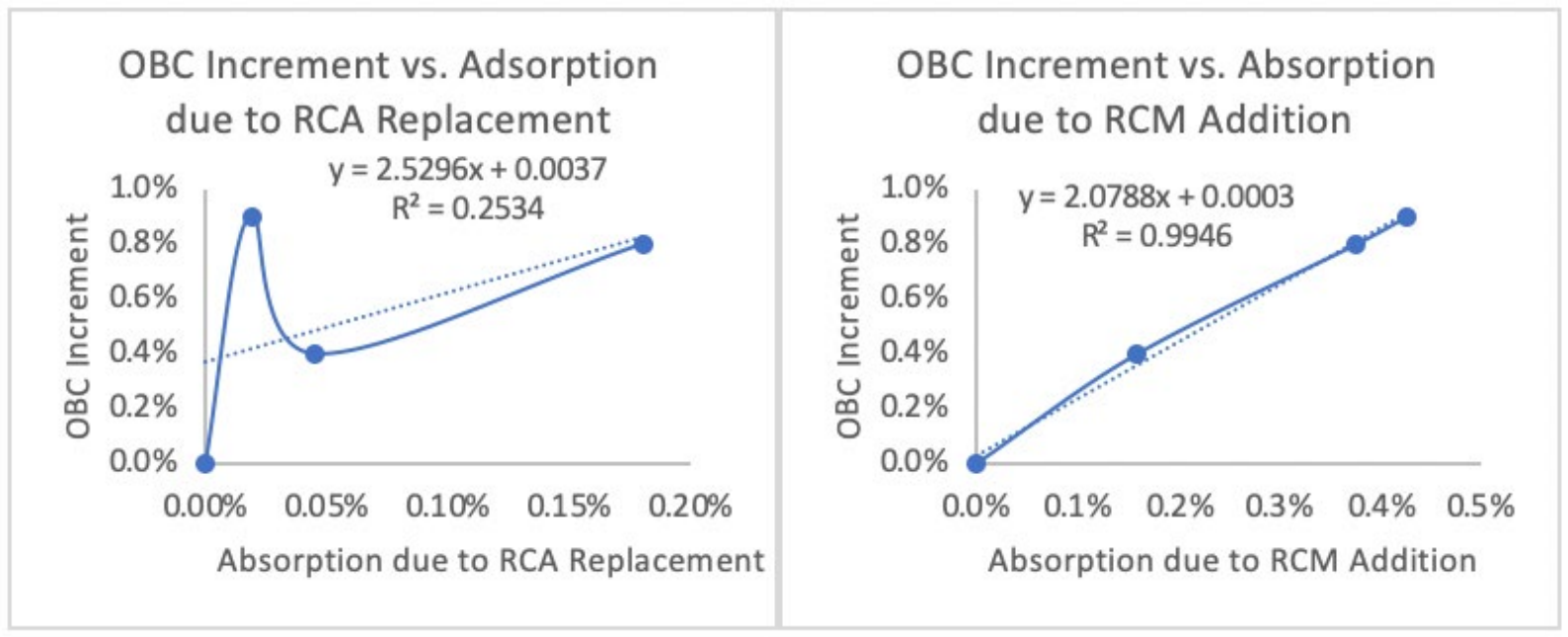

(a)

(b)

Figure 23. Relationship between OBC Increment and Absorption due to RCA Replacement or Absorption due to RCM Addition

\section{Correlation between RCA/RCM Properties and VMA/VFA}

Figure 24 (a) and (b) shows the relationship between VMA increment and RCA replacement rate, and between VMA increment and RCM addition rate, respectively. The results shows that there is a better correlation between the VMA increment and the RCM addition rate, as shown in Figure 24 (b), compared to the correlation between the VMA increment rate and 
the RCA replacement rate, as shown in Figure 24 (a). The RCA replacement rate is not a good predictor of the VMA increment. Instead, the RCM addition rate can be used to quantify the change of the VMA when using RCA to replace virgin aggregate.

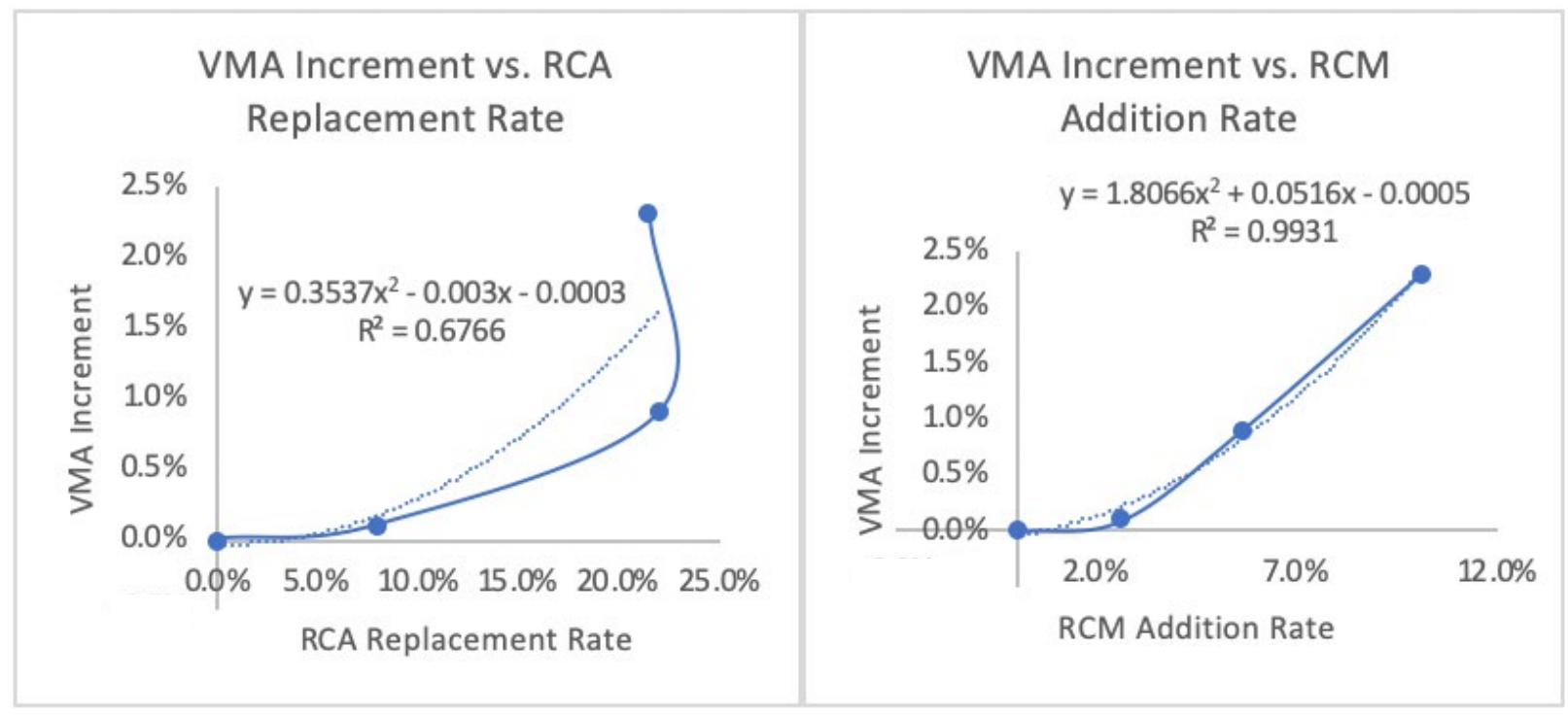

(a)

(b)

Figure 24. Relationship between VMA Increment and RCA Replacement Rate or RCM Addition Rate

Figure 25 plots the VFA increment versus RCA replacement rate and the VFA increment versus RCM addition rate. The results show that there is better correlation between the VFA increment and the RCM addition rate, as shown in Figure 25 (b), than the correlation between the VFA increment and the RCA replacement rate, as shown in Figure 25 (a). This result once again shows that only considering the RCA replacement rate is not sufficient for the characterization of the volumetrics of RCA-HMA. RCM plays a more critical role in the RCA-HMA mix design. 


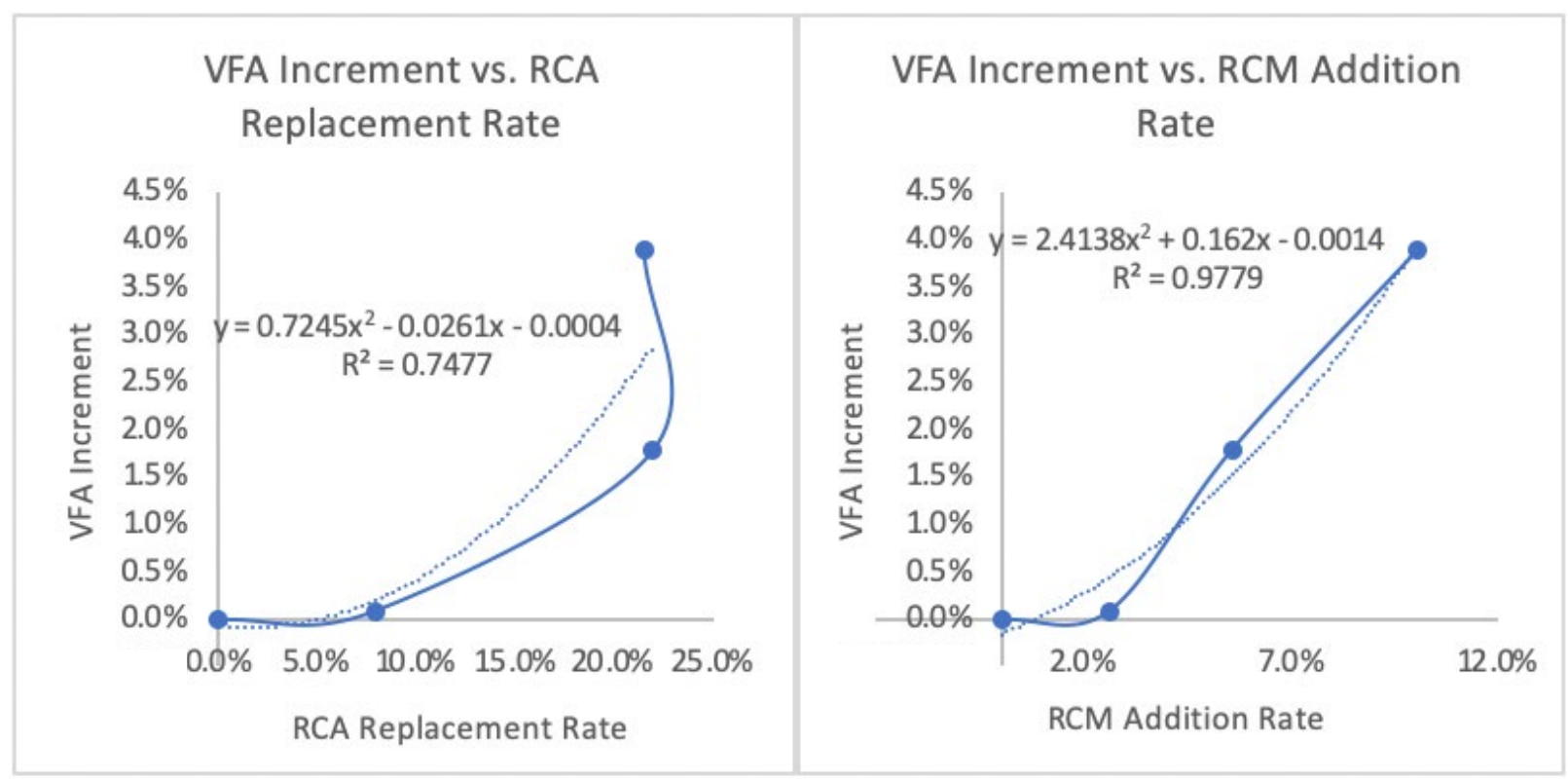

(a)

(b)

Figure 25. Relationship between VFA Increment and RCA Replacement Rate or RCM Addition Rate

Results of the correlation between RCA/RCM properties and volumetrics of RCA-HMA (i.e. OBC, VFA, and VMA) indicate that RCM plays a critical role in the study of RCAHMA performance. It is important to characterize properties of RCM when studying RCAHMA performance.

\section{Correlation between RCA/RCM Properties and Resistance to Permanent Deformation of Mixtures}

The permanent deformation of the control HMA and RCA-HMA was characterized using HWTT. The results shown in previous sections indicate that there are variations among the loading cycles until the failure criterion is reached (12.5mm rutting depth). The HWTT for some specimens, such as RCA 4.75-9.5mm at OBC and RCA 12.5-19.1mm at OBC, stopped before 13,000 cycles, while other specimens were loaded for much larger loading cycles. For the purpose of comparison, the rutting depths measured at the same 12,000 loading cycles as shown in Figure 26 was used for correlation analysis in this study. 


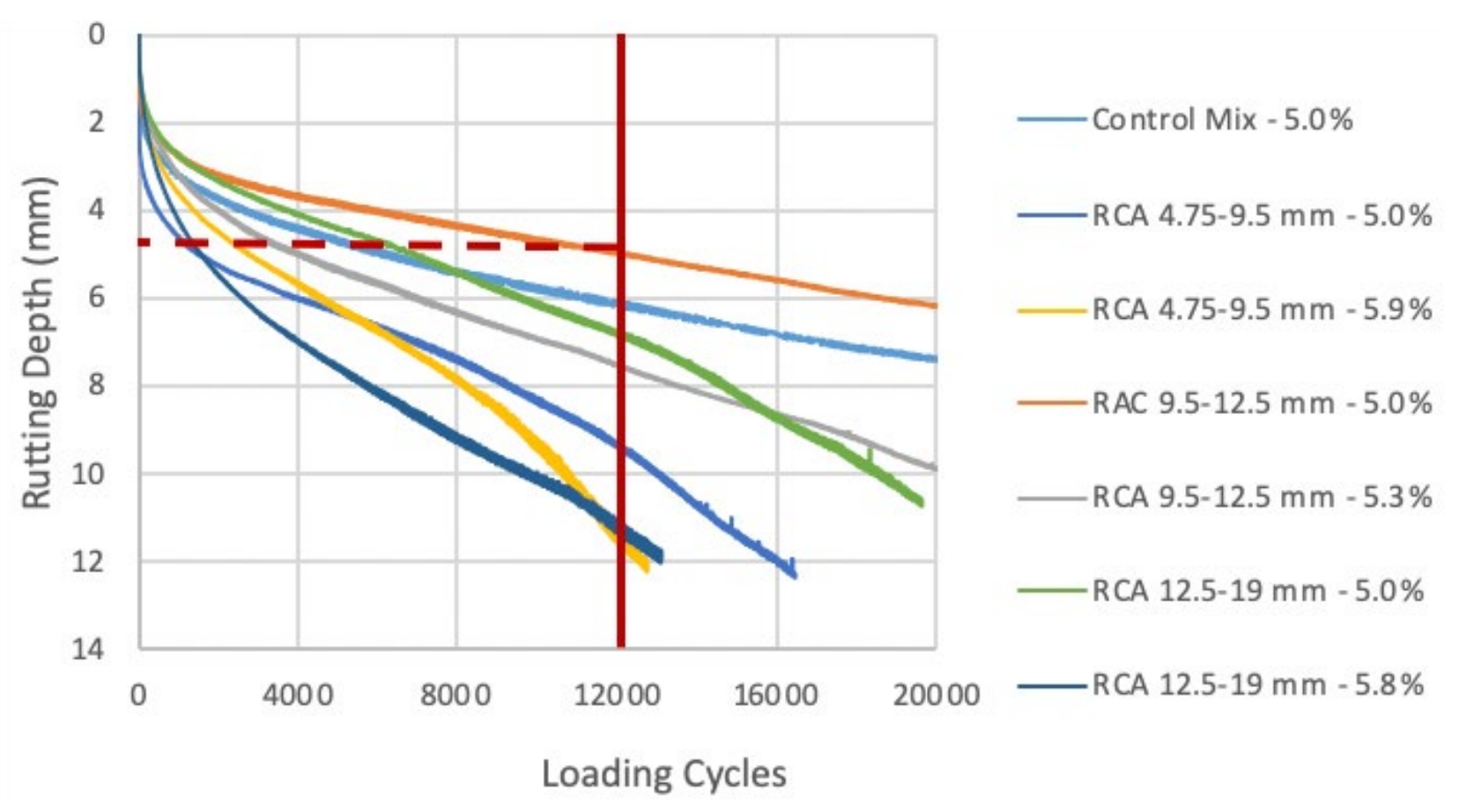

Figure 26. Relationship between Rutting Depth and Loading Cycles of HWTT

Figure 27 (a) shows the relationship between the rutting depth at 12,000 loading cycles and the RCA replacement rate for the HMA and RCA-HMA mixtures using both $5.0 \%$ asphalt binder content (which is the $\mathrm{OBC}$ of the control mixture) and the OBC of each RCA-HMA mixture. Although there is a good correlation between the rutting depth at 12,000 cycles and the RCA replacement rate, the trend as shown by the solid trend line of Figure 27 (a) indicates that the RCA replacement rate may not be a good predictor of the rutting depth since when the RCA replacement rate increased from $21.5 \%$ to $22 \%$, the rutting depth at 12,000 loading cycles reduced significantly from $9.4 \mathrm{~mm}$ to $6.8 \mathrm{~mm}$ for mixes using $5.0 \%$ binder content and from $11.5 \mathrm{~mm}$ to $11.2 \mathrm{~mm}$ for mixes using each $\mathrm{OBC}$.

Figure 27 (b) shows the relationship between the rutting depth at 12,000 loading cycles and the RCM addition rate for the HMA and RCA-HMA mixtures using both 5.0\% asphalt binder content (which is the $\mathrm{OBC}$ of the control mixture) and the $\mathrm{OBC}$ of each mixture. There is a good correlation between the rutting depth at 12,000 cycles and the RCM addition rate. More importantly, the trend as show by the solid trend line in Figure 27 (b) indicates that the RCM addition rate can be used as a predictor of the rutting depth. One can observe a trend: the rutting depth is increasing with the increase of the RCM addition rate. 


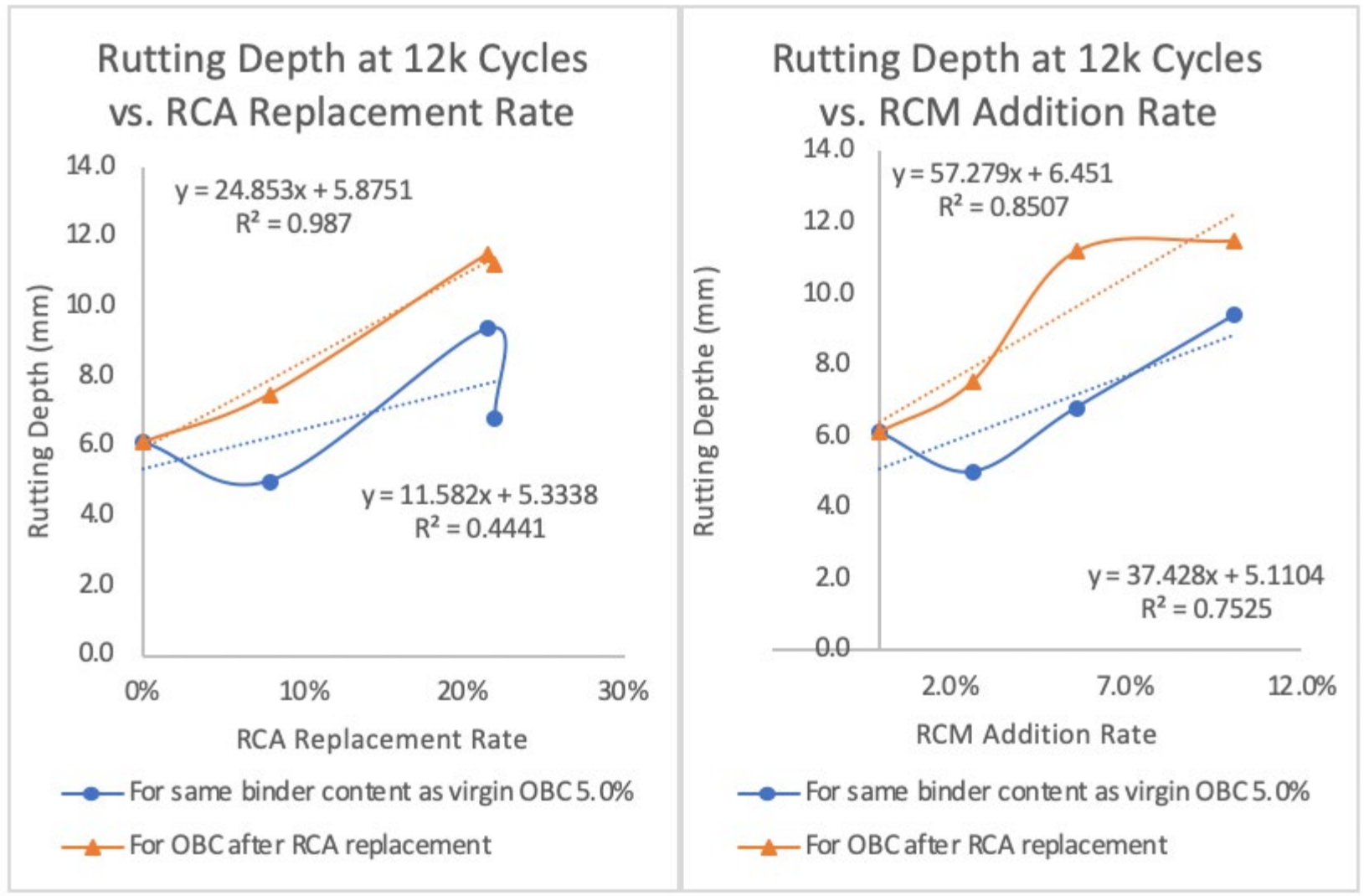

(a)

(b)

Figure 27. Relationship between Rutting Depth at 12k Loading Cycles and RCA Replacement Rate or RCM Addition Rate

Similar to the relationship between the rutting depth at 12,000 loading cycles and the RCA replacement rate or the RCM addition rate, the relationship between the rutting depth at 12,000 loading cycles and the absorption increment due to RCA replacement (as defined by Equation (5)), or the absorption increment due to RCM addition (as defined by Equation (6)), as shown in Figure 28, indicates that the absorption increment due to RCM addition is a better predictor of the rutting depth for RCA-HMA compared with the absorption increment due to RCA replacement. The results of this study cannot explain this phenomenon. It might be related to the pore structure in the RCA and RCM. Since the absorption measured in this study is actually water absorption, if the pore structure in the RCM is larger than that of the natural aggregates in RCA and that of the virgin aggregates, it is possible that the pores in the RCM are more related to asphalt binder absorption than the pores in aggregate due to higher viscosity of the asphalt binder compared with water. 


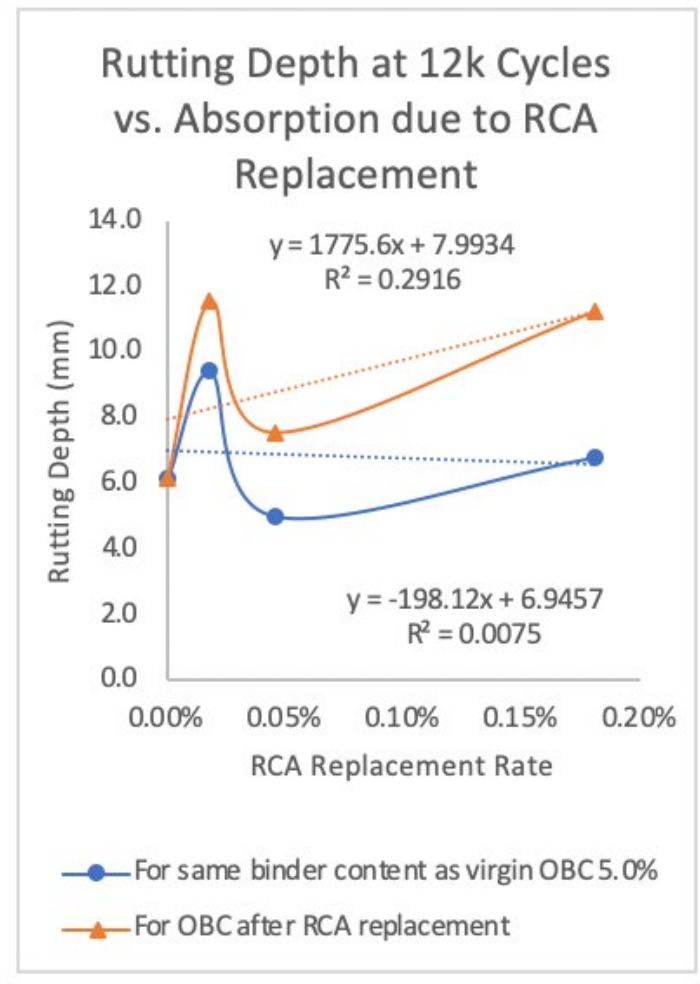

(a)

\section{Rutting Depth at $12 \mathrm{k}$ Cycles \\ vs. Absorption due to RCM \\ Addition}

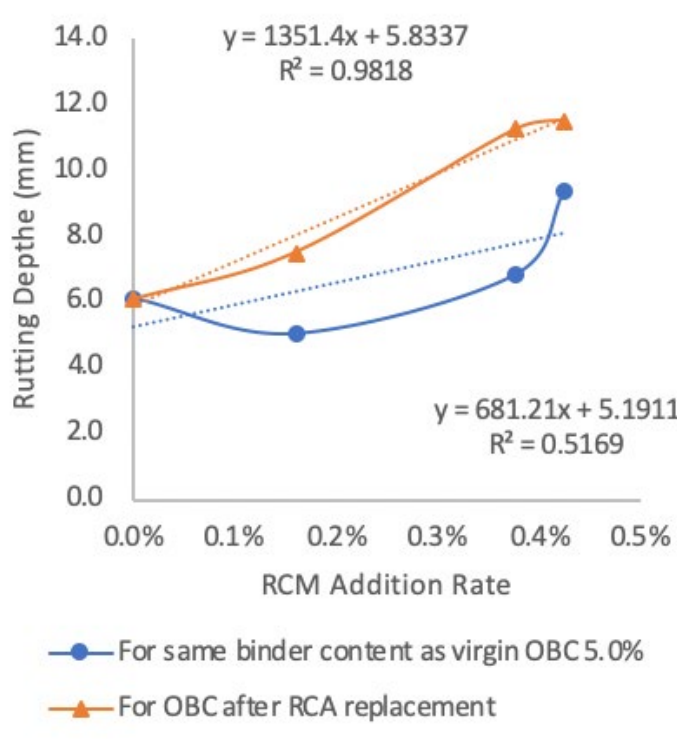

(b)

Figure 28. Relationship between Rutting Depth at 12k Loading Cycles and Absorption due to RCA Replacement or Absorption due to RCM Addition

\section{Correlation between RCA/RCM Properties and Moisture Damage Susceptibility of Mixtures}

Figure 29 (which has been shown as Figure 19 previously) shows the dry strength of specimens without conditioning, the wet strength of specimens after freezing-thawing conditing, and the TSR from moisture susceptibility test following AASHTO T-283. The results indicate that for the RCA replacement of all three size groups (RCA replacement of $4.75-9.5 \mathrm{~mm}, 9.5-12.5 \mathrm{~mm}$, and $12.5-19.1 \mathrm{~mm}$ ), at each OBC after RCA replacement, the TSRs are increased compared to the TSR of the control mix. The RCA-HMA mix with RCA replacement of $9.5-12.5 \mathrm{~mm}$ particles, which has the smallest $\mathrm{RCA}$ replacement rate $(8.0 \%)$ and the smallest RCM addition rate (2.6\%), shows the highest TSR value (best moisture damage resistance). The improvement of the moisture damage resistance of the RCA-HMA is possibly due to the increase of the OBC. 


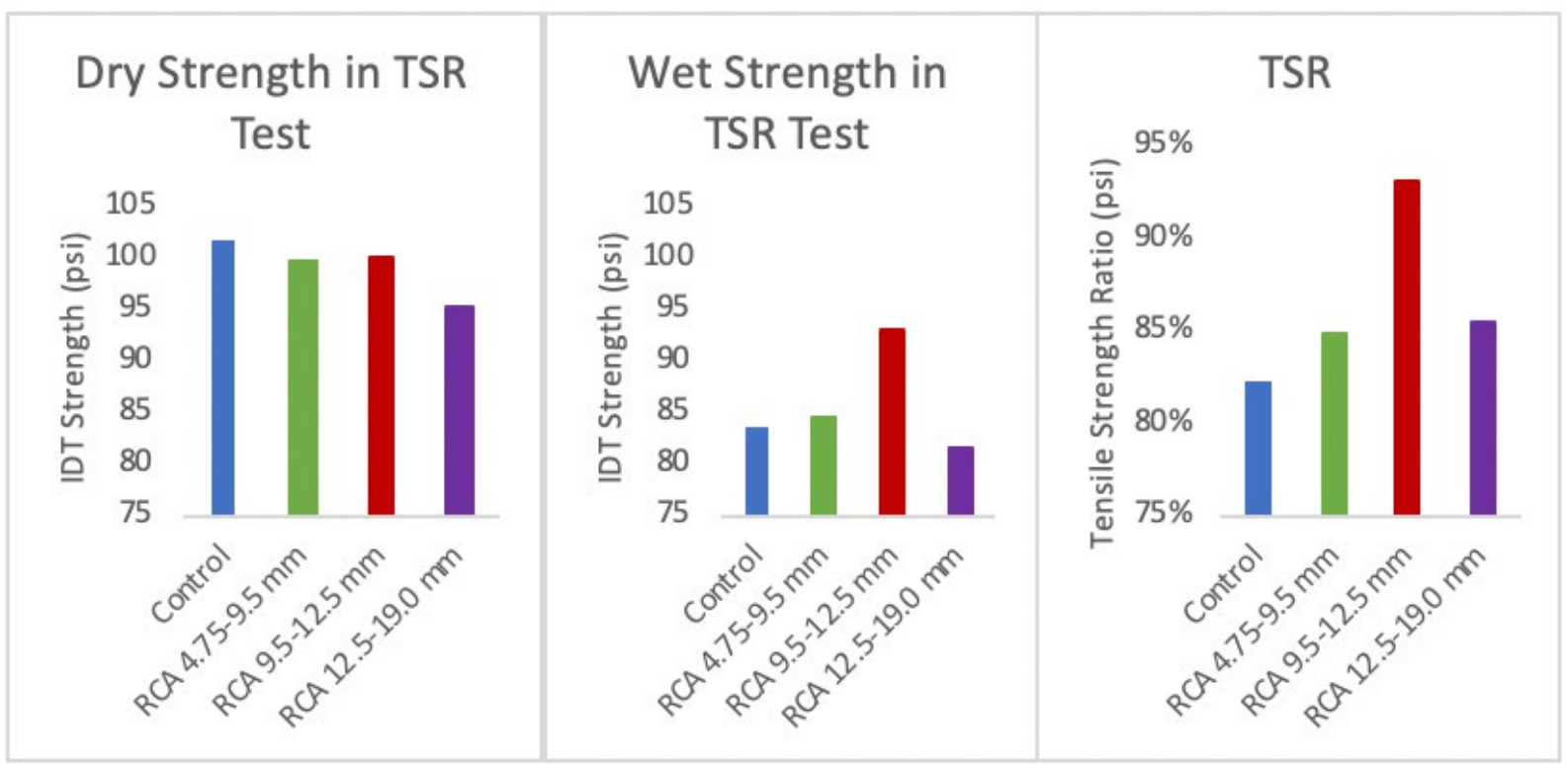

Figure 29. Dry Strength, Wet Strength, and TSR Results of HMA and RCA-HMA

If one defines the TSR change as the change of the TSR of RCA-HMA compared with the TSR of control HMA, Figure 30 shows the relationship between the TSR changes and the RCA replacement rate or the RCM addition rate. Figure 30 (a) cannot show a clear trend according to which the TSR change is reducing with the increase of the RCA replacement rate. The TSR change reduced from $10.8 \%$ to $2.6 \%$ when the RCA replacement rate increased from $8.0 \%$ to $21.5 \%$, while the TSR change increased from $2.6 \%$ to $3.2 \%$ when the RCA replacement rate further increased from $21.5 \%$ to $22.0 \%$.

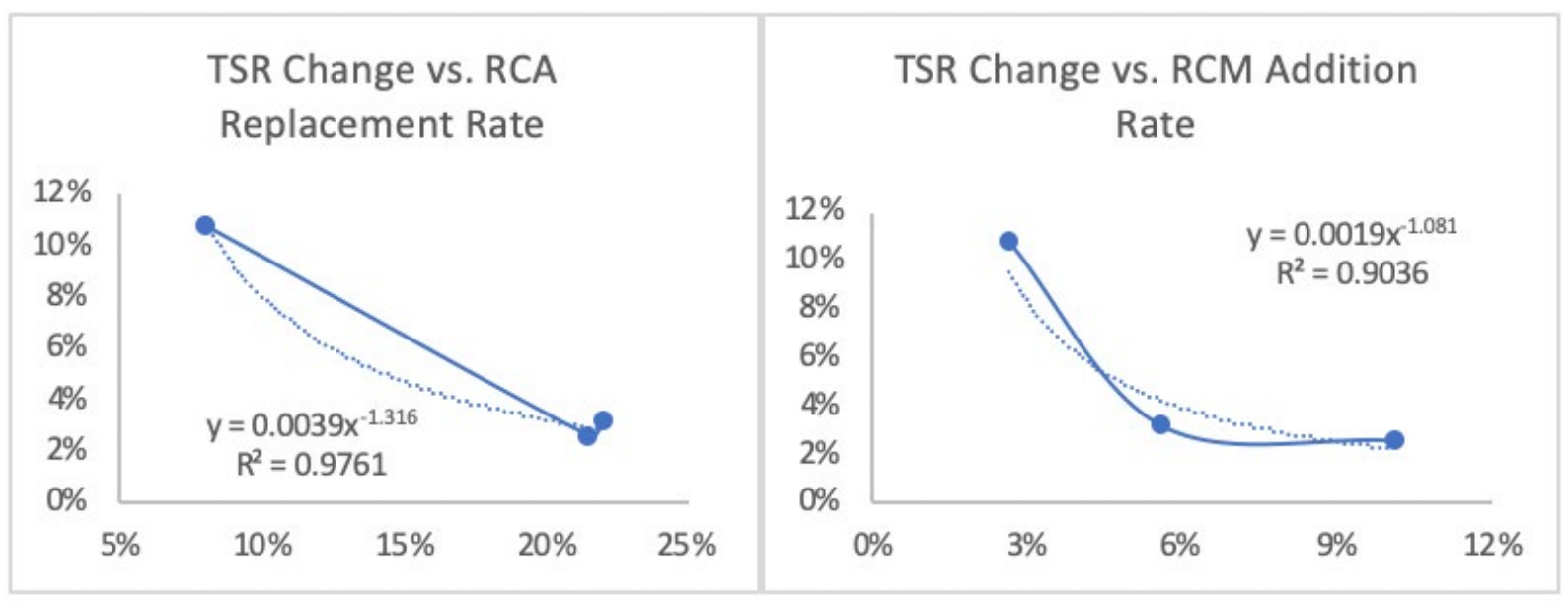

(a)

(b)

Figure 30. Relationship between TSR Change and RCA Replacement Rate or RCM Addition Rate

However, Figure 30 (b) shows a clear trend that the TSR change is reducing with the RCM addition rate. It shows that the TSR change reduced sharply when the RCM addition rate was less than $6.0 \%$, and thereafter started to level out. This is possibly because of the increment of the OBC after RCA replacement. 
Figure 31 (a) shows that there is no clear correlation between the TSR change (TSR of the RCA-HMA compared with the TSR of the control HMA) and the absorption increment due to RCA replacement (as defined in Equation (5)). However, as shown in Figure 31 (b), there is a good correlation between the TSR change and the absorption increment due to RCM addition (as defined in Equation (6)). This result, again, shows that the information of the RCA only is not sufficient to predict the properties and performance of the RCA-HMA. The information about the RCM is critical in this prediction.

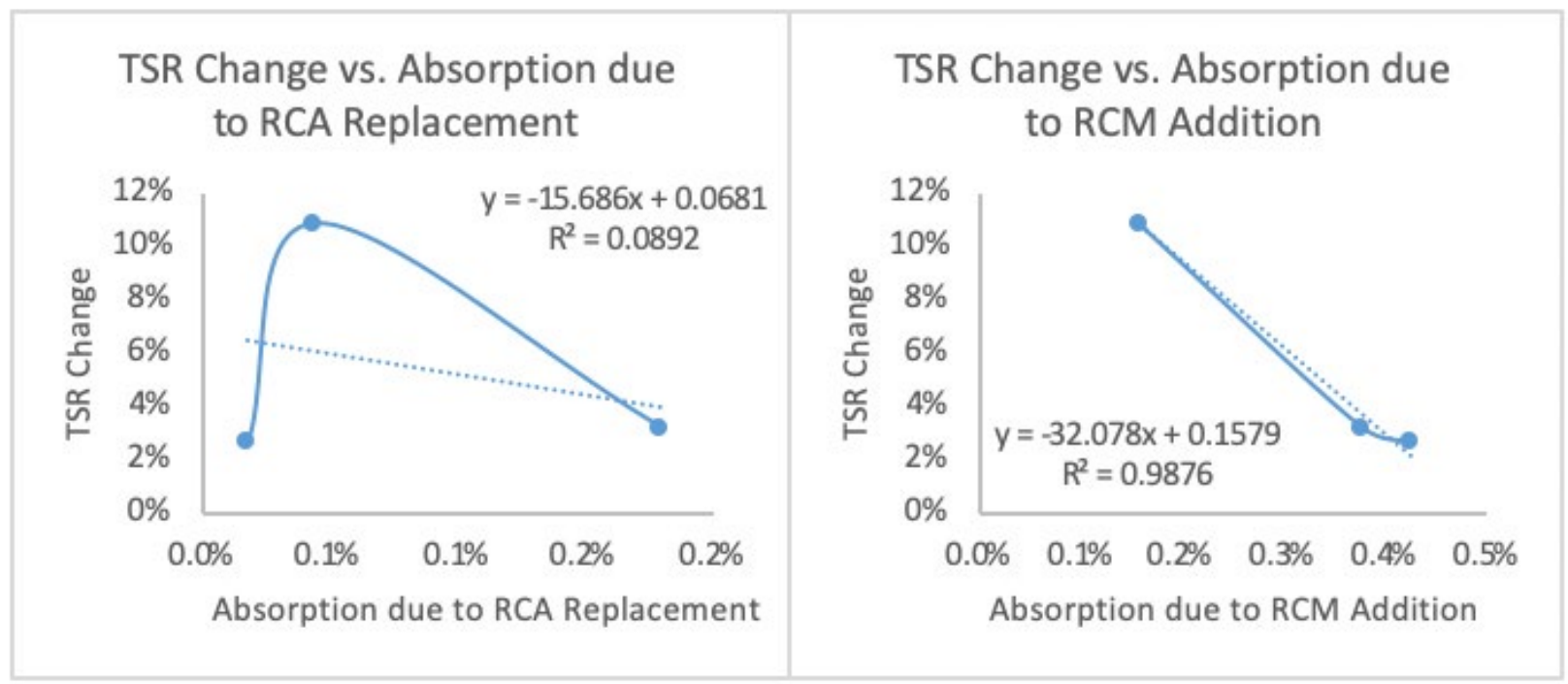

\section{Figure 31. Relationship between TSR Change and Absorption due to RCA Replacement or Absorption due to RCM Addition}

In summary, the results of this study indicate that RCM properties are correlated with RCAHMA volumetrics and performance indicators at a much higher level of agreement compared to RCA properties. One fundamental difference between RCA and virgin aggregate is the $\mathrm{RCM}$ on the surface of RCA. RCA content is not directly related to RCM content due to the variation of RCM contents among different RCA sources as well as among different RCA particle size groups; therefore RCA content cannot be directly related to RCA-HMA performance.

The RCAs used in this study were randomly sampled from local plants or concrete demolition sites. The RCAs used to fabricate RCA-HMA specimens were randomly sampled at two different dates (December 2018 and March 2019) with no information of the demolition source concrete. Considering the possibilities and variation of the source concrete used to produce $\mathrm{RCA}$, the results are representative of a typical RCA plant. Although the specific results must be different for different sources due to the variations of local materials, the trend ought to be generalizable. At the same time, the authors of this study realize the importance of a more comprehensive research to further support the claims raised in this study. 


\section{CONCLUSIONS AND RECOMMENDATIONS}

\section{CONCLUSIONS}

This study investigated the variation of the material properties of RCA from different sources along with their effects on the performance indicators of RCA-HMA. Of particular interest were the properties of RCM (i.e. RCM content and specific gravity and absorption of RCM), which were further characterized and correlated with RCA-HMA performance. The results of this study provide a different viewpoint for the study of RCA-HMA performance by indicating critical effects of RCM on performance of RCA-HMA. Based on the experimental results and data analysis, the following conclusions can be made:

1. There are significant variations in terms of the specific gravity, absorption, and RCM content among different sources of RCA. The specific gravity and absorption of the $\mathrm{RCM}$ from different sources vary significantly as well. These variations also exist among different size groups of the RCA from the same source. The variation of the RCA properties is mainly due to the variations of the RCM contents and its absorption. This finding indicates that only considering the replacement rate and gradation of RCA without considering properties of RCM is not sufficient in the RCA-HMA mix design and the study of the RCA-HMA performance.

2. The variation of the RCA and RCM properties has effects on the performance of the RCA-HMA in terms of OBC, VMA, VFA, resistance to permanent deformation, and moisture damage susceptibility. Generally, the OBC increased after RCA replacement. The resistance to permanent deformation was reduced and the moisture damage resistance improved after RCA replacement and OBC increments.

3. The OBC increment of the RCA-HMA compared with the control HMA has good correlation with the RCM addition rate and the absorption due to RCM addition. There is a clear trend that the OBC increment increases with the increase of RCM addition rate and absorption due to RCM's addition. For the materials used in this study, the OBC increment increases linearly with the RCM addition rate until about $6 \%$ and then levels out. The OBC increment almost increases linearly with the increase of the absorption due to RCM addition. However, the RCA replacement rate and the absorption due to RCA replacement do not show a clear trend with respect to the $\mathrm{OBC}$ increment. The results of this study also demonstrate that there is a stronger correlation between the VMA increments and the RCM addition rates rather than between the VMA increments and the RCA replacement rates. Similarly, there is a stronger correlation between the VFA increments and the RCM addition rates, rather than between VFA increments and RCA replacement rates. These results indicate that solely considering the RCA replacement rate is insufficient for the characterization of the volumetrics of RCA-HMA. RCM plays a more critical role in the mix design of RCA-HMA.

4. The resistance to permanent deformation characterized by the rutting depth at 12,000 loading cycles in HWTT has good correlation with the RCM addition rate and absorption due to RCM addition. There is a clear trend that the rutting depth at 12,000 loading 
cycles in HWTT increases with the increase of RCM addition rate and the absorption due to RCM addition. However, the RCA replacement rate and the absorption due to RCA replacement do not show a clear trend with respect to the rutting depth at 12,000 loading cycles in HWTT.

5. The moisture damage susceptibility characterized by the TSR has good correlation with the RCM addition rate and absorption due to RCM addition. There is a trend that the TSR change compared with the TSR of the control HMA reduces with the increase of RCM addition rate and the absorption due to RCM addition. However, the RCA replacement rate and the absorption due to RCA replacement do not show a clear trend with respect to the TSR change.

6. The results of this study indicate that information about the RCM properties, such as the RCM content, specific gravity, and absorption of the RCM, is critical for the prediction of the RCA-HMA properties, such as OBC, VMA, VFA, resistance to permanent deformation, and moisture damage susceptibility. Information about the RCA properties such as RCA replacement rates and gradation, which have been used in previous studies, are not sufficient for these predictions. The nature of the RCM in the RCA must be characterized and controlled when studying the performance of RCA-HMA mixture and when using RCA for the production of HMA in practice.

\section{RECOMMENDATIONS}

1. RCA replacement rate is not a good indicator of the volumetrics and performance indicators of RCA-HMA. Using RCA replacement rate as a RCA-HMA mix design control parameter or criterion is not recommended.

2. Since the RCM content can be closely related to the volumetrics, resistance to permanent deformation, and moisture damage susceptibility of the RCA-HMA, it is recommended that the RCM content should be monitored and controlled in the RCAHMA mix design. A criterion setting out the RCM content upper limit based on local materials needs to be determined through extensive experimental study. As long as RCM content is controlled below some criterion, the performance of RCA-HMA can be well controlled. Based on the results of this study, further research on potential ways of controlling the RCM content within RCA practically and effectively may become a viable way for using RCA in HMA.

3. The results of this study show that the OBC will be increased after the addition of the RCA compared with the OBC of $100 \%$ virgin aggregate mix. However, the increase of the OBC could be detrimental to the resistance to permanent deformation of the RCAHMA based on the results of this study. It is recommended to control the absorption increment due to addition of the RCA through the control of RCM addition rate, in order to control the $\mathrm{OBC}$ increment. 


\section{APPENDIX A: GRADATION TEST RESULTS}

Table Appendix A: Mixture Design Results

\begin{tabular}{lllllll}
\hline \multicolumn{1}{c}{ Sieve Size } & JMF & Control Mix 1 & Control Mix 2 & Control Mix 3 & $\begin{array}{c}\text { Control } \\
\text { Mix (used) }\end{array}$ & $\begin{array}{c}\text { Caltrans } \\
\text { Spec. }\end{array}$ \\
\hline $25.4 \mathrm{~mm}(1 ")$ & 100 & 100 & 100 & 100 & 100 & 100 \\
$19.1 \mathrm{~mm}(3 / 4 ")$ & 98 & 98 & 98 & 98 & 93 & $90-98$ \\
$12.5 \mathrm{~mm}(1 / 2 ")$ & 82 & 82 & 82 & 82 & 71 & $70-90$ \\
$9.5 \mathrm{~mm}(3 / 8 ")$ & 74 & 73 & 74 & 73 & 63 & \\
No.4 & 47 & 46 & 48 & 47 & 42 & $42-58$ \\
No.8 & 30 & 29 & 32 & 30 & 29 & $29-43$ \\
No.16 & 20 & 19 & 22 & 20 & 17 & \\
No.30 & 14 & 13 & 16 & 14 & 14 & $10-23$ \\
No.50 & 9 & 9 & 12 & 10 & 7 & \\
No.100 & 6 & 6 & 8 & 7 & 6 & \\
No.200 & 3.4 & 3.6 & 6.0 & 4.5 & 4.5 & $2.0-7.0$ \\
Optimal Binder & $4.5 \%$ & $6.0 \%$ & $4.8 \%$ & $5.3 \%$ & $5.0 \%$ & \\
Content (OBC) & & 13.9 & 13.5 & 14.2 & 14.2 & $13.5-16.5$ \\
VMA (\%) & 13.8 & 15.9 & 70.6 & 71.9 & 71.8 & \\
VFA (\%) & 72.9 & 74.9 & 1.50 & 1.05 & 1.05 & $0.6-1.3$ \\
Dust Proportions & 0.82 & 0.71 & & &
\end{tabular}




\section{APPENDIX B: HWTT TEST RESULTS}

Table Appendix B-1: HWTT Results of Control Mix (100\% virgin aggregate) Theoretical Maximum Specific Gravity

2.549

\begin{tabular}{|c|c|c|c|c|c|c|}
\hline \multirow{12}{*}{ 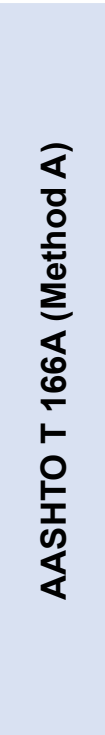 } & $\begin{array}{l}\text { Gyratory Compactor Manufacturer } \\
\text { Calibration Date }\end{array}$ & \multicolumn{5}{|c|}{$\begin{array}{l}\text { Pine Instruments } \\
7 / 31 / 2015\end{array}$} \\
\hline & Sample ID & $\mathrm{G} 1$ & G2 & G3 & G4 & G5 \\
\hline & Date Tested & $6 / 12 / 2019$ & $6 / 13 / 2019$ & $6 / 14 / 2019$ & 6/14/2019 & $6 / 14 / 2$ \\
\hline & Number of Gyrations & 125 & 107 & 74 & 76 & 72 \\
\hline & Specimen Height, mm & 60 & 60 & 60 & 60 & 60 \\
\hline & Mass of Dry Specimen in Air, g & 2326.4 & 2408.6 & 2395.7 & 2395.9 & 2396. \\
\hline & Mass of Specimen in Water, $\mathrm{g}$ & 1363.9 & 1418.7 & 1403.7 & 1404.6 & 1407. \\
\hline & $\begin{array}{l}\text { Mass of Surface-Dry Specimen in } \\
\text { Air, } g\end{array}$ & 2340.5 & 2423.9 & 2414 & 2412.2 & 2411. \\
\hline & Volume & 976.6 & 1005.2 & 1010.3 & 1007.6 & 1004. \\
\hline & Bulk Specific Gravity, SSD & 2.382 & 2.396 & 2.371 & 2.378 & 2.386 \\
\hline & Water Absorption & $0.61 \%$ & $0.64 \%$ & $0.76 \%$ & $0.68 \%$ & $0.64^{\circ}$ \\
\hline & Air Voids, \% & 6.6 & 6 & 7 & 6.7 & 6.4 \\
\hline \multirow{9}{*}{ 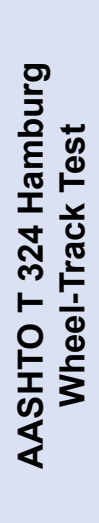 } & $\begin{array}{l}\text { Hamburg Wheel Manufacturer } \\
\text { Calibration Date }\end{array}$ & \multicolumn{5}{|c|}{ Pavement Technology Inc. } \\
\hline & Briquette Sample ID (from T166) & G2 & \multicolumn{2}{|l|}{ G3 } & G4 & G5 \\
\hline & Date Tested & $6 / 15 / 2019$ & & & & \\
\hline & Sample Location (LR, LF, RR, RF) & LR & \multicolumn{2}{|l|}{ LF } & RR & RF \\
\hline & Total Submersion Time, mins. & 45 & & & & \\
\hline & Rut Depth at 5,000 cycles $(\mathrm{mm})$ & 4.783 & & & 4.719 & \\
\hline & Rut Depth at 10,000 cycles $(\mathrm{mm})$ & 5.540 & & & 5.995 & \\
\hline & Rut Depth at 15,000 cycles $(\mathrm{mm})$ & 6.090 & & & 7.197 & \\
\hline & Rut Depth at 20,000 cycles $(\mathrm{mm})$ & 6.595 & & & 8.147 & \\
\hline
\end{tabular}


Table Appendix B-2: HWTT Results of RCA 4.75-9.5mm Mix: $5.0 \%$ binder content (OBC of control mix)

\section{Theoretical Maximum \\ Specific Gravity}

Gyratory Compactor

Manufacturer

Calibration Date

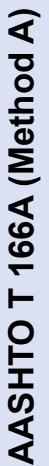

Sample ID

Date Tested

Number of Gyrations

Specimen Height, mm

Mass of Dry Specimen in Air, $g$

Mass of Specimen in Water, $g$

Mass of Surface-Dry Specimen

in Air, $\mathrm{g}$

Volume

Bulk Specific Gravity, SSD

Water Absorption

Air Voids, \%
Pine Instruments

7/31/2015

G1

$$
\text { G2 }
$$

Aug24-25

152

60

$2361.4 \quad 2362.3 \quad 2361.6$

1362.6

1360.6

$2375.9 \quad 2376$

1013.3

2.33

$0.61 \%$

6.3

2377

1018.1

2.32

$0.65 \%$

6.7

6.5

Pavement Technology Inc.

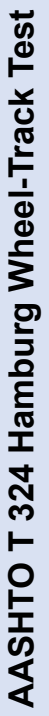

Hamburg Wheel Manufacturer

Calibration Date

Briquette Sample ID (from

T166)

Date Tested

G3

G4

G2

G5

Aug 27th

Sample Location (LR, LF, RR,

$\mathrm{RF}$ )

LF LR

LR

RF

RR

Total Submersion Time, mins. $\quad 45$

Rut Depth at 5,000 cycles (mm) 6.647

Rut Depth at 10,000 cycles

(mm)

8.996

7.734

Rut Depth at 15,000 cycles

( $\mathrm{mm}$ )

13.636

9.055

Rut Depth at 20,000 cycles

(mm)

---Fail at 16458 cycles

10.599

G6

Aug24-25 20-Aug

$137 \quad 192$

$60 \quad 60$

$2363.5 \quad 2358.5$

$1363.8 \quad 1360.1$

$2376.3 \quad 2383.1$

$1012.5 \quad 1023$

$2.334 \quad 2.305$

$0.54 \% \quad 1.04 \%$

$6.2 \quad 7.3$ 


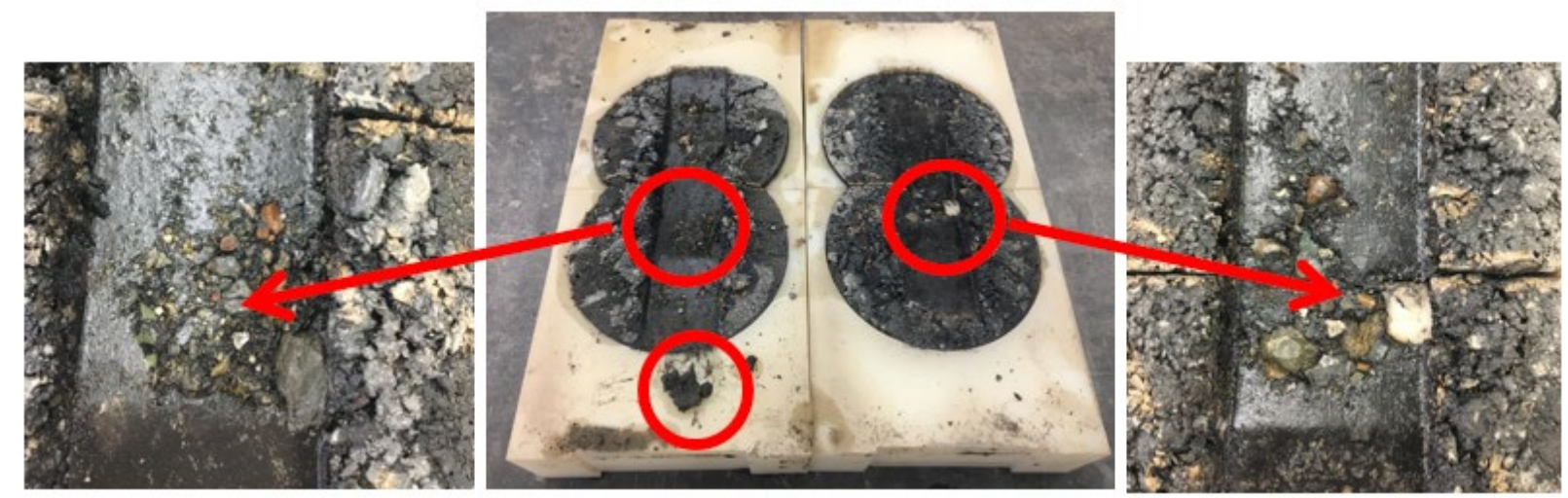

Figure Appendix B-1: HWTT Photo of RCA 4.75-9.5mm with 5.0\% Binder Content (OBC of control mix)

Table Appendix B-3: HWTT Results of RCA 4.75-9.5mm Mix: 5.9\% OBC

Theoretical Maximum Specific

Gravity

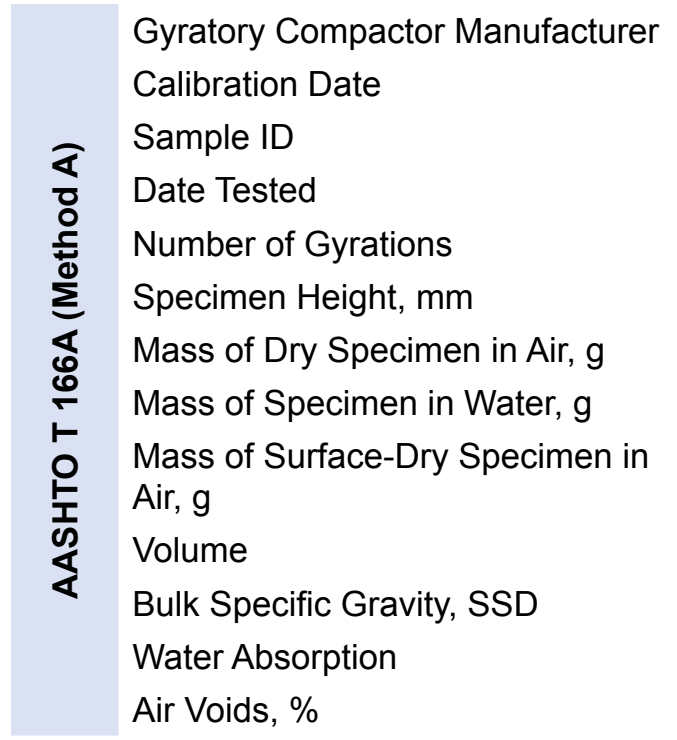

Hamburg Wheel Manufacturer

Calibration Date

Briquette Sample ID (from T166)

Date Tested

Sample Location (LR, LF, RR, RF)

Total Submersion Time, mins.

Rut Depth at 5,000 cycles ( $\mathrm{mm}$ )

Rut Depth at 10,000 cycles (mm)

Rut Depth at 15,000 cycles (mm)

Rut Depth at 20,000 cycles (mm)
Pine Instruments $7 / 31 / 2015$

$\begin{array}{llllll}\text { G1 } & \text { G2 } & \text { G3 } & \text { G4 } & \text { G5 } & \text { G6 }\end{array}$

Sep. 2 Sept 2-3 Sept 2-3 Sept 2-3 Sept 2-3 Sept 2-3

$\begin{array}{llllll}96 & 98 & 65 & 47 & 63 & 49\end{array}$

$\begin{array}{llllll}60 & 60 & 60 & 60 & 60 & 60\end{array}$

$\begin{array}{llllll}2339 & 2320 & 2322.4 & 2319.3 & 2319.8 & 2320.2\end{array}$

$\begin{array}{llllll}1345.3 & 1323.8 & 1326.6 & 1323.4 & 1322 & 1324.6\end{array}$

$\begin{array}{llllll}2350.4 & 2329.4 & 2335.5 & 2338.5 & 2331.9 & 2333.5\end{array}$

$\begin{array}{llllll}1005.1 & 1005.6 & 1008.9 & 1015.1 & 1009.9 & 1008.9\end{array}$

$\begin{array}{llllll}2.327 & 2.307 & 2.302 & 2.285 & 2.297 & 2.3\end{array}$

$\begin{array}{llllll}0.49 \% & 0.41 \% & 0.56 \% & 0.83 \% & 0.52 \% & 0.57 \%\end{array}$

$\begin{array}{llllll}5.9 & 6.7 & 6.9 & 7.6 & 7.1 & 7.0\end{array}$

Pavement Technology Inc.

$\begin{array}{llll}\text { G5 } & \text { G6 } & \text { G2 } & \text { G3 }\end{array}$

Sept 4th

$\begin{array}{llll}\text { LF } & \text { LR } & \text { RF } & \text { RR }\end{array}$

45

$7.073 \quad 5.403$

$9.941 \quad 8.699$

---Fail at 12756 cycles ---Failure at 14756 cycles 


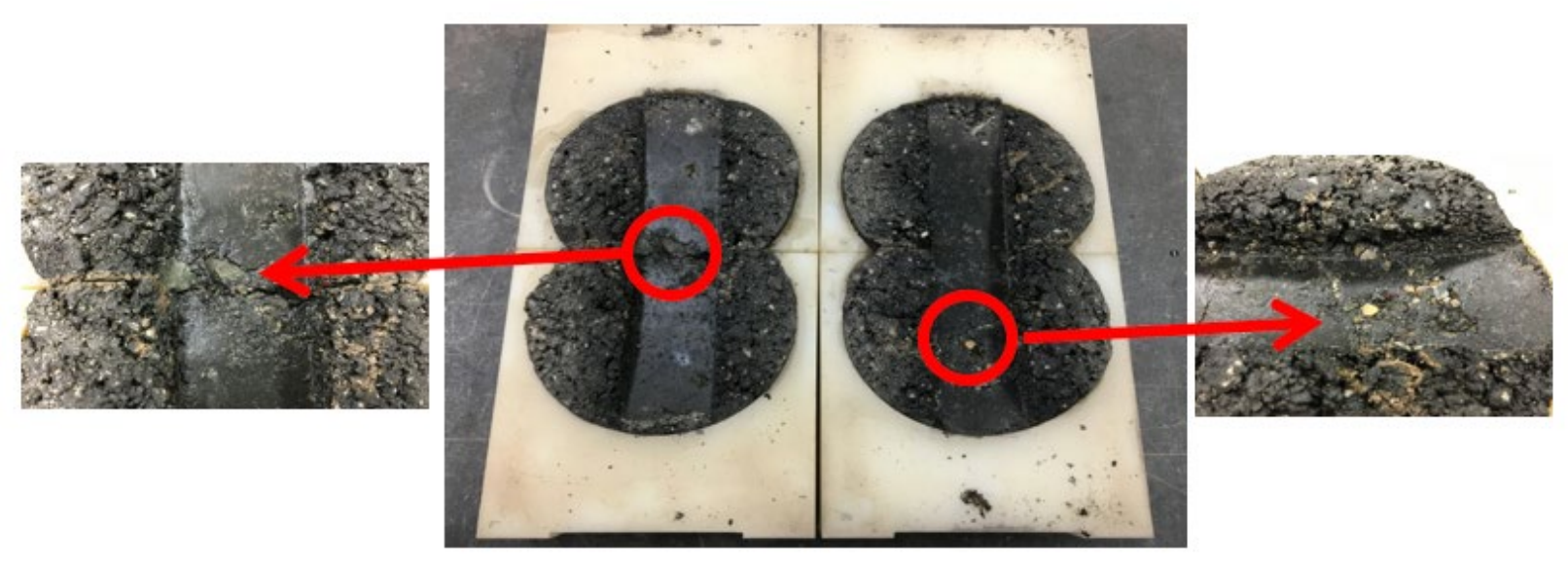

Figure Appendix B-2: HWTT Photo of RCA 4.75-9.5mm with 5.9\% OBC

Table Appendix B-4: HWTT Results of RCA 9.5-12.5mm Mix: $5.0 \%$ binder content (OBC of control mix)

Theoretical Maximum

Specific Gravity

\begin{tabular}{|c|c|c|c|c|c|c|}
\hline \multirow{12}{*}{ 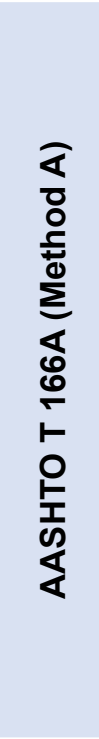 } & $\begin{array}{l}\text { Gyratory Compactor Manufacturer } \\
\text { Calibration Date }\end{array}$ & \multicolumn{5}{|c|}{$\begin{array}{l}\text { Pine Instruments } \\
7 / 31 / 2015\end{array}$} \\
\hline & Sample ID & $\mathrm{G} 1$ & G2 & G3 & G4 & G5 \\
\hline & Date Tested & $6-17-18-2019$ & $6 / 18 / 2019$ & $6 / 18 / 2019$ & $6 / 18 / 2019$ & $6 / 18 /$ \\
\hline & Number of Gyrations & 117 & 88 & 120 & 93 & 102 \\
\hline & Specimen Height, mm & 60 & 60 & 60 & 60 & 60 \\
\hline & Mass of Dry Specimen in Air, $\mathrm{g}$ & 2400.5 & 2393.9 & 2397.3 & 2398.9 & 2401 \\
\hline & Mass of Specimen in Water, g & 1404.2 & 1396.7 & 1398.9 & 1402.9 & 1395 \\
\hline & $\begin{array}{l}\text { Mass of Surface-Dry Specimen in } \\
\text { Air, } g\end{array}$ & 2414.8 & 2409.2 & 2407.7 & 2415.5 & 2419 \\
\hline & Volume & 1010.6 & 1012.5 & 1008.8 & 1012.6 & \\
\hline & Bulk Specific Gravity, SSD & 2.375 & 2.364 & 2.376 & 2.369 & \\
\hline & Water Absorption & $0.60 \%$ & $0.64 \%$ & $0.43 \%$ & $0.69 \%$ & 0.74 \\
\hline & Air Voids, \% & 6.4 & 6.9 & 6.4 & 6.7 & 7.6 \\
\hline \multirow{9}{*}{ 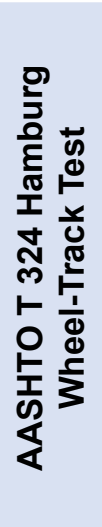 } & $\begin{array}{l}\text { Hamburg Wheel Manufacturer } \\
\text { Calibration Date }\end{array}$ & \multicolumn{5}{|c|}{ Pavement Technology Inc. } \\
\hline & Briquette Sample ID (from T166) & $\mathrm{G} 1$ & \multicolumn{2}{|l|}{ G3 } & $\mathrm{G} 2$ & G4 \\
\hline & Date Tested & $6 / 19 / 2019$ & & & & \\
\hline & Sample Location (LR, LF, RR, RF) & LR & \multicolumn{2}{|l|}{ LF } & $\mathrm{RR}$ & RF \\
\hline & Total Submersion Time, mins. & \multirow{2}{*}{\multicolumn{3}{|c|}{$\begin{array}{l}45 \\
3.802\end{array}$}} & & \\
\hline & Rut Depth at 5,000 cycles (mm) & & & & 3.949 & \\
\hline & Rut Depth at 10,000 cycles $(\mathrm{mm})$ & \multicolumn{3}{|l|}{4.397} & 4.958 & \\
\hline & Rut Depth at 15,000 cycles (mm) & \multicolumn{3}{|l|}{5.258} & 5.626 & \\
\hline & Rut Depth at 20,000 cycles (mm) & \multicolumn{3}{|l|}{6.164} & 6.190 & \\
\hline
\end{tabular}


Table Appendix B-5: HWTT Results of RCA 9.5-12.5mm Mix: 5.4\% OBC

Theoretical Maximum

Specific Gravity

2.523

\begin{tabular}{|c|c|c|c|c|c|c|c|}
\hline \multirow{12}{*}{ 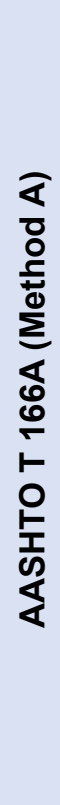 } & $\begin{array}{l}\text { Gyratory Compactor } \\
\text { Manufacturer } \\
\text { Calibration Date }\end{array}$ & $\begin{array}{l}\text { Pine Instrul } \\
7 / 31 / 2015\end{array}$ & ents & & & & \\
\hline & Sample ID & $\mathrm{G} 1$ & G2 & $\mathrm{G} 1$ ' & G2' & G5 & G6 \\
\hline & Date Tested & July23-24 & July $24-26$ & August 20 & August 20 & July $24-26$ & July $24-26$ \\
\hline & Number of Gyrations & 123 & 84 & 77 & 77 & 78 & 84 \\
\hline & Specimen Height, mm & 60 & 60 & 60 & 60 & 60 & 60 \\
\hline & $\begin{array}{l}\text { Mass of Dry Specimen in Air, } \\
\mathrm{g}\end{array}$ & 2392.6 & 2373.6 & 2366.8 & 2366.6 & 2383.6 & 2368.9 \\
\hline & Mass of Specimen in Water, $\mathrm{g}$ & 1391.8 & 1379.9 & 1377.8 & 1372.8 & 1386.2 & 1373.4 \\
\hline & $\begin{array}{l}\text { Mass of Surface-Dry } \\
\text { Specimen in Air }\end{array}$ & 24055 & 23904 & 23837 & 23812 & 23959 & 23842 \\
\hline & Volume & 1013.7 & 1010.5 & 1005.9 & 1008.4 & 1009.7 & 1010.8 \\
\hline & Bulk Specific Gravity, SSD & 2.360 & 2.349 & 2.353 & 2.347 & 2.361 & 2.344 \\
\hline & Water Absorption & $0.54 \%$ & $0.71 \%$ & $0.71 \%$ & $0.62 \%$ & $0.52 \%$ & $0.65 \%$ \\
\hline & Air Voids, \% & 6.5 & 6.9 & 6.7 & 7.0 & 6.4 & 7.1 \\
\hline & $\begin{array}{l}\text { Hamburg Wheel } \\
\text { Manufacturer }\end{array}$ & Pavement & echnology In & & & & \\
\hline & Calibration Date & & & & & & \\
\hline 帝 & $\begin{array}{l}\text { Briquette Sample ID (from } \\
\text { T166) }\end{array}$ & G1 & G5 & & G1' & G2' & \\
\hline $\bar{\Phi}$ & Date Tested & $8 / 22 / 2019$ & & & & & \\
\hline$\frac{5}{3}$ & $\begin{array}{l}\text { Sample Location (LR, LF, RR, } \\
\text { RF) }\end{array}$ & LF & LR & & RF & $\mathrm{RR}$ & \\
\hline 를 & Total Submersion Time, mins. & 45 & & & & & \\
\hline $\begin{array}{l}\frac{\pi}{1} \\
\frac{7}{4}\end{array}$ & $\begin{array}{l}\text { Rut Depth at } 5,000 \text { cycles } \\
(\mathrm{mm})\end{array}$ & 5.186 & & & 5.507 & & \\
\hline స్ & $\begin{array}{l}\text { Rut Depth at } 10,000 \text { cycles } \\
\text { (mm) }\end{array}$ & 6.806 & & & 7.081 & & \\
\hline 喪 & $\begin{array}{l}\text { Rut Depth at } 15,000 \text { cycles } \\
(\mathrm{mm})\end{array}$ & 8.351 & & & 8.417 & & \\
\hline & $\begin{array}{l}\text { Rut Depth at } 20,000 \text { cycles } \\
\text { (mm) }\end{array}$ & 10.253 & & & 9.545 & & \\
\hline
\end{tabular}

Gyratory Compactor

Manufacturer

Calibration Date

Date Tested

Number of Gyrations

Mass of Dry Specimen in Air,

Mass of Specimen in Water, $g$

Mass of Surface-Dry

specimen in Air, $g$

Volume

Water Absorption

Air Voids, \%

Hamburg Wheel

acturer

Briquette Sample ID (from

Pine Instruments

$7 / 31 / 2015$

August 20

July 24-26

uly $24-26$

123

84

77

77

78

84

2392.6

2373.6

2366.8

2366.6

2383.6

2368.9

2405.5

2390

2383.7

2381.

2395

1013.7

2.349

2.353

2.347

2361

2.344

$0.54 \%$

$0.71 \%$

$0.71 \%$

$0.62 \%$

$0.52 \%$

$0.65 \%$ 


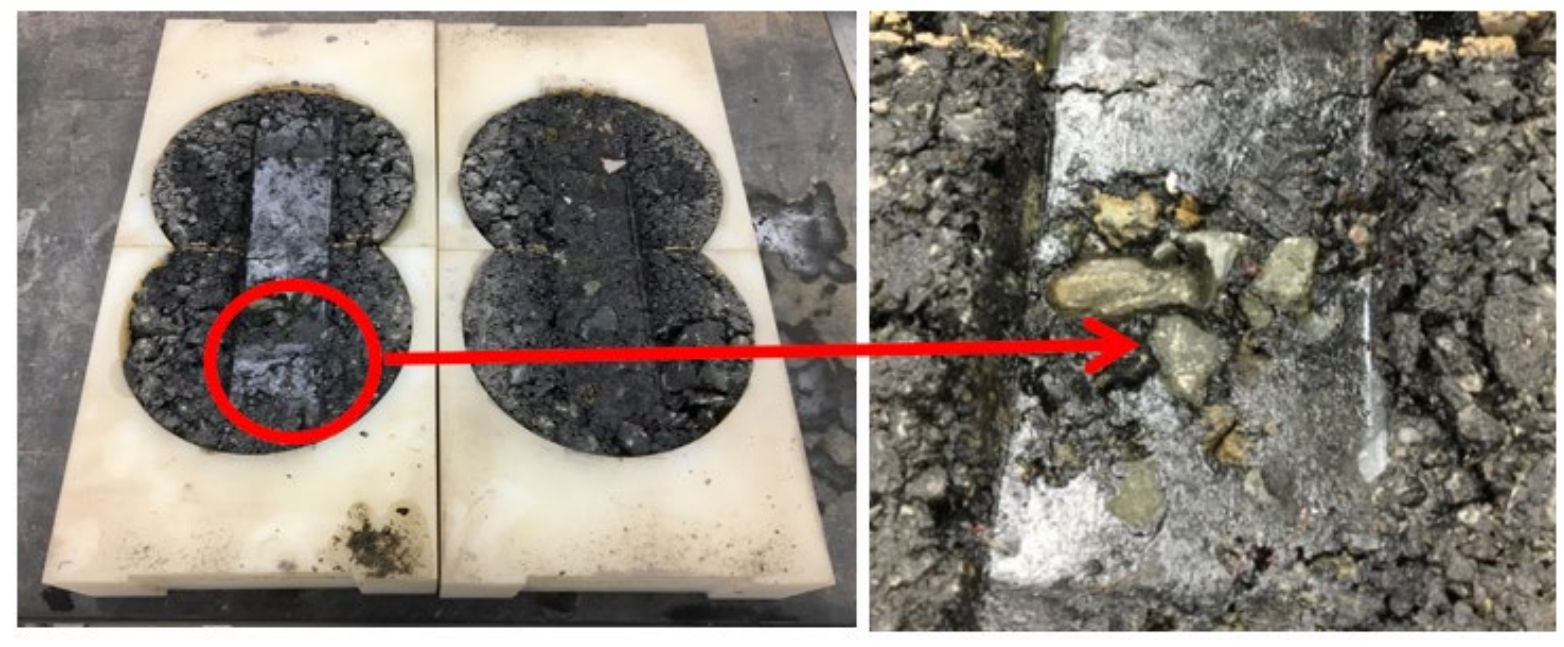

Figure Appendix B-3: HWTT Photo of RCA 9.5-12.5mm with 5.4\% OBC 
Table Appendix B-6: HWTT Results of RCA 12.5-19.1mm Mix: 5.0\% binder content (OBC of control mix)

\section{Theoretical Maximum Specific Gravity}

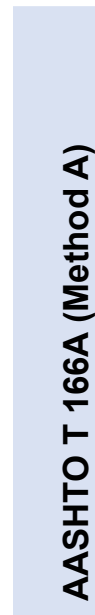

Calibration Date

Sample ID

Number of Gyrations

Specimen Height, $\mathrm{mm}$

Mass of Dry Specimen in Air, $g$

Mass of Specimen in Water, $g$

Mass of Surface-Dry Specimen in

Air, $g$

Volume
Gyratory Compactor Manufacturer Pine Instruments

Date Tested

Bulk Specific Gravity, SSD

Water Absorption

Air Voids, \%

Hamburg Wheel Manufacturer

Calibration Date

Briquette Sample ID (from T166)

Date Tested

Sample Location (LR, LF, RR, $\mathrm{RF}$ )

Total Submersion Time, mins.

Rut Depth at 5,000 cycles (mm)

Rut Depth at 10,000 cycles $(\mathrm{mm})$

Rut Depth at 15,000 cycles (mm)

Rut Depth at 20,000 cycles (mm)

$8 / 29 / 2019$

45

3.625
$7 / 31 / 2015$

$\begin{array}{llllll}\text { G1 } & \text { G2 } & \text { G3 } & \text { G4 } & \text { G5 } & \text { G6 }\end{array}$

Aug20-21 Aug20-21

$104 \quad 128$

$60 \quad 60$

$2341.3 \quad 2348.6$

$1355.4 \quad 1363.4$

Aug27-28

134

60

2353.1

1353.6

2352.6

1352.8

Aug27-28

Aug27-28

$\begin{array}{llllll}2370.4 & 2376.3 & 2367.4 & 2367.9 & 2366.4 & 2368.7\end{array}$

$\begin{array}{llllll}1015 & 1012.9 & 1013.8 & 1015.1 & 1008.9 & 1011.5\end{array}$

$\begin{array}{llllll}2.307 & 2.319 & 2.321 & 2.318 & 2.329 & 2.326\end{array}$

$1.24 \% \quad 1.18 \%$

$0.61 \%$

$0.65 \%$

$0.70 \%$

$0.69 \%$

7.8

7.3

7.2

7.4

6.9

7.0

Pavement Technology Inc.

$\begin{array}{llll}\text { G3 } & \text { G4 } & \text { G5 } & \text { G6 }\end{array}$

LF $\quad$ LR $\quad$ RF $\quad$ RR

5.210

7.140

10.124

---Fail at 19634 cycles 

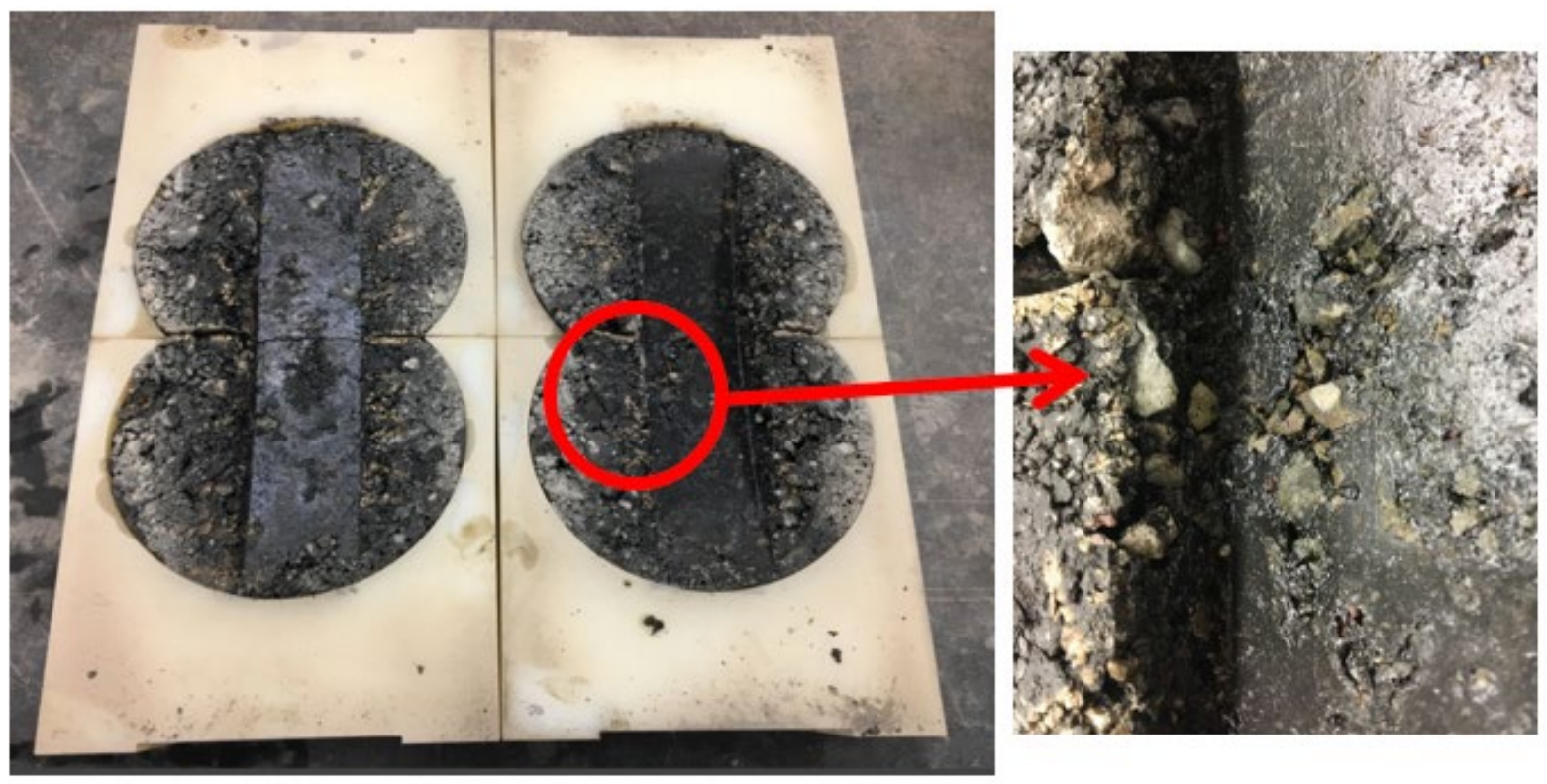

Figure Appendix B-4: HWTT Photo of RCA 12.5-19.1mm with 5.0\% Binder Content (OBC of control mix) 
Table Appendix B-7: HWTT Results of RCA 12.5-19.1mm Mix: 5.8\% OBC

Theoretical Maximum Specific

Gravity

2.466

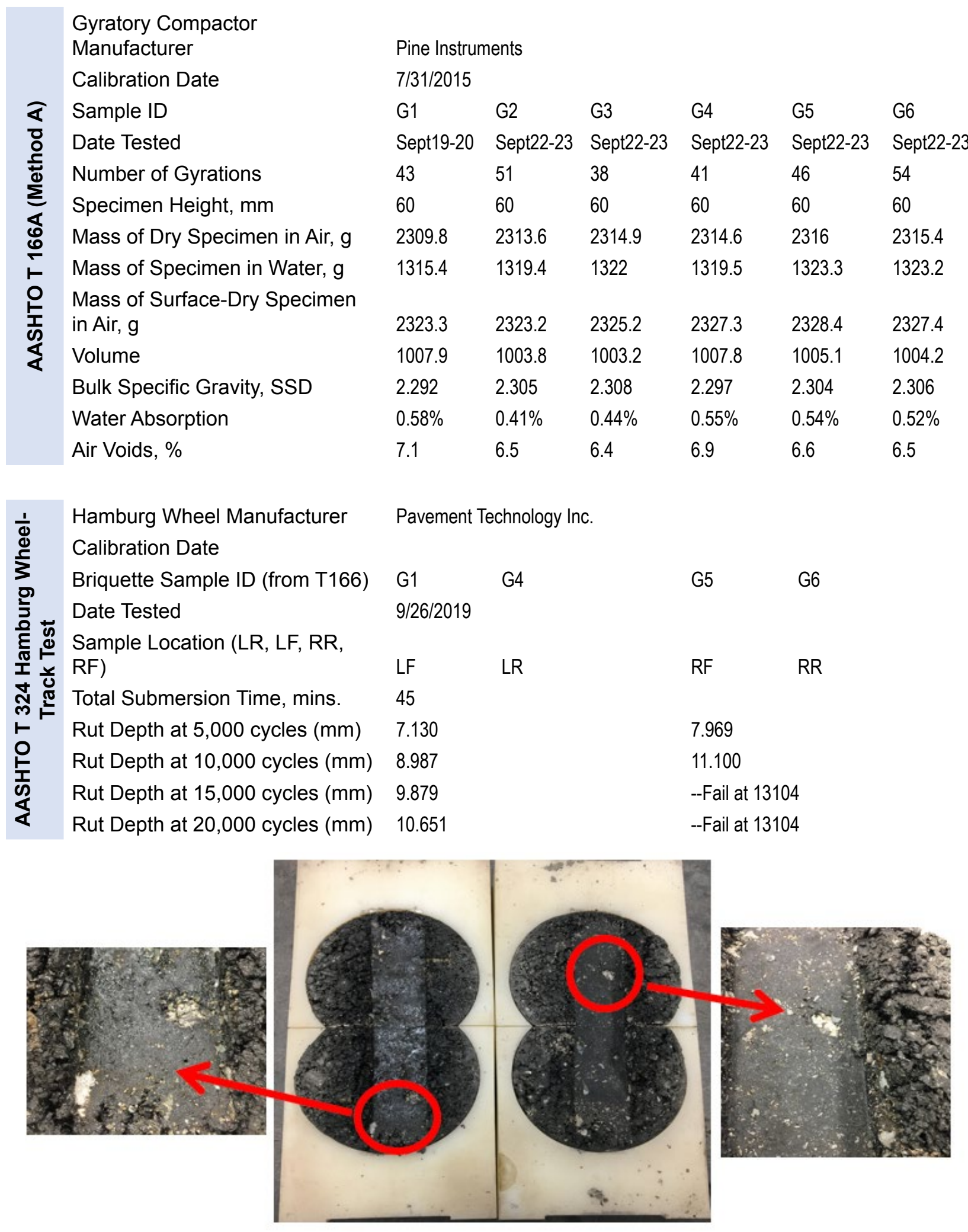

Figure Appendix B-5: HWTT Photo of RCA 12.5-19.1mm with 5.8\% OBC 


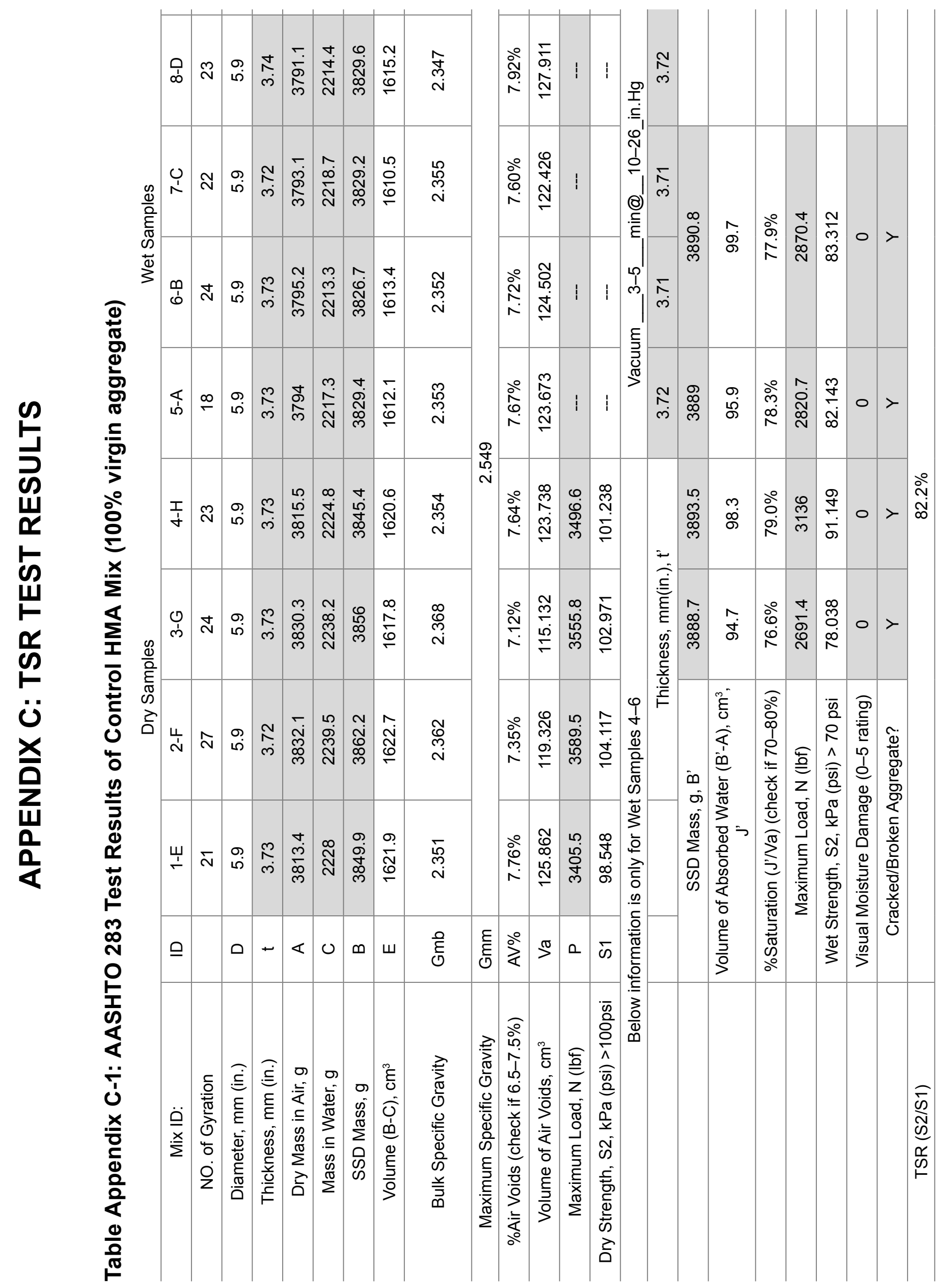



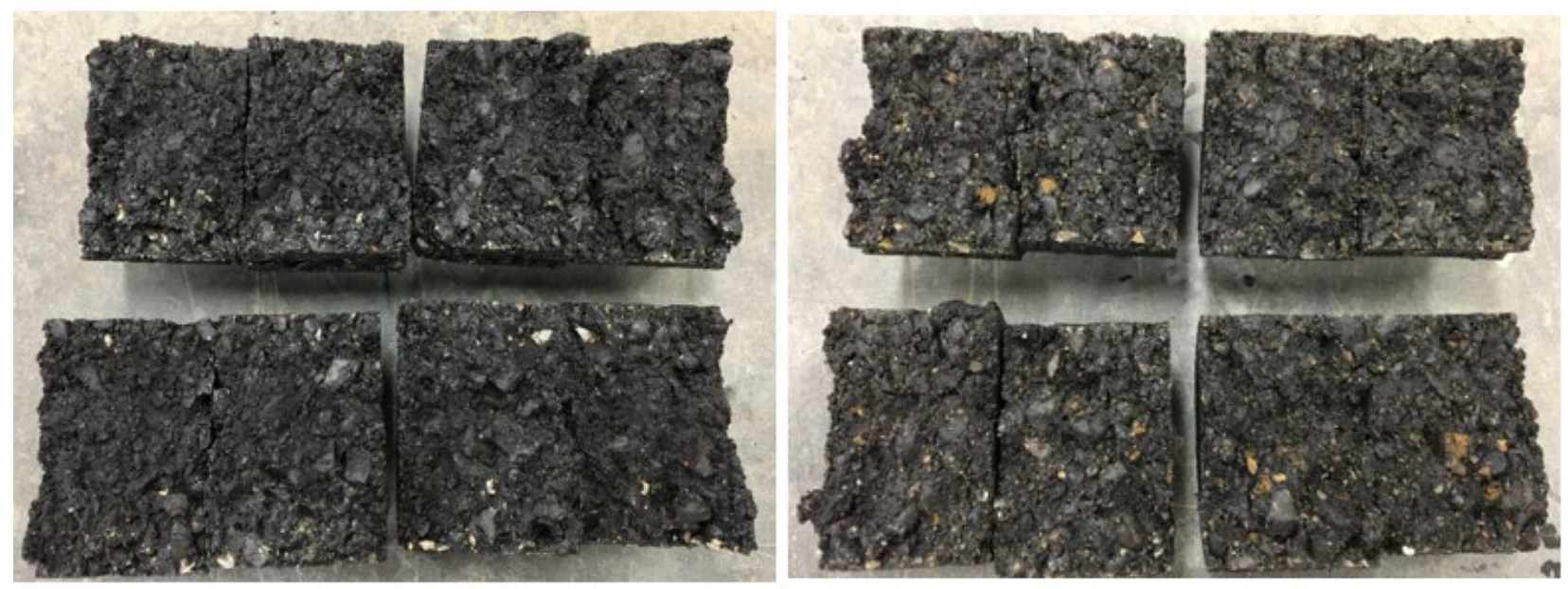

Figure Appendix C-1: AASHTO 283 Test Photos of Control HMA Mix (100\% virgin aggregate). Left (Dry), Right (Wet) 


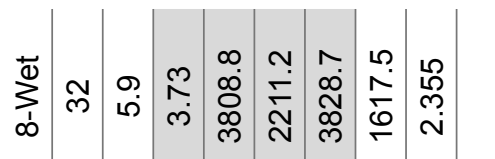

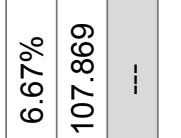

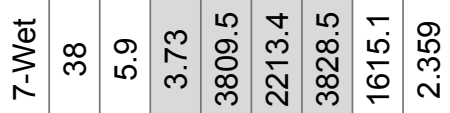

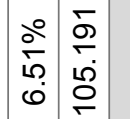

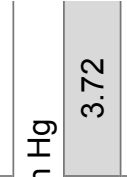

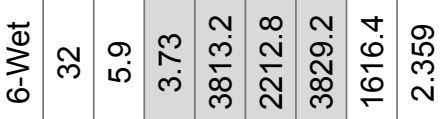

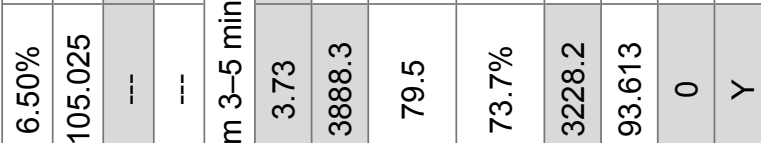

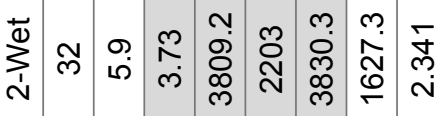

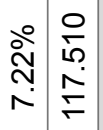

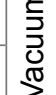

$\underset{\substack{1 \\ \infty}}{N}$

(8)

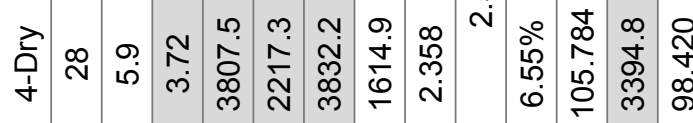

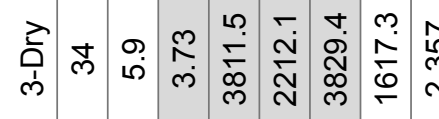

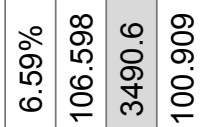

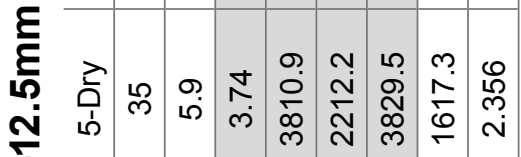

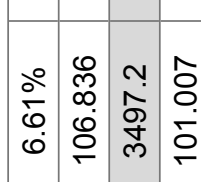

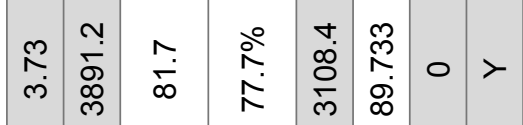

กุ

(1)

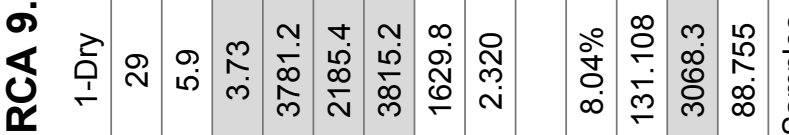

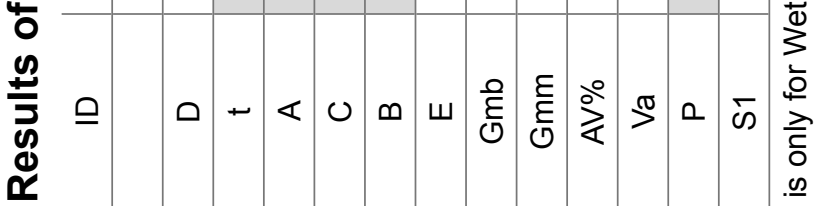

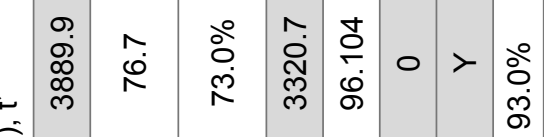

官

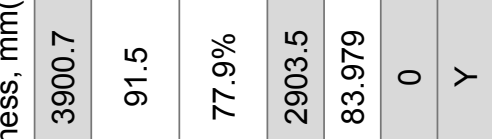

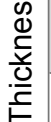

을

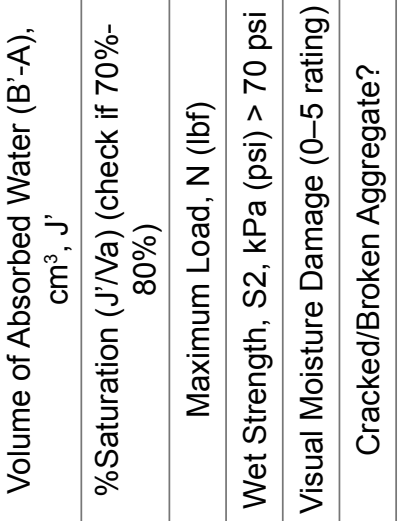

感

œ

$\stackrel{2}{\frac{1}{1}}$

j̇

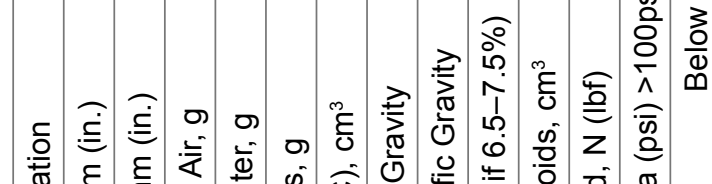

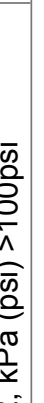

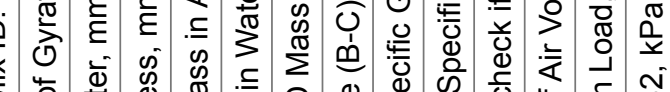

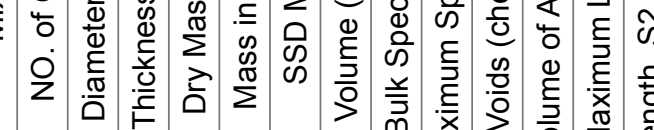

产 

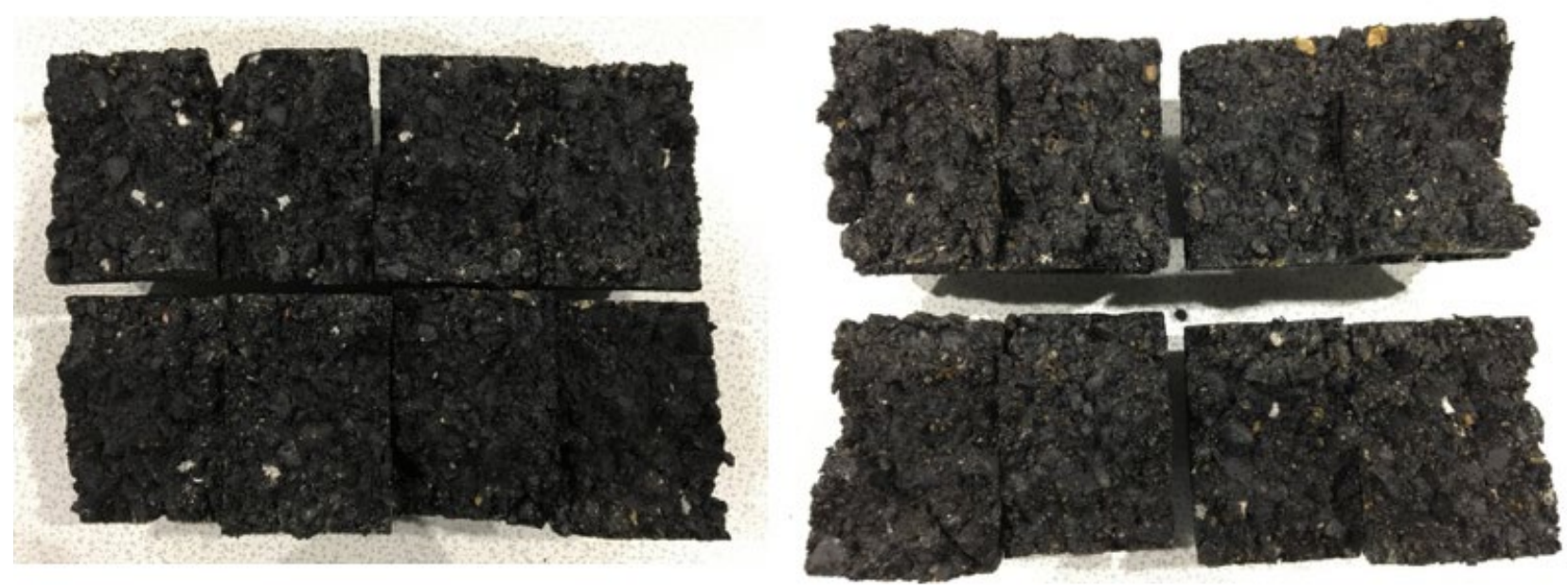

Figure Appendix C-2: AASHTO 283 Test Photos of RCA 9.5-12.5mm Mix. Left (Dry), Right (Wet) 


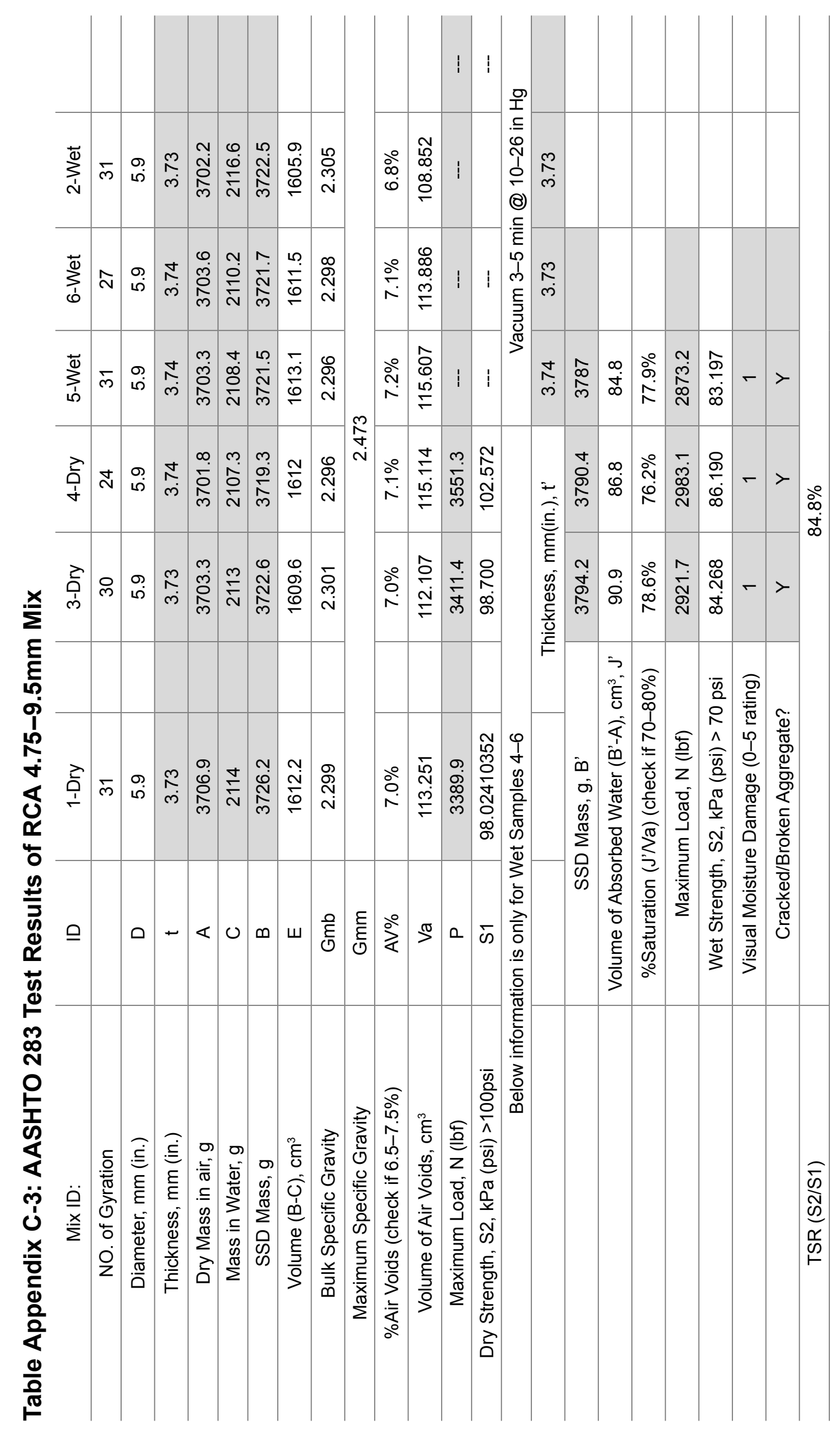



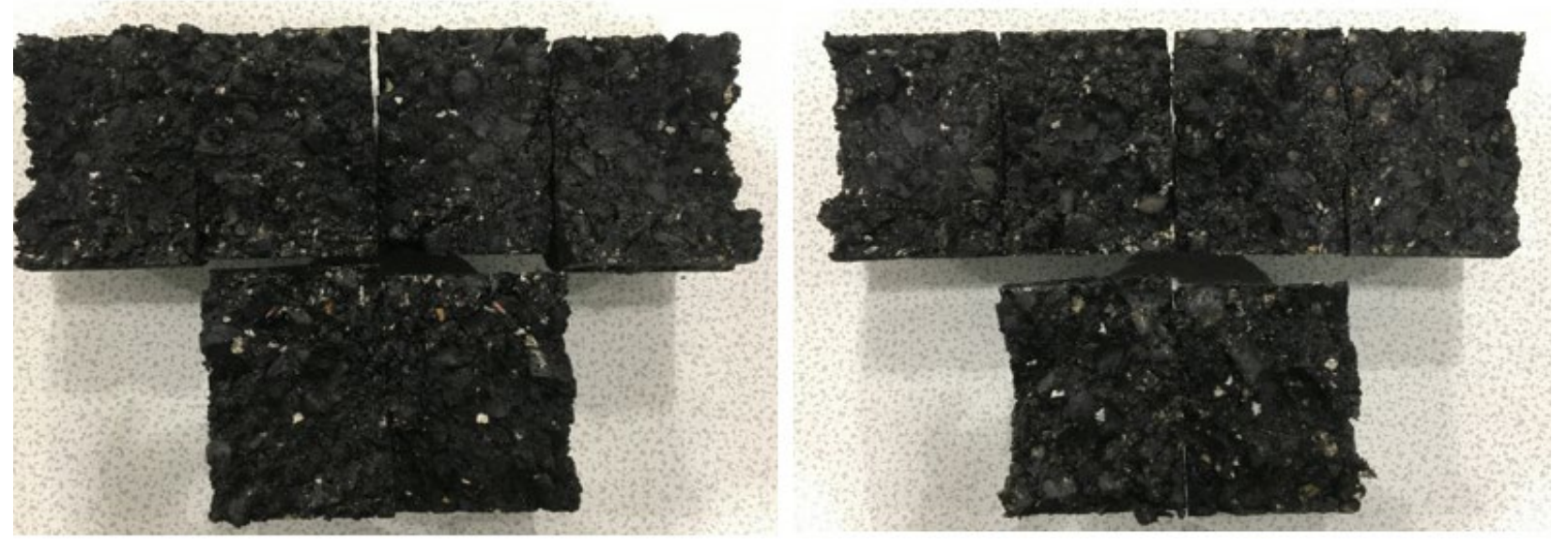

Figure Appendix C-3: AASHTO 283 Test Photos of RCA 4.75-9.5mm Mix. Left (Dry), Right (Wet) 


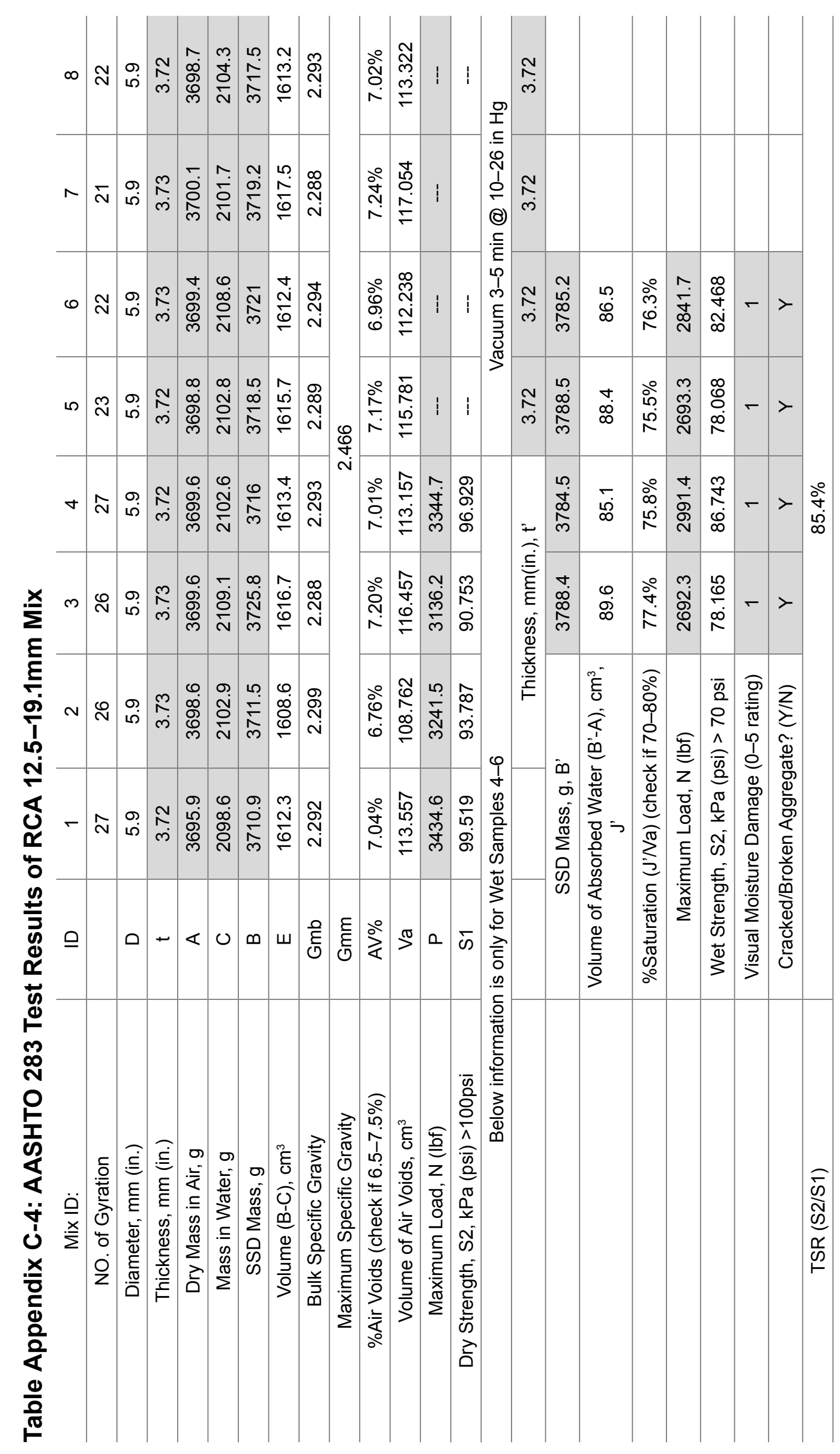




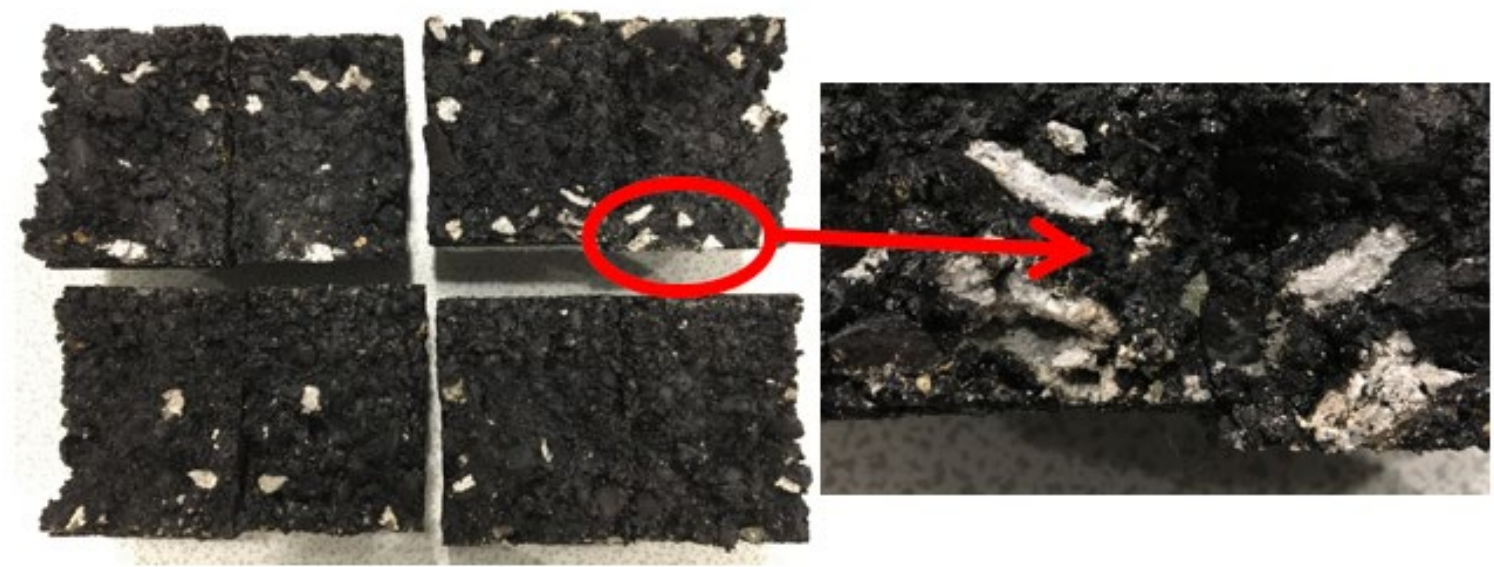

(a) Dry Test

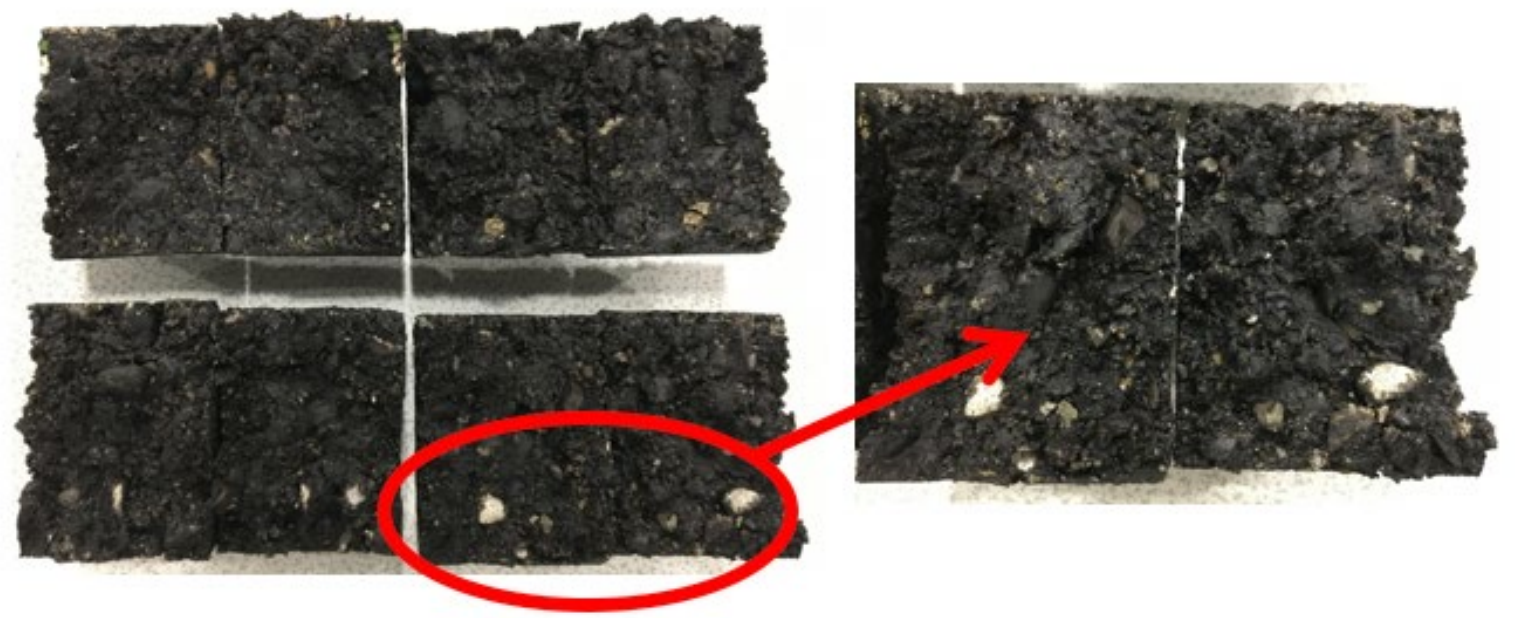

(b) Wet Test

Figure Appendix C-4: AASHTO 283 Test Photos of RCA 12.5-19.1mm Mix. Upper (Dry), Lower (Wet) 


\section{ABBREVIATIONS AND ACRONYMS}

\begin{tabular}{ll}
\hline HMA & Hot Mix Asphalt \\
HWTT & Hamburg Wheel Tracking Test \\
IDT & Indirect Tensile \\
OBC & Optimum Binder Content \\
RAP & Reclaimed Asphalt Pavement \\
RCA & Recycled Concrete Aggregate \\
RCA-HMA & Hot Mix Asphalt using Recycled Concrete Aggregate \\
RCM & Residual Cement Mortar \\
TSR & Tensile Strength Ratio \\
VFA & Voids in Mineral Aggregate \\
VMA & Voids Filled with Asphalt \\
\hline
\end{tabular}




\section{ENDNOTES}

1. U.S. Geological Survey, Mineral Commodity Summaries, 2016.

2. Bolen, W. P., Sand and gravel, construction, U.S. Geological Survey Minerals Yearbook, 2000.

3. U.S. Geological Survey, U.S. Department of the Interior, 2000, Recycled aggregatesProfitable resource conservation, USGS Fact Sheet FS-181-99.

4. Mostafa, A. E. A, Ouf, M. S., and Jamal, A. L., Developing an Environmentally Sustainable Hot Mix Asphalt Using Recycled Concrete Aggregates, Int. Journal of Engineering Research and Applications ww.ijera.com, ISSN: 2248-9622, 5 (2015): 1-6

5. U.S. Geological Survey, Mineral Commodity Summaries, 2016.

6. Kim, S., Ceylan, H., Gopalakrishnan, K., White, D. J., Jahren, C. T., and Phan T. H., 2011, T \& DI Congress 2011.

7. Shen, D. and Du, J., Evaluation of building materials recycling on HMA permanent deformation, Construction and Building Materials 18 (2004): 391-7; Shen, D. and Du, J., Application of gray rational analysis to evaluate HMA with reclaimed building materials, Journal of Materials in Civil Engineering 17 (2005): 400-6.

8. Wong, Y. D., et al., Value-added utilisation of recycled concrete in hot mix asphalt. Waste Management 27 (2007): 294-301; Pérez, I., et al., Hot mix asphalt using C\&D waste as coarse aggregates. Materials \& Design 36 (2012): 840-6.

9. Bhusal, S. and Wen, H., Evaluating recycled concrete aggregate as hot mix asphalt aggregate, Advances in Civil Engineering Materials 2 (2013): 252-265; Wu, S., et al., Influence of demolition waste used as recycled aggregate on performance of asphalt mixture, Road Materials and Pavement Design 14 (2013): 679-88; Zhu, J., et al., Investigation of asphalt mixture containing demolition waste obtained from earthquakedamaged buildings, Construction and Building Materials 29 (2012): 466-75.

10. Paranavithana, S. and Mohajerani, A., Effects of recycled concrete aggregates on properties of asphalt concrete, Resources, Conservation and Recycling 48 (2006): 1-12; Pérez, I., et al., 2007, Mechanical properties of hot mix asphalt made with recycled aggregates from reclaimed construction and demolition debris, Materials of Construction 57 (2007): 17-29.

11. Bhusal, S. and Wen, $\mathrm{H}$., Evaluating recycled concrete aggregate as hot mix asphalt aggregate, Advances in Civil Engineering Materials 2 (2013): 252-265; Paranavithana, $\mathrm{S}$. and Mohajerani, A., Effects of recycled concrete aggregates on properties of asphalt concrete, Resources, Conservation and Recycling 48 (2006): 1-12; Mills-Beale, J. and You, Z., The mechanical properties of asphalt mixtures with recycled concrete aggregates, Construction and Building Materials 24 (2010): 340-5. 
12. Shen, D. and Du, J., Application of gray rational analysis to evaluate HMA with reclaimed building materials, Journal of Materials in Civil Engineering 17 (2005): 400-6; Wong, Y. D., et al., Value-added utilisation of recycled concrete in hot mix asphalt, Waste Management 27 (2007): 294-301; Pérez, I., et al., Mechanical properties of hot mix asphalt made with recycled aggregates from reclaimed construction and demolition debris, Materials of Construction 57 (2007):17-29; Pérez, I., et al., Asphalt mixtures with construction and demolition debris. In: Proceedings of the institution of civil engineers, Transport 163 (2010): 165-174; Zulkati, A., et al., Mechanistic performance of asphaltconcrete mixture incorporating coarse recycled concrete aggregate, Journal of Materials in Civil Engineering 25 (2013): 1299-305.

13. Paranavithana, S. and Mohajerani, A., Effects of recycled concrete aggregates on properties of asphalt concrete, Resources, Conservation and Recycling 48 (2006): 1-12; Pérez, I., et al., Hot mix asphalt using C\&D waste as coarse aggregates, Materials \& Design 36 (2012): 840-6; Pérez, I., et al., Mechanical properties of hot mix asphalt made with recycled aggregates from reclaimed construction and demolition debris, Materials of Construction 57 (2007): 17-29; Pérez, I., et al., Asphalt mixtures with construction and demolition debris. In: Proceedings of the institution of civil engineers, Transport 163 (2010): 165-174.

14. Pérez, I., et al., Hot mix asphalt using C\&D waste as coarse aggregates, Materials \& Design 36 (2012): 840-6; Mills-Beale, J. and You, Z., The mechanical properties of asphalt mixtures with recycled concrete aggregates, Construction and Building Materials 24 (2010): 340-5.

15. Shen, D. and Du, J., Application of gray rational analysis to evaluate HMA with reclaimed building materials, Journal of Materials in Civil Engineering 17 (2005): 400-6; Pérez, I., et al., Hot mix asphalt using C\&D waste as coarse aggregates, Materials \& Design 36 (2012): 840-6; Bhusal, S. and Wen, H., Evaluating recycled concrete aggregate as hot mix asphalt aggregate, Advances in Civil Engineering Materials 2 (2013): 252-265; Pérez, I., et al., Mechanical properties of hot mix asphalt made with recycled aggregates from reclaimed construction and demolition debris, Materials of Construction 57 (2007): 17-29; Chen, M., et al., 2011, Potential of recycled fine aggregates powder as filler in asphalt mixture, Construction and Building Materials 3909-14; Nehad, F. M., et al., The effects of using recycled concrete on fatigue behavior of hot mix asphalt, Journal of Civil Engineering and Management 19 (2014): 561-8; Pasandin, A. R. and Perez, I., Overview of bituminous mixtures made with recycled concrete aggregates, Construction and Building Materials 74 (2015): 151-161.

16. Pérez, I., et al., Mechanical properties of hot mix asphalt made with recycled aggregates from reclaimed construction and demolition debris, Materials of Construction 57 (2007): 17-29; Pérez, I., et al., Asphalt mixtures with construction and demolition debris, in Proceedings of the institution of civil engineers, Transport 163 (2010): 165-174; Chen, M., et al., 2011, Potential of recycled fine aggregates powder as filler in asphalt mixture, Construction and Building Materials 3909-14; Nehad, F. M., et al., The effects of using recycled concrete on fatigue behavior of hot mix asphalt, Journal of Civil Engineering and Management 19 (2014): 561-8. 
17. Bhusal, S. and Wen, H., Evaluating recycled concrete aggregate as hot mix asphalt aggregate, Advances in Civil Engineering Materials 2 (2013): 252-265; Wu, S., et al., Influence of demolition waste used as recycled aggregate on performance of asphalt mixture, Road Materials and Pavement Design 14 (2013): 679-88; Zhu, J., et al., Investigation of asphalt mixture containing demolition waste obtained from earthquakedamaged buildings, Construction and Building Materials 29 (2012): 466-75; Chen, M., et al., 2011, Potential of recycled fine aggregates powder as filler in asphalt mixture, Construction and Building Materials, 3909-14.

18. Pérez, I., et al., Hot mix asphalt using C\&D waste as coarse aggregates, Materials \& Design 36 (2012): 840-6; Pérez, I., et al., Mechanical properties of hot mix asphalt made with recycled aggregates from reclaimed construction and demolition debris, Materials of Construction 57 (2007): 17-29; Pérez, I., et al., Asphalt mixtures with construction and demolition debris, in Proceedings of the institution of civil engineers, Transport 163 (2010): 165-174; De Juan M.S., and Gutiérrez, P.A., Study on the influence of attached mortar content on the properties of recycled concrete aggregate, Construction and Building Materials 23 (2009): 872-877.

19. Chen, M., et al., 2011, Potential of recycled fine aggregates powder as filler in asphalt mixture, Construction and Building Materials, 3909-14; Arabani, M. and Azarhoosh, A. R., The effect of recycled concrete aggregate and steel slag on the dynamic properties of asphalt mixtures, Construction and Building Materials 35 (2012): 1-7; Arabani, M., et al., Laboratory evaluation of recycled waste concrete into asphalt mixtures, International Journal of Pavement Engineering 14 (2012): 531-9.

20. Shen, D. and Du, J., Evaluation of building materials recycling on HMA permanent deformation, Construction and Building Materials 18 (2004): 391-7; Shen, D. and Du, J., Application of gray rational analysis to evaluate HMA with reclaimed building materials, Journal of Materials in Civil Engineering 17 (2005):400-6; Wong, Y. D., et al., Valueadded utilisation of recycled concrete in hot mix asphalt, Waste Management 27 (2007): 294-301; Zhu, J., et al., Investigation of asphalt mixture containing demolition waste obtained from earthquake-damaged buildings, Construction and Building Materials 29 (2012): 466-75; Paranavithana, S. and Mohajerani, A., Effects of recycled concrete aggregates on properties of asphalt concrete, Resources, Conservation and Recycling 48 (2006): 1-12; Mills-Beale, J. and You, Z., The mechanical properties of asphalt mixtures with recycled concrete aggregates Construction and Building Materials 24 (2010): 340-5; Pérez, I., et al., Asphalt mixtures with construction and demolition debris, in Proceedings of the institution of civil engineers, Transport 163 (2010): 165-174.

21. Abbas, A., et al., Quantification of the residual mortar content in recycled concrete aggregates by image analysis, Materials Characterization 60 (2009): 716-728; De Juan M.S., and Gutiérrez, P.A., Study on the influence of attached mortar content on the properties of recycled concrete aggregate, Construction and Building Materials 23 (2009): 872-877.

22. Abbas, A., et al., Quantification of the residual mortar content in recycled concrete aggregates by image analysis, Materials Characterization 60 (2009): 716-728; 
Etxeberria, M., Vazquez, E., Mari, A., Barra, M., Influence of amount of recycled coarse aggregates and production process on properties of recycled aggregate concrete, Construction and Building Materials 26 (2007): 735-742.

23. Chen, M., et al., 2011, Potential of recycled fine aggregates powder as filler in asphalt mixture, Construction and Building Materials 3909-14; Wong, Y. D., Sun, D. D., Lai, D. Value-added utilisation of recycled concrete in hot mix asphalt, Waste Manage 27 (2007): 294-301

24. Chen, M., et al., 2011, Potential of recycled fine aggregates powder as filler in asphalt mixture, Construction and Building Materials, 3909-14.

25. Fathifazl, G., Abbas, A., Razaqpur, A. G., Isgor, O. B., Fournier, B., and Foo, S., New Mixture Proportioning Method for Concrete Made with Coarse Recycled Concrete Aggregate, Journal of Materials in Civil Engineering 21 (2009): 601-611; Abbas, A., et al., Quantification of the residual mortar content in recycled concrete aggregates by image analysis, Materials Characterization 60 (2009): 716-728; Abbas, A., et al., Proposed method for determining the residual mortar content of recycled concrete aggregates, Journal of ASTM International 5 (2008): 1-12.

26. Fathifazl, G., Abbas, A., Razaqpur, A. G., Isgor, O. B., Fournier, B., and Foo, S., New Mixture Proportioning Method for Concrete Made with Coarse Recycled Concrete Aggregate, Journal of Materials in Civil Engineering 21 (2009): 601-611.

27. Mamlouk, M. S. and Zaniewski, J. P., 2017, Materials for Civil and Construction Engineers, $4^{\text {th }}$ edition, Pearson.

28. Mamlouk, M. S. and Zaniewski, J. P., 2017, Materials for Civil and Construction Engineers, $4^{\text {th }}$ edition, Pearson.

29. Wong, Y. D., Sun, D. D., Lai, D. Value-added utilisation of recycled concrete in hot mix asphalt, Waste Manage 27 (2007): 294-301.

30. Yildirim, Y., and Kennedy, T. W., 2001. "Correlation of Field Performance to Hamburg Wheel Tracking Device Results." Report No. FHWA/TX-04/0-4185-1, Texas Department of Transportation, Austin, Texas; Yildirim, Y., Jayawickrama, P. W., Hossain, M. S., Alhabshi, A., Yildirim, C., Smit, A. F., and Little, D., 2007. Hamburg Wheel Tracking Database Analysis. Report No. FHWA/TX-05/0-1707-7. Texas Department of Transportation, Austin, Texas; Rahman, F. and Hossain, M., 2014, Review and analysis of Hamburg wheel tracking device test data, Report No. KS-14-1, Kansas Department of Transportation.

31. Fathifazl, G., Abbas, A., Razaqpur, A. G., Isgor, O. B., Fournier, B., and Foo, S., New Mixture Proportioning Method for Concrete Made with Coarse Recycled Concrete Aggregate, Journal of Materials in Civil Engineering, 21 (2009): 601-611.

32. Fathifazl, G., Abbas, A., Razaqpur, A. G., Isgor, O. B., Fournier, B., and Foo, S., New 
Mixture Proportioning Method for Concrete Made with Coarse Recycled Concrete Aggregate, Journal of Materials in Civil Engineering, 21 (2009): 601-611.

33. Fathifazl, G., Abbas, A., Razaqpur, A. G., Isgor, O. B., Fournier, B., and Foo, S., New Mixture Proportioning Method for Concrete Made with Coarse Recycled Concrete Aggregate, Journal of Materials in Civil Engineering, 21 (2009): 601-611.

34. Asphalt Institute, MS-2 Asphalt Mix Design Methods, 2015.

35. Caltrans, 2018 Standard Specifications. Sacramento, CA, 2018.

36. Caltrans, 2018 Standard Specifications. Sacramento, CA, 2018. 


\section{BIBLIOGRAPHY}

Abbas, A., et al. Proposed method for determining the residual mortar content of recycled concrete aggregates. Journal of ASTM International 5 (2008): 1-12. https://doi. org/10.1520/JAl101087

Abbas, A., et al. Quantification of the residual mortar content in recycled concrete aggregates by image analysis. Materials Characterization 60 (2009): 716-728. https://doi.org/10.1016/j.matchar.2009.01.010

Arabani, M. and Azarhoosh, A. R. The effect of recycled concrete aggregate and steel slag on the dynamic properties of asphalt mixtures. Construction and Building Materials 35 (2012): 1-7. https://doi.org/10.1016/j.conbuildmat.2012.02.036

Arabani, M., et al. Laboratory evaluation of recycled waste concrete into asphalt mixtures. International Journal of Pavement Engineering 14 (2012): 531-9. DOI: 10.1080/10298436.2012.747685

Aydilek, A. H. Environmental Suitability of Recycled Concrete Aggregates in Highways. Final Report to Maryland State Highway Administration, 2015.

Bhusal, S. and Wen, $\mathrm{H}$. Evaluating recycled concrete aggregate as hot mix asphalt aggregate. Advances in Civil Engineering Materials 2 (2013): 252-265. DOI: 10.1520/ACEM20120053

Bolen, W. P. Sand and gravel, construction. U.S. Geological Survey Minerals Yearbook, 2000.

Caltrans. 2015 State of the pavement report. California Department of Transportation Division of Maintenance Pavement Program, 2015.

Chen, M., et al. 2011. Potential of recycled fine aggregates powder as filler in asphalt mixture. Construction and Building Materials vol. 25, 3909-14. doi:10.1016/j. conbuildmat.2011.04.022

Cho, Y. H., et al. 2011. The application of Recycled Concrete Aggregate (RCA) for Hot Mix Asphalt (HMA) base layer aggregate. KSCE Journal of Civil Engineering 15 (2011): 473-8.

Copeland, A. 2011. Reclaimed asphalt pavement in asphalt mixtures: State of the practice. Final report to FHWA Publication No. FHWA-HRT-11-021.

Davis, M. and Yahya, C. K. Use of Recycled concrete aggregates for improved sustainability of reinforced concrete building structures-economic considerations. Proceedings of the 2015 ASEE Gulf-Southwest Annual Conference, 2015.

De Juan M.S., and Gutiérrez, P.A. Study on the influence of attached mortar content on the 
properties of recycled concrete aggregate. Construction and Building Materials 23 (2009): 872-877. https://doi.org/10.1016/j.conbuildmat.2008.04.012

El-Tahan, D., Gabr, A., El-Badawy, S., Shetawy, M. 2018. Evaluation of recycled concrete aggregate in asphalt mixes. Innovative Infrastructure Solutions, Vol. 3, Iss. 1.

Giri, J. P., Panda, M., Sahoo, U. C. 2018. Impact of Filler on Engineering Characteristics of Bituminous Paving Mixes with Recycled Concrete Aggregates. Advances in Civil Engineering Materials, ASTM International, Vol. 7, Iss. 2, 73-91. DOI: 10.1520/ ACEM20170021

Gul, W.A. 2008. Effect of recycled cement concrete content on rutting behaviour of asphalt concrete. Doctoral Thesis. Middle East Technical University. Ankara.

Gul, W. A., Guler, M., Torino, P. D. Rutting Behavior of Asphalt Concrete Modified with Recycled Concrete Aggregate, International Conference on Maintenance and Rehabilitation of Pavements and Technological Control (MAIREPAV6). Sixth Proceedings, 2009.

Harrington, J, 2005. RECYCLED ROADWAYS, Public Roads Vol. 68, Iss. 4. Federal Highway Administration. 9-17.

Jones, D., Harvey, J., and Kohler, E. 2007. Summary report on the evaluation of rigid pavement long-life strategies. Final report to Caltrans FHWA No. CA081075A.

Etxeberria, M., Vazquez, E., Mari, A., Barra, M. Influence of amount of recycled coarse aggregates and production process on properties of recycled aggregate concrete. Construction and Building Materials 37 (2007): 735-742. https://doi.org/10.1016/j. cemconres.2007.02.002

Lotf, M. A., Ramezanianpour, A. M., Palassi, M.. 2018. Evaluating the Frost Resistance of Recycled Concrete Aggregate by Various Standards, Journal of Materials in Civil Engineering, American Society of Civil Engineers. https://doi.org/10.1061/(ASCE) MT.1943-5533.0002254

Mamlouk, M.S. and Zaniewski, J.P. 2017. Materials for Civil and Construction Engineers, 4th Edition.

Mills-Beale, J. and You, Z. The mechanical properties of asphalt mixtures with recycled concrete aggregates. Construction and Building Materials 24 (2010): 340-5. https:// doi.org/10.1016/j.conbuildmat.2009.08.046

Nehad, F. M., et al. The effects of using recycled concrete on fatigue behavior of hot mix asphalt. Journal of Civil Engineering and Management 19 (2014): 561-8. DOI: $10.3846 / 13923730.2013 .801892$

Paranavithana, S. and Mohajerani, A. Effects of recycled concrete aggregates on 
properties of asphalt concrete. Resources, Conservation and Recycling 48 (2006): 1-12. https://doi.org/10.1016/j.resconrec.2005.12.009

Pasandin, A. R. and Perez, I. Overview of bituminous mixtures made with recycled concrete aggregates. Construction and Building Materials 74 (2015): 151-161. https://doi.org/10.1016/j.conbuildmat.2014.10.035

Pasandin, A. R., Pérez, I., and Gómez-Meijide, B. Treatments Applied to Recycled Concrete Aggregates Used in Hot-Mix Asphalt, TRB 94th Annual Meeting Compendium of Papers, Transportation Research Board, Washington, D.C., 2015.

Pérez, I., et al. Mechanical properties of hot mix asphalt made with recycled aggregates from reclaimed construction and demolition debris. Materials of Construction 57 (2007):17-29.

Pérez, I., et al. Asphalt mixtures with construction and demolition debris. In: Proceedings of the institution of civil engineers. Transport 163 (2010): 165-174.

Pérez, l., et al. Hot mix asphalt using C\&D waste as coarse aggregates. Materials \& Design 36 (2012): 840-6. https://doi.org/10.1016/j.matdes.2010.12.058

Prakash Giri, J., Panda, M., Sahoo, U. C. Performance of Bituminous Mixes Containing Treated Recycled Concrete Aggregates and Modified by Waste Polyethylene. Journal of Materials in Civil Engineering 30 (2018). https://doi.org/10.1061/(ASCE) MT.1943-5533.0002384

Shen, D. and Du, J. Evaluation of building materials recycling on HMA permanent deformation. Construction and Building Materials, 18 (2004): 391-7. https://doi. org/10.1016/j.conbuildmat.2004.03.007

Shen, D. and Du, J. Application of gray rational analysis to evaluate HMA with reclaimed building materials. Journal of Materials in Civil Engineering 17 (2005): 400-6. DOI: 10.1061/(ASCE)0899-1561(2005)17:4(400)

Smith, J. T., Tighe, S. L. Recycled Concrete Aggregate Coefficient of Thermal Expansion: Characterization, Variability, and Impacts on Pavement Performance. Transportation Research Record: Journal of the Transportation Research Board 2113 (2009): 5361. https://doi.org/10.3141/2113-07

Sun, D., Tian, Y., Sum G. Pang, Q., Yu, F, Zhu, X. Performance evaluation of asphalt mixtures containing recycled concrete aggregates. International Journal of Pavement Engineering 19 (2018): 422-428. https://doi.org/10.1080/10298436.2017 .1402594

U.S. Geological Survey. Mineral Commodity Summaries, 2016.

U.S. Geological Survey. U.S. Department of the Interior, 2000, Recycled aggregates: 
Profitable resource conservation. USGS Fact Sheet FS-181-99.

Wong, Y. D., et al. Value-added utilisation of recycled concrete in hot mix asphalt. Waste Management 27 (2007): 294-301. https://doi.org/10.1016/j.wasman.2006.02.001

$\mathrm{Wu}, \mathrm{S}$., et al. Influence of demolition waste used as recycled aggregate on performance of asphalt mixture. Road Materials and Pavement Design 14 (2013): 679-88. https:// doi.org/10.1080/14680629.2013.779304

Zhu, J., et al. Investigation of asphalt mixture containing demolition waste obtained from earthquake-damaged buildings. Construction and Building Materials 29 (2012): 466-75. https://doi.org/10.1016/j.conbuildmat.2011.09.023

Zulkati, A., et al. Mechanistic performance of asphalt-concrete mixture incorporating coarse recycled concrete aggregate. Journal of Materials in Civil Engineering 25 (2013): 1299-305. https://doi.org/10.1061/(ASCE)MT.1943-5533.0000668 


\section{ABOUT THE AUTHORS}

\section{XIAOJUN LI, PHD}

Dr. Xiaojun Li is assistant professor at Department of Civil \& Geomatics Engineering, California State University, Fresno. Dr. Li's research focuses on sustainable pavement materials, and on developing sustainable solutions for transportation, with emphasis on recycled materials, industrial/municipal waste/byproducts, bio-materials, and composite materials. Dr. Li's research goal is to achieve more sustainable transportation infrastructure that satisfies the concerns of the economy, environment, and society.

DINGXIN CHENG, PHD, P.E.

Dr. DingXin (Ding) Cheng is a professor of the department of civil engineering at the California State University, Chico, director of the California Pavement Preservation (CP2) Center, and the director of the Tire Derived Aggregate Technology Center. He has worked actively with the CP2 Center since he joined the department of civil engineering of CSU Chico in 2006. He obtained his PhD in the areas of pavement materials and transportation from Texas A\&M University in College Station, Texas in 2002. He worked in private industry for Parsons Brinckerhoff in Houston, TX before joining the Chico State University. He has extensive experiences in Hot Mix Asphalt (HMA) materials and pavement preservation on both asphalt and concrete pavements. He has more than 55 peer-reviewed publications related to pavement materials and preservation in Transportation Research Board, AAPT, ASCE, and other conferences. Ding has co-managed or managed more than $\$ 7$ million research projects funded by California Department of Transportation (Caltrans), California Department of Resources Recycling and Recovery (CalRecycle), Metropolitan Transportation Commissions (MTC) of San Francisco Bay Area, and other agencies and industry participants.

\section{KUN ZHANG, PHD}

Dr. Kun Zhang is an Assistant Professor at the Department of Civil Engineering at California State University, Chico and Senior Pavement Researcher at California Pavement Preservation Center. His featured research interests and efforts focus on advanced numerical modeling for particulate systems processing and mechanical behaviors of geo and pavement Materials, including the use of computational fluid dynamics (CFD), discrete element method (DEM), and finite element method (FEM); and optimization recycling of waste pavement materials and industrial by-products in asphalt materials, including RAP/RAS, waste carbon fiber composite materials, recycled concrete aggregate, and waste cooking oil for bio-binder development, etc. He has served as $\mathrm{PI} / \mathrm{Co}-\mathrm{PI}$ for several projects funded by various agencies, including FHWA, DOTs, and industrial companies. 


\section{PEER REVIEW}

San José State University, of the California State University system, and the Mineta Transportation Institute (MTI) Board of Trustees have agreed upon a peer review process required for all research published by MTI. The purpose of the review process is to ensure that the results presented are based upon a professionally acceptable research protocol. 


\author{
Founder, Honorable \\ Norman Mineta (Ex-Officio) \\ Secretary (ret.), \\ US Department of Transportation \\ Chair, \\ Abbas Mohaddes (TE 202I) \\ President \& COO \\ Econolite Group Inc. \\ Vice Chair, \\ Will Kempton (TE 2022) \\ Retired \\ Executive Director, \\ Karen Philbrick, PhD \\ (Ex-Officio) \\ Mineta Transportation Institute \\ San José State University \\ Richard Anderson \\ (Ex-Officio) \\ President \& CEO \\ Amtrak \\ David Castagnetti (TE 202 I) \\ Co-Founder \\ Mehlman Castagnetti \\ Rosen \& Thomas \\ Maria Cino (TE 202 I) \\ Vice President \\ America \& U.S. Government \\ Relations Hewlett-Packard Enterprise
}

\author{
Grace Crunican* \\ (TE 2022) \\ Retired
}

Donna DeMartino (TE 202I)

General Manager \& CEO

San Joaquin Regional Transit District

Nuria Fernandez* (TE 2020)

General Manager \& CEO

Santa Clara Valley

Transportation Authority (VTA)

John Flaherty (TE 2020)

Senior Fellow

Silicon Valley American

Leadership Form

Rose Guilbault (TE 2020)

Board Member

Peninsula Corridor

Joint Powers Board

Ian Jefferies (Ex-Officio)

President \& CEO

Association of American Railroads

Diane Woodend Jones

(TE 2022)

Principal \& Chair of Board

Lea + Elliott, Inc.
Therese McMillan

(TE 2022)

Executive Director

Metropolitan Transportation

Commission (MTC)

Bradley Mims (TE 2020)

President \& CEO

Conference of Minority

Transportation Officials (COMTO)

Jeff Morales (TE 2022)

Managing Principal

InfraStrategies, LLC

Dan Moshavi, PhD

(Ex-Officio)

Dean, Lucas College and

Graduate School of Business

San José State University

Takayoshi Oshima (TE 202 I)

Chairman \& CEO

Allied Telesis, Inc.

Toks Omishakin

(Ex-Officio)

Director

California Department of

Transportation (Caltrans)
Paul Skoutelas (Ex-Officio)

President \& CEO

American Public Transportation

Association (APTA)

Dan Smith (TE 2020)

President

Capstone Financial Group, Inc.

Beverley Swaim-Staley (TE 2022)

President

Union Station Redevelopment

Corporation

\section{Jim Tymon (Ex-Officio)}

Executive Director

American Association of

State Highway and Transportation

Officials (AASHTO)

\section{Larry Willis (Ex-Officio)}

President

Transportation Trades

Dept., AFL-CIO

$(\mathrm{TE})=$ Term Expiration

* = Past Chair, Board of Trustees

\section{Directors}

Karen Philbrick, Ph.D.

Executive Director

Hilary Nixon, Ph.D.

Deputy Executive Director

\section{Asha Weinstein Agrawal,}

\section{Ph.D.}

Education Director

National Transportation Finance

Center Director

\section{Brian Michael Jenkins}

National Transportation Security

Center Director

\title{
Research Associates Policy Oversight Committee
}

Jan Botha, Ph.D.

Civil \& Environmental Engineering

San José State University

Katherine Kao Cushing,

\section{Ph.D.}

Enviromental Science

San José State University

Dave Czerwinski, Ph.D. Marketing and Decision Science San José State University
Frances Edwards,

Ph.D.

Political Science

San José State University

Taeho Park, Ph.D.

Organization and Management

San José State University

\section{Christa Bailey}

Martin Luther King, Jr. Library

San José State University

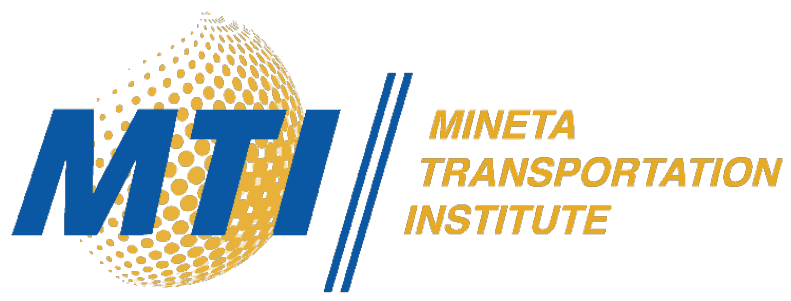

